\title{
Research and practice on progressive collapse and robustness of building structures in the $21^{\text {st }}$ century
}

\author{
Jose M. Adama ${ }^{a^{*}}$, Fulvio Parisi ${ }^{b}$, Juan Sagasetac ${ }^{c}$ Xinzheng Lu ${ }^{d}$ \\ a'ICITECH, Universitat Politècnica de València. Camino de Vera s/n, 46022 Valencia, Spain
}

${ }^{\mathrm{b}}$ Department of Structures for Engineering and Architecture, University of Naples Federico II. Via Claudio 21, 80125 Naples, Italy

${ }^{c}$ University of Surrey, Guildford, Surrey GU2 7XH, United Kingdom

${ }^{d}$ Key Laboratory of Civil Engineering Safety and Durability of Ministry of Education, Tsinghua University, Beijing 100084, China

\section{Abstract}

Extreme events (i.e. terrorist attacks, vehicle impacts, explosions, etc.) often cause local damage to building structures and pose a serious threat when one or more vertical load-bearing components fail, leading to the progressive collapse of the entire structure or a large part of it. Since the beginning of the $21^{\text {st }}$ century there has been growing interest in the risks associated with extreme events, especially after the attacks on the Alfred P. Murrah Federal Building in Oklahoma in 1995 and on the World Trade Center in New York in 2001. The accent is now on achieving resilient buildings that can remain operational after such an event, especially when they form part of critical infrastructures, are occupied by a large number of people, or are open to the public. This paper presents an ambitious review that describes all the main advances that have taken place since the beginning of the $21^{\text {st }}$ century in the field of progressive collapse and robustness of buildings. Widely diverse aspects are dealt with, including: 1) a collection of conceptual definitions, 2) bibliometric details, 3) the present situation and evolution of codes and design recommendations, 4) quantification of robustness, 5) assessing the risk of progressive collapse, 6) experimental tests, 7) numerical modelling, and 8) research needs. Considering the comprehensive range of these aspects, this paper could be of great use to professionals and researchers who intend to enter the field of the progressive collapse of building structures and also to other experts who require an extensive and up-to-date view of this topic.

Keywords: Progressive collapse; Accidental actions; Extreme events; Robustness; State of the art; Codes; Buildings; Review

\footnotetext{
* Corresponding author. Tel.: +34 963877562; fax: +34 963877568.

E-mail address: joadmar@upv.es (J.M. Adam).
} 


\section{Introduction}

All types of public and private buildings may be subjected to extreme events, caused, for example, by hurricanes, tsunamis, earthquakes, explosions, vehicle impacts, fires and human errors, or even terrorist attacks. Such events usually cause local damage to the structure of buildings, which can lead to a complete collapse. This is where the term progressive collapse comes in, understood as the process by which local damage sets in motion a chain of failures, leading to the collapse of the entire building or a large part of it. A progressive building collapse is always accompanied by serious personal and material losses [1].

In recent years the press has spotlighted a number of notorious progressive collapses; the most important for the numbers of victims, extent of the damage or social impact at the time include the classics Ronan Point (London, 1968) and Capitán Arenas (Barcelona, 1972), the U.S. Marine Barracks (Beirut, 1983), the Argentine Israelite Mutual Association (Buenos Aires, 1994), the A.P. Murrah Federal Building (Oklahoma, 1995), the Sampoong Department Store (Seoul, 1995), the buildings of the World Trade Center (New York, 2001), and the Achimota Melcom Shopping Centre (Acra, 2012). From the attention given to these and many other collapses, the idea has become generally accepted that there is a need for robust buildings that can sustain local damage without suffering disproportionate collapse. This performance objective may be further expanded in the case of buildings that form part of critical infrastructures (e.g. hospitals, power stations, passenger terminals), are occupied by a large number of people or are open to the public (e.g. schools, sports and commercial centres). In those situations, there is even the need for resilient buildings, which can be defined as buildings that are able to absorb and recover from an extreme event, maintaining operation and functionality, according to what is generally defined as physical resilience at the larger scale of urban infrastructure systems. Therefore, the resilience of a building includes not only the structural property of robustness, which contributes to the capacity of absorbing an extreme event, but also a recovery capacity that allows the pre-event performance level to be quickly restored or even improved.

As it is difficult to predict the probability of occurring and the magnitude of extreme events, it is neither practical nor possible to design a structure against them through the traditional methods for conventional loads. Present-day design standards instead try to minimise the risk and provide a minimum level of control over progressive collapse by incorporating in the codes the design concept of robustness as the insensitivity of a structure to local damage. By contrast, the insensitivity of a structure to abnormal events is referred to as collapse resistance. According to this concept, no action is taken against the extreme event itself, as this risk cannot be eliminated, but the aim is rather to control its consequences.

In a building structure, the most serious local damage occurs when one or more vertical load-bearing 
components (e.g. columns or walls) fail, leading to a chain of failures that ends in the total collapse of the entire building or a large part of it. To avoid progressive collapses, alternative load paths must be available for the load supported by the damaged column to be transferred to neighbouring elements. If efficient alternative paths are not available, progressive collapse is inevitable unless further design measures are introduced (e.g. key element design, segmentation).

In the case of framed buildings, five resisting mechanisms can provide alternative load paths and minimise the risk of progressive collapse:

a) Bending of the beam where the column has failed (generally ineffective mechanism since the beams have to be over-dimensioned, so this design criterion is seldom used).

b) Vierendeel behaviour of the frame over the failed column (Fig.1a).

c) Arch effect of the beams where the column has failed (effective mechanism when horizontal displacement of the neighbouring columns is small).

d) Catenary/membrane behaviour of beams/slabs, bridging the damaged column (Fig.1b) by means of large rotations and displacements.

e) Contribution of non-structural elements such as external walls and partitions (Fig. 1c).

The most widely studied mechanism and on which most research has been done to date is undoubtedly the catenary behaviour of beams, as this is considered to be a building's last line of defence against progressive collapse.
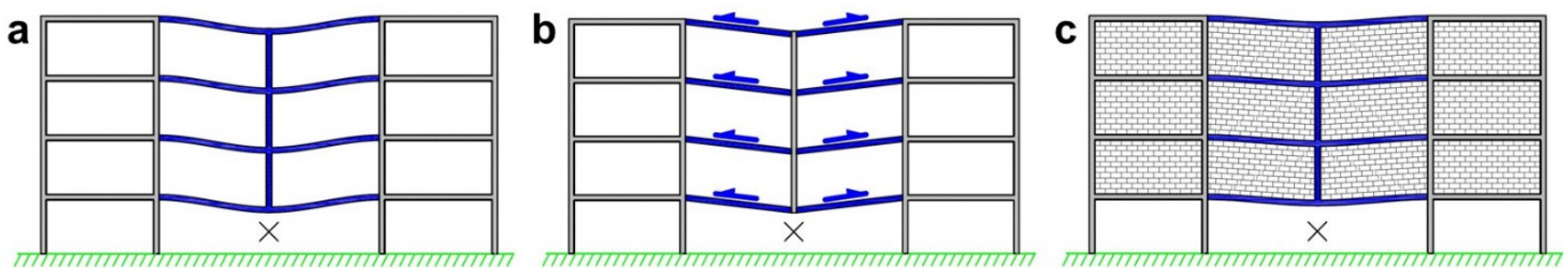

Fig. 1. Alternative load paths: (a) Vierendeel action; (b) catenary action; (c) contribution of non-structural elements

Studies on the progressive collapse of structures began in the early 1940s when Lord Baker analysed the behaviour of bomb-damaged buildings in London during the Second World War [2]. The collapse of the Ronan Point apartment block (London, 1968) was a milestone after which building codes and design recommendations began to consider the risk of progressive collapse. However, it was only after the collapse of the A.P. Murrah Federal Building (Oklahoma, 1995) and the buildings of the World Trade Center (New York, 2001) had alarmed public opinion and led to the introduction of new standards and recommendations that the scientific community became interested in studying this field.

The aim of this paper is thus to carry out a wide-ranging review of the main advances made in the $21^{\text {st }}$ 
century in the field of robustness and progressive collapse of building structures. In view of the content and range of the aspects dealt with, it can be considered a complete guide for anyone interested in entering this field of study. It could also be of great use to those experts who wish to obtain an extensive up-to-the-minute view of the present state-of-the-art on this topic.

Even though other authors have previously provided excellent reviews of aspects associated with regulations and research on progressive collapse of building structures [3-6], the present review is probably the most ambitious so far since it deals with such a wide range of aspects, including:

- A compilation of conceptual definitions (Section 2) of different terms, such as progressive collapse, disproportionate collapse, and robustness.

- Bibliometric details (Section 3) giving the present situation of research on progressive collapse and robustness of building structures.

- The present state of the regulations, recommendations and design methods on the subject of progressive collapse and robustness as well as their evolution in recent years (Section 4).

- Formulations for quantification of structural robustness (Section 5).

- Methods of evaluating the risk of progressive structural collapse (Section 6)

- A compilation and classification of the most important experimental tests made to date (Section 7).

- A description of the techniques most frequently used in numerical simulation of progressive collapse of building structures (Section 8).

- The authors' reflections on present and future needs in the field of robustness and progressive collapse of building structures (Section 9).

\section{Conceptual definitions}

After many years of research and applications on the assessment and mitigation of consequences from abnormal loads on structures, several definitions of progressive collapse, disproportionate collapse and robustness have been proposed in research papers, books, building codes and guidelines. Nonetheless, a general consensus on terminology and procedures is still lacking, even though requested by professional engineers and stakeholders, e.g. building officials, owners, lenders, insurers, government agencies, and emergency planners. This is the main motivation of this section, which first attempts to provide major conceptual definitions and measures for quantitative assessment of robustness. This is deemed to form a sound basis for a comprehensive discussion of experimental and numerical studies in the field.

An interesting matter of discussion is the difference between progressive and disproportionate collapse. 
Progressive collapse is a collapse that begins with localised damage to a single or a few structural components and develops throughout the structural system, affecting other components. Starossek [7] identified six types of progressive collapse, namely, pancake-, zipper-, domino-, section-, instability-, and mixed-type collapses. Each type of collapse was characterised in terms of failure propagation, outlining the propagating action resulting from the failure of a component and leading to the failure of further components. Pancake- and domino-type collapses were grouped into the impact class, as in both cases failure propagates as a result of the transformation of potential energy into kinetic energy during the fall/overturning of elements and their impact on the others. Zipper- and section-type collapses were collected in the redistribution class, because in both cases failure propagation is caused by the redistribution of forces carried by failing elements in the remaining structure. Disproportionate collapse is a collapse characterised by a disproportion in size between a relatively minor damaging event (or the resulting initial damage) and the final collapse configuration that involves a major part or the whole of the structural system. Based on these simple definitions, it can be deduced that progressive collapse is associated with propagation of failure within the structure, hence describing the response of the structural system to the damaging event. By contrast, disproportionate collapse is related to the final size of damaged structure compared to the initial amount of damage, without providing any description of the structural behaviour. Whilst progressive collapse can be qualitatively identified and described, disproportionate collapse needs to be quantified through one or more measures. Furthermore, a progressive collapse may be proportionate in size, for instance if failure propagation is arrested by some elements, without spreading over a major portion of the structure. Vice versa, a collapse may be disproportionate in size even without failure propagation, for example in case the collapse of a statically determinate structure is originated from the failure of a single member. A major issue in structural design is thus to set appropriate performance objectives in terms of damage tolerance under an abnormal event, that is, a loading case normally neglected in design. This damage threshold should be calibrated in relation to the potential indirect consequences of structural collapse to the public. Some definitions of progressive and disproportionate collapse are outlined in Table 1 where, in some cases, progressive collapse is assumed to be disproportionate. It is also noted that the issues of progressive/disproportionate collapse and related damage tolerance are typically considered in the case of ordinary structures, for which an initial damage involving a major portion of structure cannot be avoided. This does not apply to protective structures, the design of which is driven by ad hoc strategies and rules. 
Table 1. Selected definitions of progressive and disproportionate collapse

\begin{tabular}{|c|c|}
\hline Source & Definition \\
\hline $\begin{array}{l}\text { Allen and Schriever } \\
\text { [8] }\end{array}$ & $\begin{array}{l}\text { Progressive collapse }[\ldots] \text { can be defined as the phenomenon in which local failure is followed by } \\
\text { collapse of adjoining members which in turn is followed by further collapse and so on, so that } \\
\text { widespread collapse occurs as a result of local failure. }\end{array}$ \\
\hline $\begin{array}{l}\text { Gross and McGuire } \\
\text { [9] }\end{array}$ & $\begin{array}{l}\text { A progressive collapse is characterized by the loss of load-carrying capacity of a relatively small } \\
\text { portion of a structure due to an abnormal load which, in turn, triggers a cascade of failure affecting } \\
\text { a major portion of the structure. }\end{array}$ \\
\hline $\begin{array}{l}\text { GSA guidelines } \\
{[10]}\end{array}$ & $\begin{array}{l}\text { Progressive collapse is a situation where local failure of a primary structural component leads to } \\
\text { the collapse of adjoining members which, in turn, leads to additional collapse. Hence, the total } \\
\text { damage is disproportionate to the original cause. }\end{array}$ \\
\hline ASCE 7-05 [11] & $\begin{array}{l}\text { Progressive collapse is defined as the spread of an initial local failure from element to element } \\
\text { resulting, eventually, in the collapse of an entire structure or a disproportionately large part of it. }\end{array}$ \\
\hline Ellingwood [1] & $\begin{array}{l}\text { A progressive collapse initiates as a result of local structural damage and develops, in a chain } \\
\text { reaction mechanism, into a failure that is disproportionate to the initiating local damage. }\end{array}$ \\
\hline Canisius et al [12] & $\begin{array}{l}\text { Progressive collapse, where the initial failure of one or more components results in a series of } \\
\text { subsequent failures of components not directly affected by the original action is a mode of failure } \\
\text { that can give rise to disproportionate failure. }\end{array}$ \\
\hline NISTIR 7396* [13] & $\begin{array}{l}\text { Progressive collapse - The spread of local damage, from an initiating event, from element to } \\
\text { element resulting, eventually, in the collapse of an entire structure or a disproportionately large part } \\
\text { of it; also known as disproportionate collapse. }\end{array}$ \\
\hline $\begin{array}{l}\text { Agarwal and } \\
\text { England [14] }\end{array}$ & $\begin{array}{l}\text { Disproportionate collapse results from small damage or a minor action leading to the collapse of a } \\
\text { relatively large part of the structure. [...] Progressive collapse is the spread of damage through a } \\
\text { chain reaction, for example through neighbouring members or storey by storey. [...] Often } \\
\text { progressive collapse is disproportionate but the converse may not be true. }\end{array}$ \\
\hline Krauthammer [15] & $\begin{array}{l}\text { Progressive collapse is a failure sequence that relates local damage to large scale collapse in a } \\
\text { structure. }\end{array}$ \\
\hline \multirow[t]{2}{*}{$\begin{array}{l}\text { Starossek and } \\
\text { Haberland [16] }\end{array}$} & $\begin{array}{l}\text { Disproportionate collapse. A collapse that is characterized by a pronounced disproportion between } \\
\text { a relatively minor event and the ensuing collapse of a major part or the whole of a structure. }\end{array}$ \\
\hline & $\begin{array}{l}\text { Progressive collapse. A collapse that commences with the failure of one or a few structural } \\
\text { components and then progresses over successively affected other components. }\end{array}$ \\
\hline $\begin{array}{l}\text { Kokot and Solomos } \\
{[17]}\end{array}$ & $\begin{array}{l}\text { Progressive collapse of a building can be regarded as the situation where local failure of a primary } \\
\text { structural component leads to the collapse of adjoining members and to an overall damage which is } \\
\text { disproportionate to the initial cause. }\end{array}$ \\
\hline $\begin{array}{l}\text { Parisi and Augenti } \\
{[18]}\end{array}$ & $\begin{array}{l}\text { Progressive collapse }[\ldots] \text { is a chain reaction mechanism resulting in a pronounced disproportion in } \\
\text { size between a relatively minor triggering event and resulting collapse, that is, between the initial } \\
\text { amount of directly damaged elements and the final amount of failed elements. }\end{array}$ \\
\hline
\end{tabular}

* Definition adopted by the 2013 revision of UFC 4-023-03 guidelines [19]

A quantitative, transparent and rational approach to mitigate consequences from progressive or disproportionate collapse is based on risk reduction through structural robustness, which allows either a new or an existing structure to meet the additional performance objective of collapse prevention under abnormal loading. In line of principle, the actual robustness of a structure is a threat-dependent property of the entire structural system because it depends not only on the system's characteristics (e.g. strength, ductility, redundancy, continuity), but also on the type of abnormal loading (e.g. single or multiple, dynamic or impulsive, monotonic or cyclic). It should be noted that, in the literature, the term "structural robustness" is 
occasionally replaced by "structural integrity" but, actually, the latter has a different meaning because it indicates the wholeness and intactness of a structure after an extreme event.

Abnormal loads are very different from their normal counterparts considered in design and assessment of structures. Indeed, abnormal loads are usually related to low-probability/high-consequence (LPHC) events that on one hand have a probability of occurrence significantly lower than that of normal events, and on the other, are expected to induce huge losses, such as casualties, repair costs, and downtime (the latter being a measure of the recovery process after an event, contributing to building resilience). LPHC events include the following: (i) extreme natural events, such as large landslides, flash floods, windstorms, megathrust earthquakes; (ii) extreme accidental events, such as explosions, impacts, and fire; (iii) malicious actions; (iv) human errors in design, construction, usage or maintenance; and (v) deterioration phenomena, such as steel corrosion and concrete delamination. If a specific threat can be identified and probabilistically modelled, either a threat-dependent or a threat-independent design/assessment can be carried out. This is the case of white swan events, as observed by Nafday [20]. Otherwise, if robustness is evaluated in relation to grey swan events (i.e. extreme events that are expected but their likelihood is unknown) or black swan events (i.e. extreme events that cannot be even imagined in a given site due to a knowledge gap), only a threat-independent design/assessment can be performed by assuming notional actions or initial damage to the structure.

Several definitions of robustness for technical applications can be found in the literature related to various fields of research and technology, such as structural and software engineering, product development and quality control, ecosystems, design optimization, Bayesian decision making, and linguistics. For example, control theory defines robustness as the degree to which a system is insensitive to effects that are not considered in design [21]. Similarly, statistics assumes that a robust statistical technique is insensitive to small deviations in the assumptions [22]. Even though a general consensus in the structural engineering community is still lacking, robustness is typically defined as the ability of the structure to avoid consequences disproportionate to the event causing failure. Robustness is thus a matter of minimum residual capacity to maintain function after a change in the structure (e.g. initial failure) or its environment (e.g. slope modification, urban site configuration due to underground excavation). Table 2 provides some definitions of robustness available in the literature.

Structural robustness strongly depends on redundancy, which is the ability of the structure to redistribute loads after damage to a single or a few members. In this respect, a robust structure is generally able to develop alternative load paths (ALPs) by means of structural ties, strength and ductility. 
Table 2. Selected definitions of structural robustness

\begin{tabular}{|c|c|}
\hline Source & Definition \\
\hline $\begin{array}{l}\text { GSA guidelines } \\
{[10]}\end{array}$ & $\begin{array}{l}\text { obustness - Ability of a structure or structural components to resist damage without premature } \\
\text { ad/or brittle failure due to events like explosions, impacts, fire or consequences of human error, } \\
\text { ue to its vigorous strength and toughness. }\end{array}$ \\
\hline EC1 - Part 1-7 [23] & $\begin{array}{l}\text { Robustness: The ability of a structure to withstand events like fire, explosions, impact or the } \\
\text { consequences of human error, without being damaged to an extent disproportionate to the original } \\
\text { cause. }\end{array}$ \\
\hline Bontempi et al. [24] & $\begin{array}{l}\text { The robustness of a structure, intended as its ability not to suffer disproportionate damages as a } \\
\text { result of limited initial failure, is an intrinsic requirement, inherent to the structural system } \\
\text { organization. }\end{array}$ \\
\hline $\begin{array}{l}\text { Agarwal and } \\
\text { England [14] }\end{array}$ & $\begin{array}{l}\text { Robustness is }[\ldots] \text { the ability of a structure to avoid disproportionate consequences in relation to } \\
\text { the initial damage. }\end{array}$ \\
\hline Biondini et al. [25] & $\begin{array}{l}\text { Structural robustness can be viewed as the ability of the system to suffer an amount of damage not } \\
\text { disproportionate with respect to the causes of the damage itself. }\end{array}$ \\
\hline $\begin{array}{l}\text { Vrouwenvelder } \\
\text { [26] }\end{array}$ & $\begin{array}{l}\text { The notion of robustness is that a structure should not be too sensitive to local damage, whatever } \\
\text { the source of damage. }\end{array}$ \\
\hline JCSS [27] & $\begin{array}{l}\text { The robustness of a system is defined as the ratio between the direct risks and the total risks (total } \\
\text { risks is equal to the sum of direct and indirect risks), for a specified time frame and considering all } \\
\text { relevant exposure events and all relevant damage states for the constituents of the system. }\end{array}$ \\
\hline $\begin{array}{l}\text { Starossek and } \\
\text { Haberland [16] }\end{array}$ & $\begin{array}{l}\text { Robustness. Insensitivity of a structure to initial damage. A structure is robust if an initial damage } \\
\text { does not lead to disproportionate collapse. }\end{array}$ \\
\hline $\begin{array}{l}\text { Fib Model Code } \\
2010[28]\end{array}$ & $\begin{array}{l}\text { Robustness is a specific aspect of structural safety that refers to the ability of a system subject to } \\
\text { accidental or exceptional loadings (such as fire, explosions, impact or consequences of human } \\
\text { errors) to sustain local damage to some structural components without experiencing a } \\
\text { disproportionate degree of overall distress or collapse. }\end{array}$ \\
\hline Brett and Lu [29] & $\begin{array}{l}{[\ldots] \text { ability of a structure in withstanding an abnormal event involving a localized failure with }} \\
\text { limited levels of consequences, or simply structural damages. }\end{array}$ \\
\hline
\end{tabular}

Alternatively (if ALPs are not available), the extent of damage and collapse propagation can be controlled by introducing a discontinuity in the structure (segmentation) or designing some critical element to resist the extreme event (key element design). In this context, robustness can be improved through either continuity or segmentation of the structural system depending on the case and design approach adopted. In any case, it should be recalled that a robust structure is not over-designed but is able to activate latent resisting mechanisms that are not usually exploited to withstand normal loads.

\section{Bibliometric details}

This section provides the results of a bibliometric study of the present state-of-the-art into robustness and progressive collapse of building structures by means of a search in Scopus database considering the following parameters:

- The presence of terms such as "progressive collapse" and "structure" in the title, abstract or keywords of documents. 
- The 50-year period considered: 1968-2017.

- Only papers published in the form of "Article" or "Review".

- Search area: "Engineering".

Fig. 2, which shows the evolution of the number of papers published each year related to the progressive collapse of structures, is a reflection of the growing interest of the scientific community in studying this topic. This figure clearly shows how the collapse of the buildings of the World Trade Center in 2001 brought about a change in the public perception of safety and led to financing a significant number of studies on extreme events, progressive collapse and structural robustness. The increased interest in this topic was also due to the higher expectations of users regarding the safety of "engineered structures" to extreme events in view of the advances in materials and design/analysis approaches available.

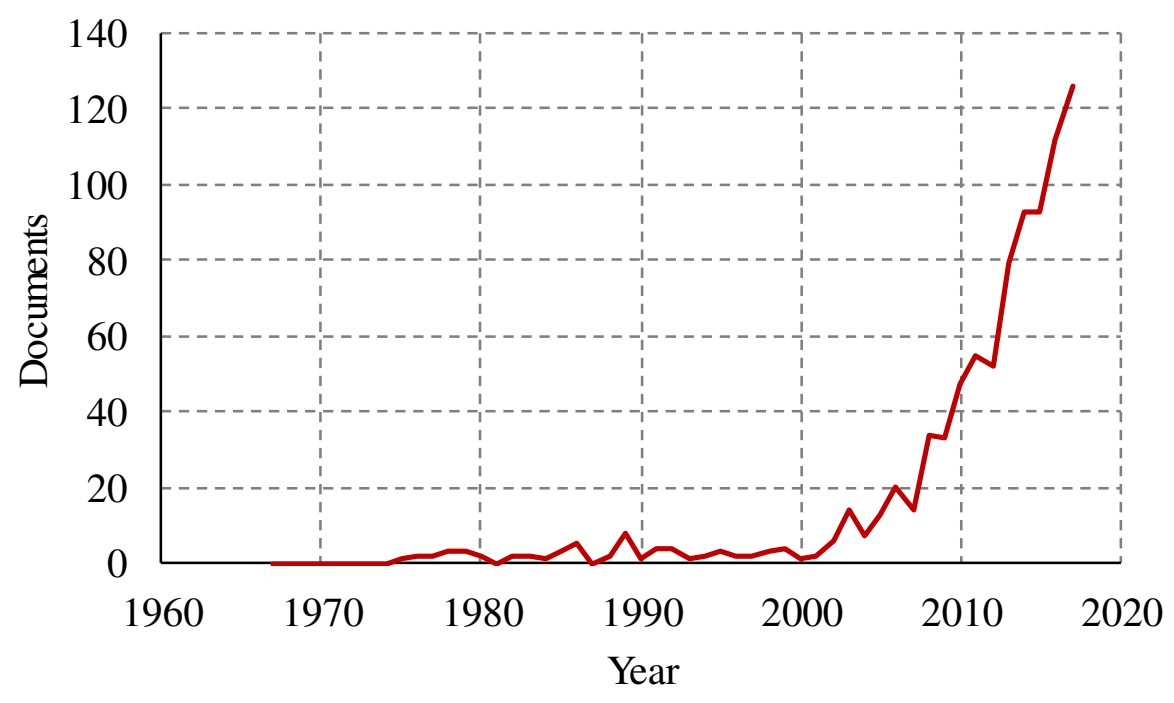

Fig. 2. Evolution of the number of papers published yearly in Scopus-indexed journals in relation to the progressive collapse of structures (1968 to 2017)

Fig. 3 shows the number of papers on progressive collapse of structures published by author's country of origin for the periods: 1968-2002, 2003-2007, 2008-2012, and 2013-2017. Only the 10 countries that have published most papers are included. Some interesting facts can be learned from Fig. 3:

- Until 2002, most of the research on progressive collapse was done in the US and the UK, where two important events had occurred: the Ronan Point collapse in London in 1968 and the Alfred P. Murrah Federal Building in Oklahoma in 1995, respectively.

- After the attacks on the World Trade Center in 2001, the research on progressive collapse intensified, especially in the US, and the UK became the second country in research on the subject (in the period 2003-2007). The studies carried out allowed the existing standards and guides to be brought up to date and new ones were brought out. 
- In the last 10 years (2009-2017), the situation has taken a significant turn and Asia has taken most of the initiative. Although both the US and UK are still among the most active in the field, China is now the leader and the country that invests most resources in this type of research, while other Asian countries such as South Korea, Singapore and Iran are playing leading roles in the international panorama.

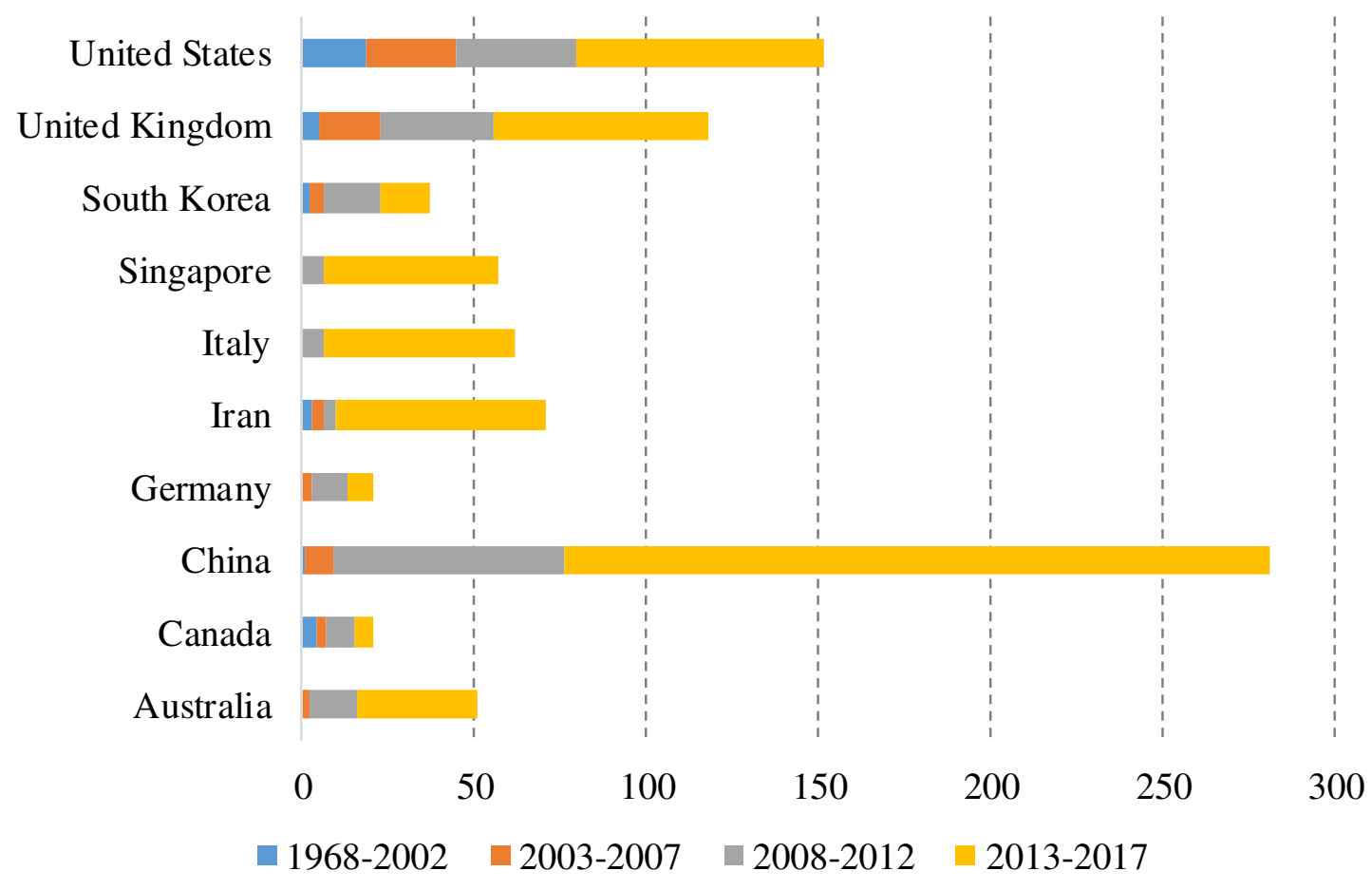

Fig. 3. Number of papers by author's country of origin for the periods: 1968-2002, 2003-2007, 2008-2012, and 20132017

As can be seen in Table 3, among the Scopus-indexed journals that publish most papers on progressive collapse, Engineering Structures (published by Elsevier) is the clear leader with 105 papers published since its creation to 2017. After Engineering Structures, the two journals that have published most on the topic are the Journal of Performance of Constructed Facilities (published by the ASCE) and the Journal of Constructional Steel Research (Elsevier). As regards the most relevant papers published to date, as indicated by the number of citations received, the following stand out (see Table 4): Izzuddin et al. [30], Ellingwood [1], and Yi et al. [31]. Table 4 includes some of the most frequently cited papers on progressive collapse up to December 2017.

The search also included the number of papers published according to the building materials used. The number of papers on cast-in-place concrete and steel-composite was found to be quite similar, very few studies included precast concrete, and timber or masonry structures were given very little attention in the research on progressive collapse. 
Table 3. Scopus-indexed journals with most papers published on progressive collapse of structures (up to 31 December 2017)

\begin{tabular}{lll}
\hline Journal & Publisher & Articles published \\
\hline Engineering Structures & Elsevier & 105 \\
Journal of Performance of Constructed Facilities & ASCE & 53 \\
Journal of Constructional Steel Research & Elsevier & 49 \\
Jianzhu Jiegou Xuebao Journal of Building Structures & Science Press & 41 \\
Gongcheng Lixue Engineering Mechanics & Tsinghua University & 35 \\
Journal of Structural Engineering & ASCE & 35 \\
ACI Structural Journal & ACI & 19 \\
Structural Design of Tall and Special Buildings & John Wiley and Sons & 19 \\
Advances in Structural Engineering & Multi-Science Publishing & 15 \\
Structural Engineering and Mechanics & Techno Press & 15 \\
\hline
\end{tabular}

Table 4. Most relevant papers on progressive collapse of structures by number of citations received (up to 31 December 2017)

Article Cites

[30] Izzuddin BA, Vlassis AG, Elghazouli AY, Nethercot DA. Progressive collapse of multi-storey buildings due to sudden column loss - Part I: Simplified assessment framework. Eng Struct 2008;30(5):1308-1318

[1] Ellingwood BR. Mitigating risk from abnormal loads and progressive collapse. J Perform Constr Facil 2006;20(4):315-323

[31] Yi W-, He Q-, Xiao Y, Kunnath SK. Experimental study on progressive collapse-resistant behavior of reinforced concrete frame structures. ACI Struct J 2008;105(4):433-439

[32] Marjanishvili S, Agnew E. Comparison of various procedures for progressive collapse analysis. J Perform Constr Facil 2006;20(4):365-374

[33] Kim J, Kim T. Assessment of progressive collapse-resisting capacity of steel moment frames. J Constr Steel Res 2009;65(1):169-179

[34] Ellingwood B, Leyendecker EV. Approaches for design against progressive collapse. ASCE J Struct Div $1978 ; 104(3): 413-423$

[35] Vlassis AG, Izzuddin BA, Elghazouli AY, Nethercot DA. Progressive collapse of multi-storey buildings due to sudden column loss-Part II: Application. Eng Struct 2008;30(5):1424-1438.

[36] Kaewkulchai G, Williamson EB. Beam element formulation and solution procedure for dynamic progressive collapse analysis. Comput Struct 2004;82(7-8):639-651

[37] Bao Y, Kunnath SK, El-Tawil S, Lew HS. Macromodel-based simulation of progressive collapse: RC frame structures. J Struct Eng 2008;134(7):1079-1091.

[38] Su, Y., Tian, Y., Song, X. Progressive collapse resistance of axially-restrained frame beams. ACI Struct J 2009;106(5):600-607 


\section{Progressive collapse and structural robustness in international codes}

\subsection{Development and evolution of provisions for robustness in international codes}

The introduction of code provisions for structural robustness was pioneered in the United Kingdom after the Ronan Point collapse in 1968 with the implementation of the Fifth Amendment [40] of the Building Regulations. Behind these first code revisions was the idea of providing minimum levels of structural robustness to enable multi-story frame buildings to redistribute and withstand gravity loads after the loss of one or more members. This concept of notional member removal evolved with time into different methods found in international codes, which are summarised in Table 5. Some of the current requirements in the UK given by the Approved Document A of the Building Regulations [41], which are an evolution from those introduced in the Fifth Amendment [40], were incorporated into the Eurocodes [23, 42], which are used across Europe. In the United States, early research in this field initiated from the evaluation of concrete panel systems [43] achieving similar conclusions to those introduced by the Fifth Amendment [40]. Current building codes in the US vary from one State and city to another, although in general design requirements regarding structural robustness are marginal except for the New York City Building Code [44] that in 1973 adopted similar rules to those in the UK. The collapse of the Alfred P. Murrah building in 1995 and the attack on the Twin Towers in 2001, amongst others, triggered the revision and introduction of design provisions for robustness across the US affecting Federal and Defense Facilities. In this context, codes such as UFC 4-023-03 [45] and the International Building Code [46] by the International Code Council were produced. The later code is similar in essence to UK Building Regulations [41], whereas the former proposes a more systematic and enhanced approach. ASCE 7-98 code [47] used in the design of civilian buildings contained some comments on structural robustness (minimum tying requirements), which were expanded considerably in the 2002 and 2016 versions [48, 49] to include specific methods for design against progressive collapse. Guidelines were also produced for new or renovated Federal buildings by the General Services Administration [10], which aligned with the DoD regulations; this code was superseded by GSA [50] with significant changes. Efforts were also made on the development of a unified terminology and procedures for disproportionate collapse standards and guidance by the ASCE SEI Committee [51]. In Canada, the National Building Code [52] was considered to be quite detailed at that time. Later versions of this code, including the current version [53], are more general giving commentary on ways how to achieve robustness without providing prescribed requirements. As pointed out by Ellingwood et al. [54] and Arup [55], the uniqueness of this code is that it provides specific values on acceptable levels of likelihood of an extreme event $\left(10^{-4}\right.$ per year or more) for which a structure should be designed. 
Table 5. Summary of design methods considered by international codes and guidelines.

\begin{tabular}{|c|c|c|c|c|c|}
\hline Area & Code & 1.Tying & 2.ALP & 3.Key & 4.Risk \\
\hline UK & Building Reg. 2010 [41] & $\checkmark$ & $\checkmark$ & $\checkmark$ & $\sim$ \\
\hline Europe & EN 1991-1-7 [23] & $\checkmark$ & $\checkmark$ & $\checkmark$ & $\checkmark$ \\
\hline US (Civil) & ASCE/SEI 7-16 [49] & $\checkmark$ & $\checkmark$ & $\checkmark$ & $\sim$ \\
\hline US (Civil) & NYC BC 2014 [44] & $x$ & $\checkmark$ & $\checkmark$ & $\sim$ \\
\hline US (Civil) & IBC 2009 [46] & $\checkmark$ & $x$ & $x$ & $x$ \\
\hline US (Gov.) & UFC 4-023-03 [45] & $\checkmark$ & $\checkmark$ & $\checkmark$ & $\sim$ \\
\hline US (Federal) & GSA 2013 [50] & $x$ & $\checkmark$ & $x$ & $\sim$ \\
\hline China & CECS 392:2014 [62] & $\checkmark$ & $\checkmark$ & $\checkmark$ & $x$ \\
\hline Canada & NBCC 1995 [53] & $\checkmark$ & $\checkmark$ & $\checkmark$ & $\sim$ \\
\hline Australia & NCC 2016 [58] & $x$ & $\checkmark$ & $\checkmark$ & $\checkmark$ \\
\hline
\end{tabular}

$\checkmark$ (method considered), $\times$ (method not considered), $\sim$ (method implicitly considered)

In other parts of the world, explicit considerations on structural robustness were not included in codes until the beginning of the 21st century. In Australia, loading code AS/NZS 1170.0 [56] includes some general principles to insure minimum levels of continuity, ductility and strength so that alternative load paths can develop. However, it has been recognised that this code does not address structural robustness explicitly and comments on minimum member and connection strengths are merely based on current accepted practice [57]. The current code in Australia [58] has introduced in 2016 general and brief requirements based on the notional member removal and key element design for all building classes. In China, the earliest robustness considerations in building codes date to 2001 [59] which only included a general requirement on global stability ("local damage due to accidental loads should not lead to progressive collapse") and detailed design methods were not included. In 2010 and 2012, some design methods against progressive collapse were considered in codes for concrete structures [60] and concrete tall building structures [61]. Some of this work and subsequent work was triggered by the large number of collapsed buildings after the 2008 Wenchuan earthquake. In 2014, the Code for Anti-Collapse Design of Building Structures [62] was released and approved by the Ministry of Housing and Urban-Rural Development of China. This code, which was developed by a special committee led by Tsinghua University and the China Academy of Building Research, is the first collapse prevention design code in China showing design methods for steel and concrete buildings that align well with other international codes.

\subsection{Review of design methods against progressive collapse}

It is clear from this review and past reviews on design codes carried out by others $[4,54,63]$ that there are no universal rules to design against progressive collapse. However, there are some groups of design methods which can be easily identified across the different international codes; there are three widely recognised 
approaches, viz. (1) tying force prescriptive rules, (2) alternative load path (ALP) methods and (3) key element design methods. Recent comprehensive reviews in this field [54, 63] identified a fourth group, (4) risk-based methods. Table 5 summarises the general codes currently available with respect to these four widely recognised groups of design approaches. The main approaches and their applications are further discussed in this section. The tying force and ALP methods consider local failure, whereas the key element design method prevents local failure of critical elements. Starossek [65] and IStructE [66] also recognise "isolation by segmentation" (sometimes referred to as compartmentalisation) as a method to limit the extent of local failure. This approach, which is particularly useful in bridge structures, it is not explicitly mentioned in codes. Lastly, risk-based approaches compare the type of extreme event, its likelihood and severity of the consequences against the cost of protection and assumed potential losses [63].

Tying force prescriptive rules are commonly recommended in codes for structures with low risk of progressive collapse and they are aimed at providing minimum levels of tying, continuity and ductility, although the latter is not normally checked explicitly. The original background of these approaches is unclear; it seems that the first proposals applied for robustness were provided by the Institution of Structural Engineers in the UK [67] influencing UK Building Regulations [40] and in parallel the US work by the Portland Cement Association for large panel construction [68] which were later on used as the basis for ACI 318 tie force requirements. That early work was based on existing knowledge at that time on the design of large panels [69] and also on previous experience from the in-field response of buildings to blast loading during the WWII (work by Christopherson [70], Baker et al. [2] and Walley [71] amongst others, which is recently reviewed by Smith et al. [72]). The tying force approach is used in many codes such as EN 1991-1-7 [23], ASCE/SEI 7-16 [49], IBC 2009 [46] and UFC 4-023-03 [45]. This method is generally classified as an "indirect design approach" (implicit consideration of resistance to progressive collapse by providing minimum levels of strength, continuity and ductility). Other codes such as GSA 2013 [50], NYC BC 2014 [44] and NCC 2016 [58] exclude the tying force design approach. Tying is generally provided through horizontal and vertical ties achieved by prescribing a minimum tying force requirement, which are generally consistent within the different codes shown in Table 5, except for IBC 2009 [46] that provides lower tying forces [55]. Research on the efficiency of tying to different types of construction including steel and concrete structures showed that the rotations required in the connections to form a pure tensile membrane that arrests progressive collapse are unachievable in some cases [63, 73-76]. In order to address this issue, some codes such as UFC 4-023-03 [45] have included rotation limits on their tying force requirements for different forms of construction. In addition, the 2009 revision of UFC 4-023-03 [45] removes the tying forces from the 
internal and edge beams relying solely on the floor system to develop the internal tie through membrane action. Although it is not possible to quantify the enhancement in the minimum levels of robustness provided by the different tying force rules (and subsequent revisions), it is generally accepted that tying has a beneficial effect on robustness [55, 73-75].

ALP approaches based on the notional member removal concept are deterministic rather than prescriptive and they are widely accepted by all codes shown in Table 5, except for IBC 2009 [46]. The aim of these approaches is to demonstrate robustness explicitly (direct design method) through the analysis of the structure under codified damage conditions, assessing the ability of the structure to redistribute the additional loads from the areas subjected to local damage. Whilst the fundamentals of this approach are clear, in practice the ALP analysis requires several assumptions and simplifications resulting into a huge number of potential assumption combinations which can in turn lead to design/assessment solutions with different levels of robustness. As described by Arup [55], these considerations include whether or not to account for the source of local damage, refinements in the dynamic assessment (e.g. direct considerations from dynamic analysis or indirect considerations using static methods with dynamic amplification factors), material nonlinearity, strain-rate effects, large deformations of members, and deformation capacity of connections. In practice, the suitable level of refinement in the ALP analysis would depend on the building classification given by risk considerations or other performance-based criteria.

Regarding the different levels of refinement in the ALP methods, scenario-independent approaches (e.g. column removal where hazard causing the local damage is not considered) are easier to be implemented in codes (e.g. UFC 4-023-03 [45], GSA 2013 [50]). These are generally targeted to provide a minimum level of robustness covering different unspecified extreme events; this is a strategy used in different codes for design against accidental actions such as EN 1991-1-7 [23] (see Section 3). Scenario-dependent approaches might be needed in addition to look at specific events (e.g. fire, blast and impact) depending on the likelihood, consequences of failure, public perception, acceptable levels of risk and measures to prevent or mitigate the risk [23]. Regarding the dynamic nature of the extreme events under consideration, codes offer different considerations on the type of dynamic assessment to be performed. For example, the notional column removal proposed by the Approved Document A in the UK Building Regulations [41] adopts a static column loss, whereas codes such as UFC 4-023-03 [45] and GSA 2013 [50] adopt a sudden column removal in order to obtain an upper bound and to test the structure under dynamic conditions. UFC 4-023-03 [45] and GSA 2013 [50] allow linear (LSP) and nonlinear (NSP) static procedures (with dynamic increase factors for gravity loads) as well as nonlinear dynamic procedures (NDP). These three alternative methods are based on 
the general approach given by ASCE 41-06 [77] code for seismic rehabilitation of existing buildings with alterations to fit it to progressive collapse situations. Similarly, the Chinese code CECS 392:2014 [62] allows the use of LSP, NSP and NDP approaches in the ALP method; in the nonlinear methods (NSP and NDP), the plastic rotations of the horizontal members are limited to some prescriptive values for different cases of steel or concrete forms of construction. The advantages and disadvantages of NDPs over LSPs and NSPs are discussed by, amongst others, Arup [55] and Byfield et al. [4]. NDP methods have the highest level of complexity but they allow considering damping, strain-rate effects $[78,79]$ and the contribution of floor systems in providing alternative load paths [80]. On the other hand, NSPs can consider both material and geometric nonlinearities in a simple static fashion but requires the use of dynamic load factors, which can be problematic depending on the expected level of ductility demand on structural members, as pointed out by Izzudin and Nethercot [81]. Nonlinear static pushover analysis such as the one proposed by Izzudin et al. [30] in their ductility-centred robustness assessment framework has been recognised to be a powerful tool in design $[55,66]$ and it has been applied to steel and concrete buildings $[35,76,82]$. Other authors such as Khandelwal et al. [83] have proposed to use the pushdown resistance in ALP analysis, as a measure of robustness inspired by earthquake engineering approaches.

The key element design approach, also known as enhanced (or specific) local resistance approach in the US, is recommended in codes and guidelines (EN 1991-1-7 [23], UFC 4-023-03 [45], Building Regulations [41], NYC BC 2014 [44] and DS/INF 146 [84]) as a method of last resort when ALP methods are unable to demonstrate sufficient load redistribution ability of the structure. In this approach, key elements (i.e. structural members the failure of which activate a progressive collapse) are identified and designed to resist accidental loads, so emphasis is given on avoiding local failure of each key element. In EN 1991-1-7 [23] and Building Regulations [41], the design of key elements is part of the ALP approach for Class $2 \mathrm{~b}$ where the area of floor at risk of collapse is greater than a prescribed value. In high-risk Class 3 structures, a risk assessment might require, amongst other measures, that certain elements or groups of elements are designed as key elements. Similarly, the Australian code NCC 2016 [58] specifies that if a structural component sustains more than $25 \%$ of the total structure, then a systematic risk assessment is needed including the identification of critical elements which should be designed to minimise the risk for the identified hazard. It is worth noting that key element design is a direct design method which is also scenario-specific. However, some codes such as Building Regulations [41] use a notional static load pressure of $34 \mathrm{kPa}$ (corresponding to 5 psi) in the key element design, which is intended to cover different unspecified extreme events. This design value is an estimated figure of the explosion pressure on the flank wall at Ronan Point, which does not 
necessarily represent large pressures in extreme events such as gas and bomb explosions $[63,85]$. In this case, the use of a notional load ( $34 \mathrm{kPa}$ ) can provide some levels of robustness but it might not necessarily prevent local failure. Depending on the case and the requirements from the client, the designer might want to assess the dynamic load from specialized literature in terms of the main parameters (e.g. in a blast: charge weight and stand-off distance; in an impact: type of vehicle and velocity). Some information is available in international codes and manuals for some typical accidental actions (EN 1991-1-7 [23], TM-5-1300 [86], GB50009-2012 [87], UFC 4-10-01 [88]) and research in this area has focused on improving the accuracy in the predictions of the resistance and/or the applied load.

In the ALP and key design approaches, the combination of loads considered for accidental situations is relevant as it affects the dynamic response, demand-capacity ratio of the components of the structure and the connections. Structures are checked to resist specific accidental actions and/or to resist the damage after the accidental event. In such cases, load combination rules in codes reflect the low probability of concurrence of the accidental action and the design live load. In Eurocodes, EN 1990 [42] recommends (for regular buildings) a load combination with a reduction factor of the live load $(L)$ equal to 0.5 ; this factor is set to 0.3 if additional variable loads (e.g. wind, snow) are considered. Load $0.5 L$ represents a frequent combination value which is similar to that used in ASCE/SEI 7-16 [49], NBCC 1995 [53], CECS 392:2014 [62] and the nonlinear dynamic method in UFC 4-023-03 [45] and GSA 2013 [50]. New York code NYC BC 2014 [44] allows using a reduced value of $0.25 \mathrm{~L}$ in buildings with structural occupancy II using the ALP method, whereas $0.5 \mathrm{~L}$ is adopted for other occupancies or when the specific local approach is used. In the static methods proposed by UFC 4-023-03 [45] and GSA 2013 [50], the loads are also multiplied by a dynamic load factor of 2 or less (in some frame construction using deformation-controlled actions). A similar consideration is adopted in the Chinese code CECS 392:2014 [62] although constant dynamic factors are given depending on the form of construction; in UFC 4-023-03 [45] and GSA 2013 [50], the dynamic amplification factors can also depend on ductility.

The last general design approaches investigated are the risk-based approaches. Risk is considered implicitly in design by most codes in Table 5 by means of the building classification and design methods recommended for each class or risk category. Risk considerations are also included in some codes in order to define the overall design strategy (EN 1991-1-7 [23], NBCC 1995 [52], ASCE/SEI 7-16 [49], UFC 4-023-03 [45], GSA 2013[50]). For example, when the accidental action is identified, EN 1991-1-7 [23] recommends considering measures to mitigate the risk of the accidental action by (a) preventing or reducing the action, (b) protecting the structure so that it resists the action and (c) providing minimum robustness by designing the 
structure for the action. In addition, codes generally provide some tolerance levels for risk of collapse (e.g. based on relative area of collapse, structural damage limits, acceptable levels of likelihood or levels of protection). Some codes give explicit requirements on risk of collapse (e.g. EN 1991-1-7 [23], NBCC 1995 [53], NYC BC 2014 [44], UFC 4-023-03 [45], GSA 2013[50]). An example is the limitation of the area at risk of collapse $\left(70 \mathrm{~m}^{2}\right.$ or $15 \%$ of the floor area) proposed in the Fifth Amendment [40], also adopted in the Building Regulations [41], and increased to $100 \mathrm{~m}^{2}$ (maintaining 15\%) in EN 1991-1-7. Code UFC 4-023-03 [45] removed similar rules in 2009 since no damage to the floor was allowed in the new version of this code. In China, tall buildings classified as Safety Class I [61] are often referred to GB50068-2001 [59] which gives requirements for the conceptual robustness design, whereas other codes [59, 62] do not specify when robustness needs to be considered.

A major drawback in many codes is that risk is not considered in a very transparent nor systematic way. Some codes only consider the occupancy of the building, whereas others look only at the likelihood of the event or the consequences of the failure (e.g. percentage of collapsed area). These approaches may not be suitable for structures with high risk of progressive collapse (e.g. Classes $2 b$ and 3 in EN 1991-1-7 [23] or Categories IV and V in UFC 4-023-03 [45]). In such cases, designers are expected to use methods with the highest level of refinement, including risk-based and probability-based design approaches. The Australian code NCC 2016 [58] refers to systematic risk-based assessments in the key element design approach, although no information is given on how to achieve this. EN 1991-1-7 [23] includes explicit guidelines for carrying out a systematic risk-based assessment for high-risk structures (Annex B); background is given by Vrouwenvelder et al. [89]. In addition, Jones and Wainwright [90] or Harding and Carpenter [91] provided some guidelines for Class 3 design, including the definition of a framework in which the probability of occurrence of the hazard and its severity are assessed by the designer. Systematic risk assessment frameworks have been published, recently including the theoretical method by COST Action TU0601 [92] and The Institution of Structural Engineers manual [66]; other authors [93] have highlighted the need for these types of methods. Many researchers and practitioners also suggest the development and implementation of probabilistic approaches to consider the uncertainty in relevant variables to improve the accuracy in the structural robustness assessment. Probabilistic approaches for robustness are fairly recent and therefore have not been implemented in current codes. Some examples of recent research in this area can be found in the literature on structural reliability [94, 95], on risk and consequence analysis [96, 97], and on probabilistic, fragility and/or simplified reliability methods [79, 98-100]. 


\subsection{Considerations on material and forms of construction}

The design approaches summarised in Table 5 are applicable to any structure; however, codes normally provide additional specific requirements for different materials and forms of construction. These specific requirements can be found in some codes in the form of additional detailing rules, as part of indirect design measures; some examples for concrete structures include tying detailing requirements and additional reinforcement given by EN 1992-1-1 [101], ACI 318 [102] and CSA A23.3 [103] in Europe, US and Canada, respectively. In other codes such as UFC 4-023-03 [45] and GSA 2013 [50], specific requirements are provided as guidance on how to obtain relevant parameters in the general robustness methods for each type of construction material. UFC 4-023-03 [45] and GSA 2013 [50] include sections on reinforced concrete (RC), structural steel, masonry, wood and cold-formed steel. Those sections are based on structural robustness requirements in material-specific standards (e.g. ACI 318 [102] and CSA A23.3-04 [103] for cast-in-place and precast concrete construction, and AINSI/AISC 360-10 [104] for steel construction). Designers can also refer to guidance documents prepared by different construction research institutes, which provide informative examples on how to interpret and apply general rules for robustness to specific materials and forms of construction. In the UK, different documents are available for structural steel [105] and concrete [106], which show how tying requirements in UK Building Regulations [41] can be met using Eurocodes EN1993-1-1 [107] and EN1992-1-1 [101]. Other forms of construction such as precast concrete have been covered extensively by research in the past, especially in the 1970s in Europe and the US [68, 108-111], leading to several guidance documents for precast structures including PCI [112], PCA [113] and fib [114] or Matthews and Reeves [115] for large panel systems. Significantly less information is available on timber and masonry construction; in Europe, robustness considerations in such forms of construction are covered mainly by EN1991-1-7 [23]. Some general recommendations are given for masonry structures by Ellingwood et al. [54], BDA/AACPA/CBA [116] and some national codes such as BS 5628-1 [117] covering only lower and upper risk Classes 2a and 2b (EN1991-1-7 [23]). For timber frame construction with upper risk (Class 2b in EN1991-1-7 [23]), a research by Grantham and Enjily [118] indicated that vertical ties are not practical in design and focus should be on ALP and key element design methods. Further work is needed to cover Class 3 timber structures, as shown by Dietsch [119] for long-span timber roof structures.

The form of construction affects the strength, ductility, energy absorption, redistribution capacity and resistance to fire and corrosion of the system, which are structural parameters influencing robustness [93]. Different forms of construction will require different levels of control to achieve acceptable levels of robustness. As highlighted by Arup [55], the intention should be to "maximise the robustness" in each case 
by recognising and accepting the benefits of the form of construction considered. This is relevant in the development of future code provisions for robustness so that innovative forms of construction are not penalised over traditional solutions. Codes are continuously evolving and provisions for structural robustness are expected to develop in future years. High-rise construction with new materials and alternative forms of construction such as modular and composite structures will introduce new challenges in the assessment of structural robustness. In 2005, the Joint Committee on Structural Safety (JCSS) and the International Association of Bridge and Structural Engineering (IABSE) concluded that codes failed at that time to ensure sufficient structural robustness, which was especially concerning for high-risk buildings. That concern led to the European initiative COST Action TU0601 [92], which concluded that future codes should include approaches informed by risk analysis to enhance structural robustness. A report on structural robustness design for practicing engineers was also published by that COST Action group in 2011. In Europe, robustness considerations in EN 1990 [42] and EN 1991-1-7 [23] will be reviewed for the new generation of Eurocodes 2020. In the US, code revisions will also take place although large efforts have been made since the early 2000s. The role of research in this field is essential and it should align with these needs from construction industry.

\section{Quantification of structural robustness}

Any qualitative definition of structural robustness does not allow consequences of future abnormal events to be assessed and mitigated in an effective way. Robustness measures are then required to assess safety against progressive collapse, to estimate losses, and to decide whether a level of robustness is acceptable or not.

According to Lind [120] and Starossek [65], a robustness measure should meet at least some of the following general requirements: expressiveness, objectivity, simplicity, calculability, and generality. Expressiveness is the ability to quantify all features of robustness without influence by other aspects and to allow robust and non-robust structures to be distinguished each other. Objectivity is the insensitivity of the robustness measure to user decisions, namely, the robustness of the robustness measure. Simplicity is an attribute of the measure's definition. Calculability is another important attribute of the robustness measure because it defines the possibility of the measure to be evaluated with relatively low computational cost, based on quantifiable input parameters associated with the properties or behaviour of the structure. Generality is the ability of the robustness measure to be appropriate for any kind of structure. Simplicity, objectivity and generality should allow the robustness measure to be widely recognised by users. Starossek 
and Haberland [121] noted that a partial conflict between these five attributes might exist, making it impossible to fulfil all of them together. Indeed, if expressiveness is improved by increasing the computational cost, the calculability of the robustness measure reduces.

According to Baker et al. [122], a good robustness measure should be applicable to general systems, allowing for the ranking of alternative system choices and verification of acceptable robustness. If robustness is considered as the insensitivity of the system to small changes, a general definition of structural robustness by Brett and Lu [29] can be employed in view of quantitative assessment. Denoting by $G$ a global property of the structural system and $X$ a system variable that is exposed to an abnormal condition, the system sensitivity to $X$ can be defined as follows:

$$
S_{X}=\frac{\partial G}{\partial X}
$$

and ranges in the interval $[0,+\infty[$. Structural robustness related to $X$, i.e. the system insensitivity to $X$, can then be generally expressed as

$$
R_{X}=\frac{1}{1+S_{X}}
$$

This measure establishes the case of extreme sensitivity (i.e. zero robustness) in which $S_{X}$ approaches infinity and $R_{X}$ approaches zero, and the case of maximum robustness (i.e. zero sensitivity) in which $S_{X}$ approaches zero and $R_{X}$ approaches unity. For notional member removal, $X$ becomes a discrete variable because it describes the member itself. In that case, the system sensitivity can be quantified as a normalised variation in $G$ as follows:

$$
\bar{S}_{X}=\delta G_{X}
$$

so sensitivity ranges in the interval $[0,1]$, where zero and one respectively indicate no variation and $100 \%$ change in $G$ under removal of member $X$. As a result, the system robustness turns out to be:

$$
\bar{R}_{X}=1-\bar{S}_{X}
$$

Tables 6, 7 and 8 provide a comprehensive selection of robustness measures proposed in the literature. Tables 6 and 7 include a summary of reliability/risk-based measures, in which robustness is assumed to be a threat-dependent characteristic that takes into account the effects of abnormal loading or initial damage to the structure. Table 8 outlines deterministic measures of structural robustness, assuming the latter to be a threat-independent characteristic of the structure regardless of the events that may trigger a disproportionate collapse. In most cases, the robustness measure compares a system performance metric in intact conditions to the same metric related to a damaged state resulting from a prescribed scenario, such as sudden damage to 
one or more components, aging and progressive deterioration.

Table 6. Threat-dependent, reliability/risk-based measures of structural robustness

\begin{tabular}{|c|c|c|}
\hline Measure & Equation & Source \\
\hline Robustness index & $\beta_{r}=\frac{\beta_{\text {intact }}}{\beta_{\text {intact }}-\beta_{\text {damaged }}}$ & [123] \\
\hline Redundancy index & $R I=\frac{P_{f(d m g)}-P_{f(s y s)}}{P_{f(s y s)}}$ & [124] \\
\hline Vulnerability index & $V=\frac{P\left(r_{d}, S\right)}{P\left(r_{i}, S\right)}$ & {$[120]$} \\
\hline Robustness index & $R O I=\min _{i} \frac{P_{f 0}}{P_{f i}}$ & {$[96]$} \\
\hline Robustness index & $I_{r o b}=\frac{R_{d i r}}{R_{d i r}+R_{\text {ind }}}$ & {$[122]$} \\
\hline Robustness index & $I_{\text {rob }}=\frac{\beta_{\text {damaged }}}{\beta_{\text {intact }}}$ & [125] \\
\hline Conditional robustness index & $I_{\text {rob|exposure }}=\frac{R_{\text {dir|exposure }}}{R_{\text {dir|exposure }}+R_{\text {ind } \mid \text { exposure }}}$ & [125] \\
\hline Robustness index for single event $i$ & $R I_{i}=1-\frac{1}{C_{n}^{1}} \sum_{k=1}^{n} \gamma_{k i} v_{k i}$ & {$[126]$} \\
\hline Robustness index for multiple discrete events & $R I=\sum_{i} \omega_{i}\left(1-\frac{1}{n} \sum_{k=1}^{n} \gamma_{k i} v_{k i}\right)$ & {$[126]$} \\
\hline Robustness index for continuous event & $R I=\int_{-\infty}^{+\infty} \omega(x)\left(1-\frac{1}{n} \sum_{k=1}^{n} \gamma_{k i} v_{k i}\right) \mathrm{d} x$ & [126] \\
\hline
\end{tabular}

Notation: $C_{n}^{1}=$ number of all possibilities when 1 out of $n$ components is removed (reciprocal of $C_{n}^{1}$ used to bound the vulnerability index $V I_{i}=1-R I_{i}$ in the interval $\left.[0,1]\right) ; P_{f(d m g)}=$ probability of damage occurrence to system; $P_{f(s y s)}=$ system failure probability; $P(\cdot)=$ failure probability of structure; $P_{f 0}=$ failure probability of undamaged system; $P_{f i}=$ system failure probability after damage to $i$-th critical member; $r_{d}=$ resistance of damaged structure; $r_{i}=$ resistance of intact structure; $R_{0}=$ load-bearing capacity of intact structure; $R_{\text {dir }}=$ direct risk level associated with localised damage to single structural components; $R_{k i}=$ load-bearing capacity of damaged structure after failure of $i$-th component; $R_{\text {ind }}=$ indirect risk level associated with disproportionate collapse; $S=$ load; $\beta_{\text {damaged }}=$ reliability index of damaged structure; $\beta_{\text {intact }}=$ reliability index of intact structure; $\gamma_{k i}=$ importance coefficient of $k$-th element under $i$-th event ( $\left.\gamma_{k i}=\left(R_{0}-R_{k i}\right) / R_{0}=1-R_{k i} / R_{0}\right) ; v_{k i}=$ vulnerability coefficient of $k$-th element under $i$-th event (here regarded as demand-to-capacity ratio in terms of strains or internal forces); $\omega=$ probability of occurrence of $i$-th event. 
Table 7. Threat-dependent, deterministic measures of structural robustness

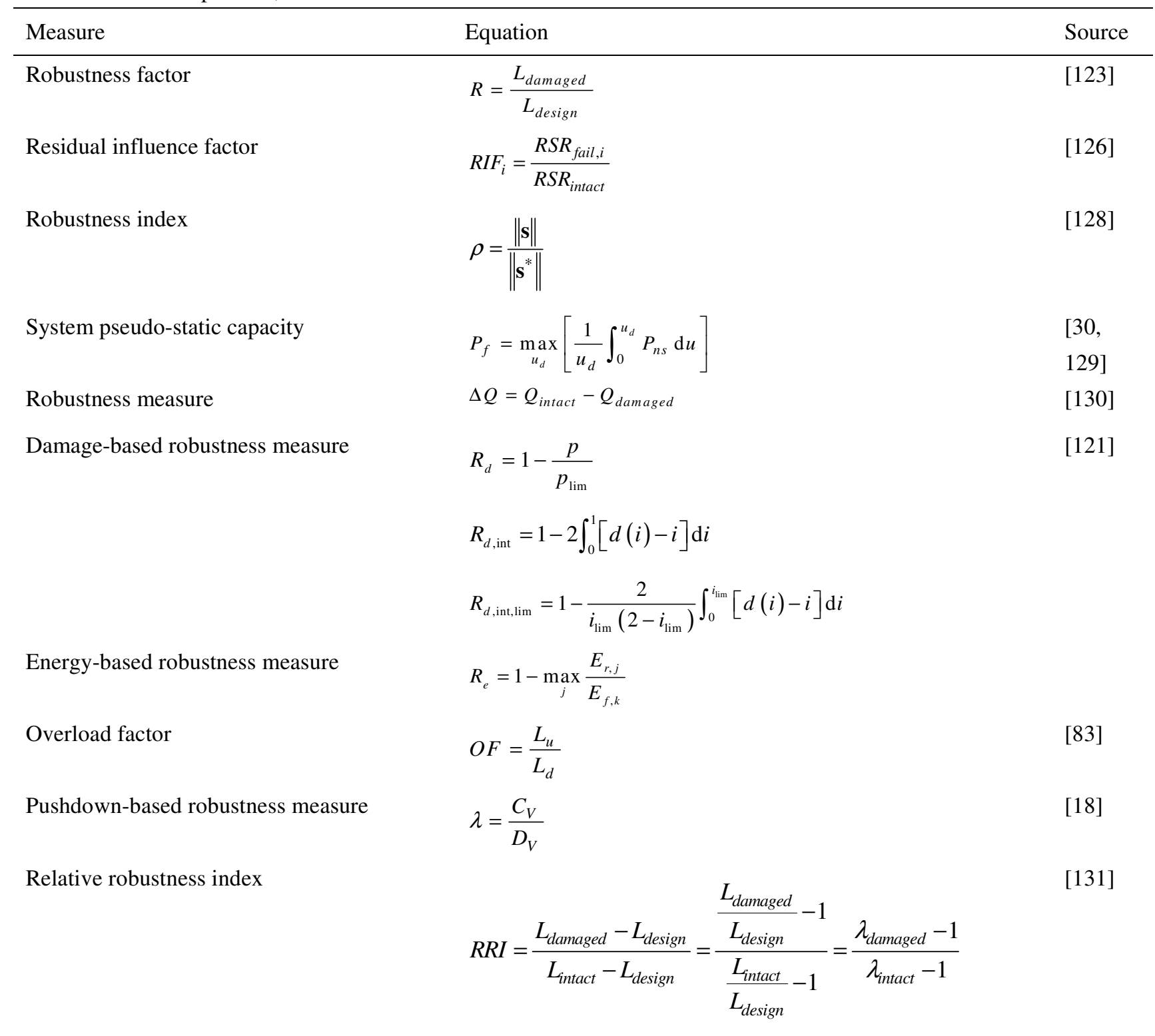

Notation: $C_{V}=$ vertical load-bearing capacity of damaged structure after single or multiple member loss; $d(i)=$ maximum total damage resulting from and including initial damage; $D_{V}=$ vertical design load corresponding to exceptional load combination; $E_{f, k}=$ energy required for damage to element $k ; E_{r, j}=$ energy released during initial failure of structural element $j$ and contributing to propagate damage to another element $k ; i=$ extent of initial damage; $L_{d}=$ nominal gravity load; $L_{\text {damaged }}=$ load-bearing capacity of damaged structure,$L_{\text {design }}=$ design load $; L_{\text {intact }}=$ load-bearing capacity of intact structure; $L_{u}=$ ultimate load of damaged structure; $p=$ maximum total damage resulting from initial failure; $p_{\text {lim }}=$ acceptable level of total damage; $P_{n s}=$ vertical load-bearing capacity of structure evaluated through nonlinear static analysis with displacement control; $Q_{\text {damaged }}=$ load-bearing capacity of damaged structure; $Q_{\text {intact }}=$ load-bearing capacity of intact structure; $R S R_{\text {fail, } i}=$ reserve strength ratio of structure after failure/removal of $i$-th member; $R S R_{\text {intact }}=$ reserve strength ratio of intact structure; $\mathbf{s}=$ displacement vector of intact structure; $\mathbf{s}^{*}=$ displacement vector of damaged structure; $u_{d}=$ vertical displacement imposed to the structure at the location of removed column; $\lambda_{\text {damaged }}=$ maximum load multiplier of damaged structure; $\lambda_{\text {intact }}=$ maximum load multiplier of intact structure; $\|\cdot\|=$ Euclidean matrix norm. 
Table 8. Threat-independent, deterministic measures of structural robustness

\begin{tabular}{lll}
\hline Measure & Equation & Source \\
\hline Stiffness-based robustness measure & $R_{s}=\min _{j} \frac{\operatorname{det} \mathbf{K}_{j}}{\operatorname{det} \mathbf{K}_{0}}$ & {$[121]$} \\
Integrity distance metric & $\delta_{S}=\frac{n}{\|\mathbf{K}\| *\left\|\mathbf{K}^{-1}\right\|}$ & {$[20]$} \\
Integrity volume metric & $\Delta_{S}=\operatorname{det} \mathbf{K}_{\mathbf{N}}$ & [29] \\
Robustness & $R=\frac{Q\left(S^{\prime}\right)}{Q(S)}$ & \\
\hline
\end{tabular}

Notation: $\mathbf{K}_{0}=$ stiffness matrix of intact structure; $\mathbf{K}_{j}=$ stiffness matrix of structure after removal of $j$-th element or connection; $\mathbf{K}_{\mathbf{N}}=$ normalised stiffness matrix obtained from $\mathbf{K}$ by dividing the $i$-th row by $\sqrt{\sum_{j=1}^{n} k_{i j}^{2}} ; n=$ size of squared matrix; $Q\left(S^{\prime}\right)$ = well-formedness of intact structure; $Q(S)=$ well-formedness of damaged structure; $\|\cdot\|=$ Euclidean matrix norm so that $\|\mathbf{K}\|=\sqrt{\sum_{i j} k_{i j}^{2}}$.

Amongst threat-dependent reliability/risk-based measures, the robustness index proposed by Frangopol and Curley [123] quantifies the level of robustness through a function $\beta_{r}$ of the reliability indices related to intact and damaged conditions (denoted by $\beta_{\text {intact }}$ and $\beta_{\text {damaged }}$, respectively), assuming the reliability index as a system performance metric for the structure. $\beta_{r}$ approaches infinity as $\beta_{\text {damaged }}$ approaches $\beta_{\text {intact }}$, meaning that the damaged structure has the same reliability level of the intact structure. Fu and Frangopol [124] proposed a redundancy index $R I$ that depends on both the probability of damage occurrence to the structure and the probability of collapse. Lind [120] introduced a vulnerability index that accounts for the increase in failure probability after initial damage to the structure. Based on the quantification of failure probability before and after damage to single members, Maes et al. [96] defined a robustness index ROI as the minimum of ratios between those probabilities over a range of damage scenarios to single components. Another robustness metric denoted by $I_{r o b}$ was proposed by Baker et al. [122] who considered robustness as a system property associated with the relative risk due to indirect consequences. This means that the system may be considered to be robust even if the risk associated with direct consequences is high, but this is only an apparent drawback of this robustness measure because high direct risk is rejected by conventional reliability criteria. From a numerical point of view, as the level of indirect risk $R_{\text {ind }}$ related to disproportionate collapse approaches zero, $I_{r o b}$ approaches unity and indicates the maximum level of structural robustness. By contrast, as $R_{\text {ind }}$ increases, $I_{\text {rob }}$ reduces and reaches unity when all risk is related to indirect consequences (case of zero robustness). These limit situations allow $I_{r o b}$ to be defined as index, because it falls in the interval $[0,1]$ with larger values indicating greater robustness. It is also emphasised that such an index is a function of consequences, so it includes the probabilities of failure at both local and global structural levels, costs and 
risk management strategies. Sørensen [125] proposed another robustness index that is the ratio of the system reliability indices related to damaged and intact conditions of the structure. For positive reliability indices, such an index falls in the interval $[0,1]$. The same researcher also proposed a conditional robustness index to overcome difficulties in modelling and quantification of the probability of exposures, i.e. hazardous events (especially if related to human/gross errors), for risk assessment. This robustness measure is a function of direct and indirect risks conditioned upon a given exposure. More recently, Chen et al. [126] developed three formulations to quantify robustness in case of discrete (either single or multiple) and continuous events, defining as many indices falling in the interval $[0,1]$. Each index depends on the impact that damage to single components has on the overall system, the number of possible local damage scenarios, and vulnerability of single components.

Deterministic measures of structural robustness in Table 7 are mostly dimensionless factors that depend on the threat. Frangopol and Curley [123] proposed a robustness factor that is a residual capacity-demand ratio falling in the interval $\left[0,+\infty\left[\right.\right.$. Another interesting measure is the residual influence factor $R I F_{i}$ corresponding to a given damage scenario $i$, which was introduced by ISO 19902:2007 [127] in the offshore industry and is sometimes referred to as damaged strength ratio. This measure falls in the interval $[0,1]$ with greater values representative of higher robustness levels. Also, RIF depends on reserve strength ratios corresponding to damaged and intact conditions. For the structure in the $j$-th state (including the intact one), $R S R_{j}=R_{c j} / S_{c j}$ where $R_{c j}$ is the characteristic value of base shear capacity of an offshore platform in $j$-th state and $S_{c j}$ is the design load corresponding to ultimate collapse of an offshore platform in $j$-th state. The minimum of RSRs over a set of member failure scenarios provides the best indication on the structural robustness level. Biondini and Frangopol [128] proposed a robustness index falling in the interval [0,1] that compares the Euclidean norms of displacement vectors of the structure in intact and damaged states. Based on energy equilibrium, Izzudin et al. [30] and Tsai and Lin [129] proposed the system pseudo-static capacity $P_{f}$ as a robustness metric for building structures. This capacity measure is defined as the maximum value of pseudo-static load $P$ for which the corresponding displacement $u_{d}$ does not exceed the displacement capacity $u_{f}$ defined for the limit state (e.g. the failure of a beam-column connection). In the case of structures without softening response due to, for instance, arch resisting mechanisms within RC beams, $P_{f}$ is usually associated with $u_{f}$ on the pseudo-static response curve. The potential of progressive collapse can be identified by means of the ratio between $P_{f}$ and the gravity load $P_{0}$. Bontempi et al. [130] proposed an alternative robustness measure which is the overstrength of the intact structure with respect to a damaged configuration. Starossek and Haberland [121] proposed damage-based and energy-based groups of robustness measures. The former 
group is based on the use of damage measures (DMs), which can be functions of affected masses, volumes, floor areas (e.g. in the case of building structures) or repair costs, the latter typically being used as economic loss metrics. After that a damage tolerance $p_{\text {lim }}$ is assumed, the first robustness measure $R_{d}$ is the complement of $p / p_{\text {lim }}$ to unity, where $p$ indicates the fraction of total damage associated with propagation of initial failure throughout the structure. In that case, one can find $R_{d}=1$ if $p=0$ and $R_{d}=0$ if $p=p_{\text {lim }}$, given a non-zero initial damage. Negative values of $R_{d}$ are attained if $p>p_{\text {lim }}$, indicating that performance objectives in terms of damage tolerance are not met. Another damage-based measure is $R_{d, \text { int }}$ which depends on the integral of the function $[d(i)-i]$ over the range [0,1], being $d(i)$ and $i$ the final and initial levels of a DM (e.g. mass) normalised to that of the intact structure. The variables $i$ and $d(i)$ range between 0 and 1 , the same situation occurring for $R_{d, \text { int }}$. According to the equation reported in Table 7, the maximum level of robustness is obtained if $d(i)=i$, meaning that total damage consists only of the initial failure of individual members without propagation. This means that the function $d(i)$ quantifies how much damage propagation increases given initial damage $i$. Nonetheless, if robustness is defined as insensitivity to local damage, huge levels of initial damage should not be considered for robustness quantification because they are associated with critical scenarios rejected by ordinary reliability verifications, as also observed for the index proposed by Baker et al. [122]. This consideration led to the proposal of a third damage-based robustness measure [119], which accounts for the limitation of the initial damage level to an upper bound $i_{\text {lim }}$ that establishes the acceptable initial damage. The additional damage-based measure was thus derived by restricting the range $[0,1]$ to $\left[0, i_{\text {lim }}\right]$ for the computation of the integral of the function $[d(i)-i]$. The energy-based robustness measure $R_{e}$ proposed by Starossek and Haberland [121] takes values in the interval ]- $\left.\infty, 1\right]$. In that measure, the energy released during the initial failure of a structural element $j$ and contributing to propagate damage to another element $k$ is compared to the energy required for damage to element $k$ (i.e. the energy dissipation capacity of that element). The following cases can be identified: (i) $R_{e}<0$ which denotes the occurrence of system collapse; (ii) $0<R_{e}<1$ which indicates acceptable levels of robustness; and (iii) $R_{e}=1$ which stands for maximum robustness. In the case of buildings, Khandelwal and El-Tawil [81] and Parisi and Augenti [18] proposed the overload factor $O F$ and pushdown-based robustness measure $\lambda$, respectively. The former measure is similar to the robustness index reported in [29], being the ratio between the ultimate load of damaged structure and design load. The measure $\lambda$ turns out to be the collapse load multiplier of the damaged structure corresponding to the vertical design load. Finally, Fallon et al. [131] proposed the relative

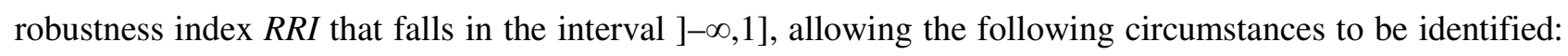
(i) $R R I<0$ which indicates that the damaged structure does not meet the design load requirements; (ii) $0<$ 
$R R I<1$ which denotes that the capacity of the damaged structure exceeds the design load, even though it is lower than the capacity of the intact structure; and (iii) $R R I=1$ which indicates that local damage does not produce a loss of structural capacity.

The last group of measures is summarised in Table 8 , according to a threat-independent and deterministic view of structural robustness. All those measures depend on some characteristics of the stiffness matrix of the structure. The robustness measure $R_{s}$ proposed by Starossek and Haberland [121] is a function of determinants of the stiffness matrix in damaged and intact conditions, which does not range between zero and unity as it needs to be normalised. This produces a low level of measure's expressiveness. Furthermore, the reduction in load-bearing capacity due to member removal or damage is not well correlated with $R_{s}$, so the latter should be regarded as a connectivity measure instead of a complete robustness measure. This is because system connectivity, and hence redundancy, provides only a partial contribution to robustness. According to a consequence-based approach to unforeseeable/unforeseen events, Nafday [20] developed two integrity measures denoted as integrity distance metric $\delta_{S}$ and integrity volume metric $\Delta_{S}$. The former accounts for the contributions of topological connectivity, geometry of members, their importance or criticality in ALPs, material behaviour and applied loading to system integrity. From a geometrical standpoint, $\delta_{\mathrm{S}}$ is the shortest distance from the $(n \times n)$ stiffness matrix $\mathbf{K}$ to the set of singular matrices. Also, $\delta_{S}$ is the reciprocal of the condition number of the matrix, which ranges from 1 (case of orthogonal matrix) to $+\infty$ (case of singular matrix). Therefore, $\delta_{S}$ falls in the interval [0,1], indicating how stable with respect to overall collapse the structure is under given loading conditions. This metric can be evaluated for both the intact and damaged structures to measure the potential of progressive collapse. The integrity volume metric $\Delta_{S}$ provides the volume of the parallelepiped defined by the column vectors of the stiffness matrix. The more the system is linearly dependent causing structure's instability and singularity of stiffness matrix, closer are the column vectors resulting in smaller volume for the parallelepiped. A zero volume stands for singular matrix, whereas the maximum value of $\Delta_{S}$ is one according to a normalisation rule for K. Finally, Brett and $\mathrm{Lu}$ [29] proposed a topology-based robustness measure $R$ relying upon the concepts of structural hierarchy [132] and well-formedness $Q(\cdot)$ [131], the latter being a stiffness-based measure of the quality of the topology and connectivity of the structure. By contrast, one can quantify the deterioration in the structural form after a damage event by means of the separateness $\gamma=\left[Q(S)-Q\left(S^{\prime}\right)\right] / Q(S)$. 


\section{Progressive collapse risk}

The deterministic nature of the majority of codes and guidelines on progressive collapse resistant design (see Section 4) reflects a dominant non-probabilistic research in the field. Nevertheless, the presence of large uncertainties in abnormal loads and nonlinear structural response highlights the need for probabilistic assessments and risk-informed design. Ellingwood and Leyendecker [34] performed one of the earliest probabilistic studies on progressive collapse, promoting the use of the ALP method to assess structural robustness. Bennett [134] developed conceptual models and formulations to compute the probability of progressive collapse under either a given abnormal load or an initial damage. That research evidenced that, even if the probability of progressive collapse given a damage level is relatively high, the reliability of the structure may be accepted if the probability of initial damage is low. Agarwal et al. [132] evaluated the vulnerability of 3D structural systems through the analysis of their structural form and connectivity, regardless of their response to specific actions. That kind of probabilistic analysis can provide useful information on the vulnerability of structures to unforeseeable events [133].

In a discussion on progressive collapse risk mitigation, Ellingwood [1] developed a mathematical framework for assessing risk from LPHC events. Two basic concepts were emphasised in that study. First, the project team should screen out trivial hazards, hence focusing on those threats that mostly contribute to risk and may lead to unacceptable risk levels. Second, performance-based design/assessment criteria based on acceptable risk should be developed to allow major hazards to be properly managed. According to Elms [135], Ellingwood [1] recalled that the concept of risk involves hazards, consequences, and context. The hazard is a potentially harmful event, action or state of nature, and is typically measured by its mean annual rate or probability of occurrence. The consequences of the hazard are usually expressed in terms of damage to buildings (e.g. local damage, partial or total collapse), infrastructure or the environment, effects on people (e.g. personal injury, loss of life, homeless), economic losses, or downtime. Probabilistic risk analysis (PRA), which is based on quantitative measures of risk, is deemed a rational approach that allows risk-informed decisions for disaster mitigation. Denoting by $H$ a LPHC event of interest, $L D$ a state of local damage to the

structure induced by $H$, and $C$ the progressive collapse caused by $L D$, the mean annual frequency (MAF) of structural collapse due to $H$ can be computed according to the total probability theorem as follows:

$$
\lambda_{C}=P[C \mid L D] P[L D \mid H] \lambda_{H}
$$

where $\lambda_{H}$ is the MAF of occurrence of $H, P[L D \mid H]$ is the conditional probability of local damage given $H$, and $P[C \mid L D]$ is the conditional probability of progressive collapse given $L D$. It should be noted that $\lambda_{H}$ is 
numerically interchangeable with the annual probability of occurrence for randomly occurring events with rates less than $10^{-2} /$ year. Ellingwood and Dusenberry [136] pointed out that the risk decomposition through Eq. (5) allows risk mitigation strategies to be straightforwardly identified and quantitatively managed. $P[L D \mid H]$ and $P[C \mid L D]$ define local and global vulnerability components of the structure, respectively. The former is related to direct consequences of a given abnormal load, the latter to indirect consequences. This means that $P[C \mid L D]$ depends on the system characteristics and defines the robustness of the structure in probabilistic terms. From a nomenclature viewpoint, some studies on robustness and progressive collapse use the term exposure to identify the hazard $\lambda_{H}$, whereas the term vulnerability is only associated with $P[L D \mid H]$ (e.g. Baker et al. [120], Starossek and Haberland [16]). Starossek and Haberland [16] stated that "The exposure results from the abnormal events that possibly affect a structure during construction and lifetime and are not considered in ordinary structural design" and assumed that vulnerability is the "Susceptibility of a structure to suffer initial damage when affected by abnormal events".

If multiple hazards and damage states are identified, Eq. (5) can be generalised to:

$$
\lambda_{C}=\sum_{H} \sum_{L D} P[C \mid L D] P[L D \mid H] \lambda_{H}
$$

Dealing with infrastructure assets exposed to natural or man-made hazards, Stewart [137] defined three risk acceptance criteria based on fatality risks, failure probabilities and cost-benefit assessment, extending Eq. (6) to the MAF of loss. If partial collapse is considered and quantified through a metric (e.g. the amount of damaged floor area), the mean annual frequency of loss $L$ can be determined as follows:

$$
\lambda_{L}=\sum_{H} \sum_{L D} \sum_{C} \sum_{L} P[L \mid C] P[C \mid L D] P[L D \mid H] \lambda_{H}
$$

Baker et al. [122] used a similar formulation in combination with an event tree approach for robustness quantification. If only total collapse is taken into account as propagation of local damage, $P[L \mid C]$ can be set to unity and the expected annual loss can be simply estimated as $\lambda_{C}$ times the number of elements at risk, i.e. an exposure measure [27]. Grant and Stewart [138] extended the mathematical formulation of loss to the case of improvised explosive devices (IEDs), including the probability of hazard given threat into Eq. (7). Based on consequence functions that define the relationship between loss and the extent of damage given the hazard intensity, Quiel et al. [139] proposed to evaluate consequences $C(T)$ by a double integration of consequence functions over all damage levels and hazard intensities given a blast threat $T$, obtaining a relative resilience index $R R I=1 / C(T)$. If a set of threat locations relative to the building is assumed, several values and statistics of $R R I$ are obtained. This is an interesting multi-deterministic approach that is compatible with the practice-oriented ALP method, allowing the level of consequences from blast-induced 
local damage to be determined and used as decision variable by which the level of risk is tolerated or reduced via structural and/or non-structural measures. Stewart [140] performed a PRA to identify the risks associated with vehicle borne improvised explosive device (VBIED) attacks to new federal government buildings in the United States. In that study, Stewart modelled not only hazard, damage and loss likelihoods, but also risk reduction, loss and protective costs as stochastic random variables (RVs).

It is worth noting that the quantification of $\lambda_{H}$ should rely on a sufficient amount of data so that engineering decisions can be made on an unconditional risk basis. This may not be the case of some threats such as terrorist attacks on a specific building. In other situations, small frequencies of occurrence may be rather complex to be interpreted with confidence. Therefore, a scenario-based (i.e. conditional) risk assessment can be carried out by replacing Eq. (5) by:

$$
P[C \mid S]=P[C \mid L D] P[L D \mid S]
$$

where $S$ denotes a given scenario [54, 136].

All conditional probabilities discussed above may be obtained from a PRA in which uncertainties in system performance are modelled and propagated. In the case of structural systems, this modus operandi is generally referred to as a structural reliability analysis. More in detail, when using a demand-and-capacity format, failure is assumed to occur when demand $D$ (i.e. the effects of loads) exceeds capacity $C$ such that the probability of failure $P_{f}$ is equal to:

$$
P_{f}=\int F_{C}(x) f_{D}(x) d x
$$

where $F_{C}(x)$ is the cumulative distribution function $(\mathrm{CDF})$ of capacity and $f_{D}(x)$ is the probability density function of demand. Both $C$ and $D$ should be quantified through a scalar or vector-valued measure that in line of principle depends on the type of loading or initial damage state. The probability of failure, also called limit state probability, is thus defined as $P_{f}=P[D \geq C]$. In the framework of first-order reliability methods, such a probability may be equivalently defined as $P_{f}=\Phi(-\beta)$, where $\beta$ is named reliability index (or safety index) and $\Phi(\cdot)$ is the CDF of the standardised Normal distribution. It should be recalled that $\beta=\Phi^{-1}\left(P_{f}\right)$ is rigorously defined as the ratio between mean $\mu_{g}$ and standard deviation $\sigma_{g}$ of the limit state function $g=C-$ $D$ if the latter is Normally distributed. For other distributions of $g, \beta$ turns out to be only a conventional measure of the reliability $R=1-P_{f}$, that is, the survival probability $P_{s}$.

In the performance-based design/assessment of a facility, decision makers should define a tolerable level of risk. Regarding the probability of collapse, the performance objective of life safety is met if the following condition is satisfied: 


$$
P[C] \leq p_{t h}
$$

in which $p_{t h}$ is the de minimis risk defining the acceptable risk level below which society normally does not impose any regulatory guidance $[54,136]$. Pate-Cornell $[141]$ took evidence that $p_{t h}$ is on the order of $10^{-}$ $7 / y e a r$. Stewart and Melchers [142] found that an annual fatality risk of less than $10^{-6}$ is generally accepted. For instance, assuming $p_{t h}=10^{-5} / 1000 \mathrm{~km} / \mathrm{year}$, Russo and Parisi [143] derived minimum (risk-targeted) safety distances of RC framed buildings from natural-gas pipelines.

If the ALP method is used, the probability of collapse reduces to $P[C \mid L D]$ and can be evaluated through the convolution of demand and capacity. Thus, the following requirement should be met $[54,136]$ :

$$
P[C \mid L D] \leq p_{t h} / \lambda_{H}
$$

Given that $\lambda_{H}$ is on the order of $10^{-6} /$ year to $10^{-5}$ /year for most extreme events, the performance objective established by Eq. (11) is met if the conditional probability of collapse is on the order of $10^{-2} /$ year to $10^{-}$ 1/year. The latter is a target probability that is two to three orders of magnitude higher than that related to structural components and systems. This is because the limit state of progressive collapse defined by Eq. (10) is conditional in nature. This causes a target reliability index $\beta_{0}$ on the order of 1.5 , which is significantly lower than that assumed for the ultimate limit state of new residential structures (i.e., $\beta_{0}=4.7$ corresponding to a target probability of failure on the order of $10^{-6} /$ year, or equivalently, $\beta_{0}=3.8$ corresponding to $p_{t h} \approx 10^{-4}$ over a reference period of 50 years).

Conditional probabilities of local damage and progressive collapse may be determined through fragility analysis, which is a well-established tool in earthquake engineering [144] and is being extended to other hazards $[145,146]$. Stewart et al. [147] defined the blast fragility of built infrastructure in the framework of PRA for terrorism hazard.

As far as material-specific studies are concerned, research on progressive collapse risk and consequences under extreme events is at an early stage. ElSayed et al. [148] proposed a simplified PRA procedure for reinforced concrete block masonry buildings, deriving fragility curves that can be used to identify the most critical locations where protective barriers should be installed.

A greater amount of probabilistic studies was carried out on RC members and buildings. Based on Monte Carlo simulation and nonlinear finite element analysis, Kelliher and Sutton-Swaby [149] derived the percentage damage sustained by a 10-storey RC building subjected to an explosive load of given magnitude located randomly in the ground floor car parking. Hao et al. [150] performed a reliability analysis to assess the performance of RC columns and frames before and after FRP strengthening in resisting blast loading. 
Uncertainties in blast load predictions, RC column, and fibre reinforced polymer (FRP) composite were taken into account and played a key role. Numerical results showed the effectiveness of FRP strengthening for blast protection. Based on incremental dynamic analysis (IDA), Brunesi et al. [100] derived fragility functions for European, low-rise, RC framed buildings representative of both gravity-load and seismically designed structures according to Eurocodes. Fragility functions at multiple damage states demonstrated a significant influence of both seismic design/detailing and secondary beams on robustness of RC buildings. $\mathrm{Yu}$ et al. [151] found that gravity loads and steel reinforcement properties have the highest influence on residual capacity of damaged $\mathrm{RC}$ frames.

In the framework of the ALP method, Arshian et al. [152] investigated the influence of modelling strategies on uncertainty propagation through a global variance-based sensitivity analysis. A 3-storey RC framed building structure with $3 \times 3$ bays was modelled through both plastic hinges and fibre-based elements. Maximum bending curvature at beam end sections and maximum vertical displacement at the location of the removed column were more sensitive to compressive concrete strength in fibre-based models and both concrete Young's modulus and steel yield strength in lumped plasticity models. This discrepancy was associated with the inability of plastic hinges in reproducing concrete cracking and compressive arch action. Correlation between compressive strength and Young's modulus of concrete dominated the sensitivity of structural response to uncertain input variables. In all cases, lumped plasticity models provided less robust results (i.e. larger variations in output) compared to distributed plasticity models. Uncertainty propagation was also investigated under increasing gravity load via IDA. A good agreement between displacement-based and force-based fibre-based models was found at low-to-moderate load levels. Nevertheless, when high load levels were considered, the structure was more prone to progressive collapse and force-based element formulation provided more reliable results because displacement-based fibre models underestimated maximum curvature demand and consequently the probability of failure. The influence of concrete strength, steel properties, dead load and damping coefficient increases as yielding develops throughout the structure, the opposite occurring for concrete Young's modulus that mainly affects structural response to low load levels.

Li et al. [153] proposed a collapse probability index that does not depend on the initial local failure and was used to derive progressive collapse fragility curves. Also, a simplified method to obtain the progressive collapse fragility curve of RC frames was developed for engineering design practice.

Xue et al. [154] used sets of coarse-scale cohesive elements in order to model the failure of potential damage zones in RC beams, columns, slabs and shear walls. It was shown that deterministic analysis 
according to UFC provisions allows the prediction of progressive collapse events with a probability of occurrence of up to $5 \%$, which is a collapse risk usually accepted for ordinary-importance buildings. By contrast, critical structures should be assessed through a probabilistic analysis.

Dealing with steel structures, Park and Kim [155] performed a pushdown-based fragility analysis to assess the progressive collapse potential of frames with different types of connections. Fragility curves were derived by computing the probability that the vertical displacement at the location of removed column exceeded a limit state level under increasing gravity load. Xu and Ellingwood [156] explored the robustness of seismically designed pre-Northridge steel moment-resisting frame buildings both deterministically and probabilistically, considering uncertainty in connection strength and performing nonlinear dynamic analysis. A negligible influence of catenary action was found, whereas flexural moment demands on connections were much larger than mean failure moment, indicating a high probability of connection failure. However, uncertainty in connection behaviour was relatively low so a mean-centred, deterministic robustness assessment of those structures should be sufficient.

\section{Experimental testing}

Research based on experimental tests has made huge advances in the field of progressive collapse and has made it possible to improve existing codes and design recommendations and calibrate numerical models. Up to only a few years ago, very few experimental studies had been carried out, but fortunately this trend has changed and at the present time a large amount of data is available thanks to some ambitious experimental campaigns. This section reviews some of the most important experimental tests made to date in relation to progressive collapse of building structures. Most of those tests simulated the failure of one or more columns and considered what have been called threat-independent scenarios on four different levels:

a) sub-assemblages usually formed by two beams and one or more columns;

b) frames formed by beams and columns;

c) building structures constructed solely for experimental purposes;

d) actual buildings condemned to demolition.

Up to now, the tests have mostly focused on concrete, steel and composite structures, while masonry and timber structures have been practically ignored. The following sections briefly enumerate and describe some of the most important among the four types cited above.

\subsection{Tests on sub-assemblages}

The experimental testing on progressive collapse of building structures has normally been done on 
sub-assemblages, which are usually composed of two span beams and one or three columns. The tests simulate the removal of a column to study the behaviour of beams and beam-column joints in order to characterise the resistance mechanisms that could help to hold up a progressive collapse (flexural, arch, and catenary action). The load is usually applied to the column whose removal is simulated, although there are other situations in which the load is applied to the beams. As tests on sub-assemblages are much less expensive than those on frames or building structures, they are naturally used more often. This section describes the tests most frequently used on sub-assemblages and other special characteristics of the procedures and specimen geometry.

\subsubsection{Steel and composite structures}

As beam-column connections are vitally important in ensuring resistance to progressive collapse of steel frame structures they have been the subject of many of the studies carried out to date. The test configuration most often used for this type of test considers that after a column fails the inflection points are located at the middle of the beam span. The specimens are designed so that the length is equal to half the span, using pin conditions at the ends. The column simulating failure is placed at the centre of the specimen, loaded by either a hydraulic jack or a direct load on the beam itself, so that it consists of two span beams and a central column. This test configuration was used by Qin et al $[157,158]$ and Wang et al. [159] to study beam-tubular column connections (see Fig. 4). Those researchers [157-159] tested specimens with different types of beam-column connections: field-welded through diaphragm connection (ST-WB), modified bolted through diaphragm connection (ST-B), reinforced welded flange-bolted web connection (ST-WBR), welded flange-weld web connection with internal diaphragms (I-W), welded flange-bolted web connection with internal diaphragms (I-WB), and welded flange-bolted web connection with short through diaphragms (ST-WB). Li et al. [160] used the same test configuration and type of specimen, but with a circular instead of square cross-section column with the following types of connection: welded flange-welded web connection (CO-W), and welded flange-bolted web connection (CO-WB). Yang and Tan $[161,162]$ also used a similar configuration on specimens with beam-column connections classified into: web cleat (W), top and seat angle (TS), top and seat with web angle (TSWA), fin plate, flush end plate (see Fig. 5), and extended end plate, to simulate the simple and semi-rigid behaviour of beam-column connections subjected to column failure. Gong [163] carried out similar tests on two types of beam-column connections: web bolted-angle, and flange and web bolted angles. To consider the dynamic behaviour associated with sudden column failure, Liu et al. [164-166] tested specimens similar to those used by Yan and Tan $[161,162]$. The principal novelty of the tests carried out by Liu et al. [164-166] was that the load was applied to the beams through steel plates instead of on the 
central column, while the sudden column failure was simulated by a quick-release mechanism. Three types of beam-column connections were tested: web cleat [164], top-and-seat with angle [165], and flush end plate [166].

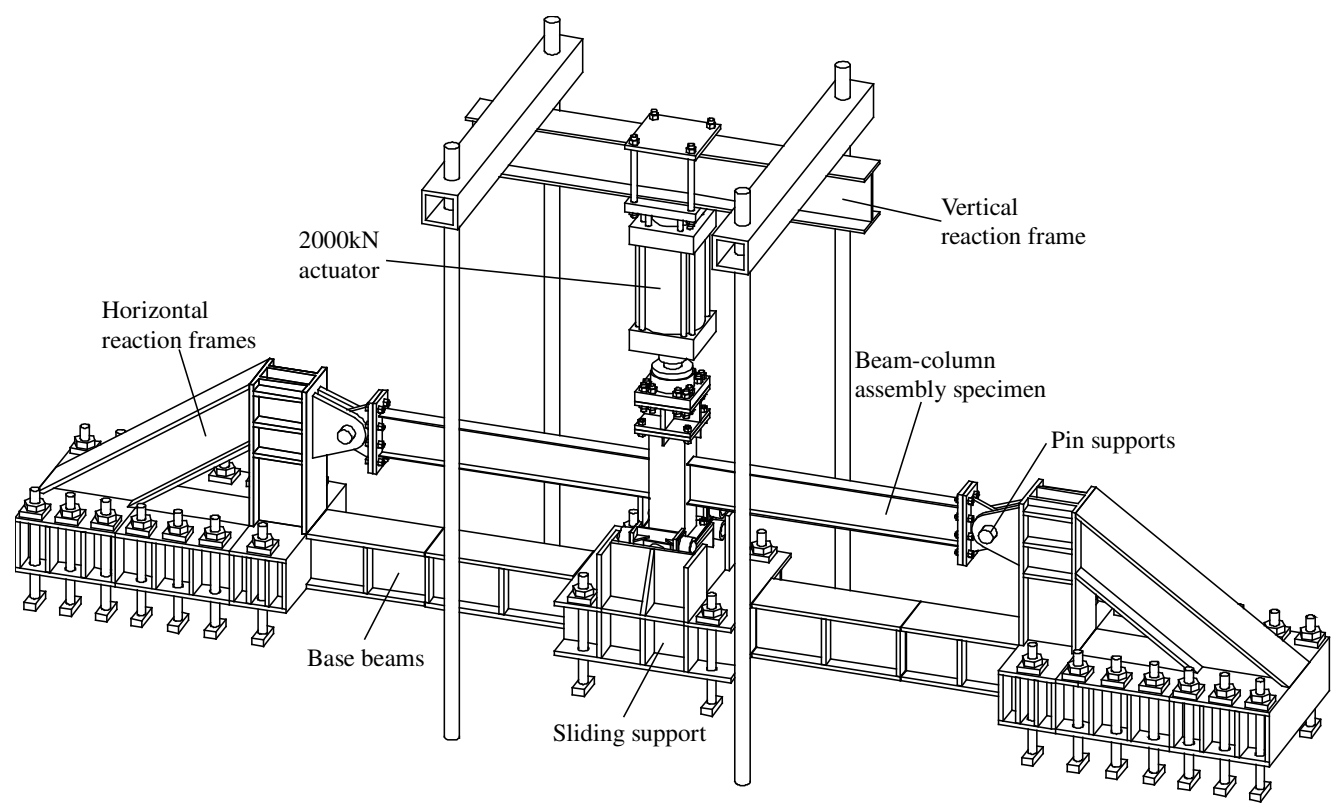

Fig. 4. Test set-up used by Qin et al. [158]. Image by courtesy of Wei Wang (Tongji University)

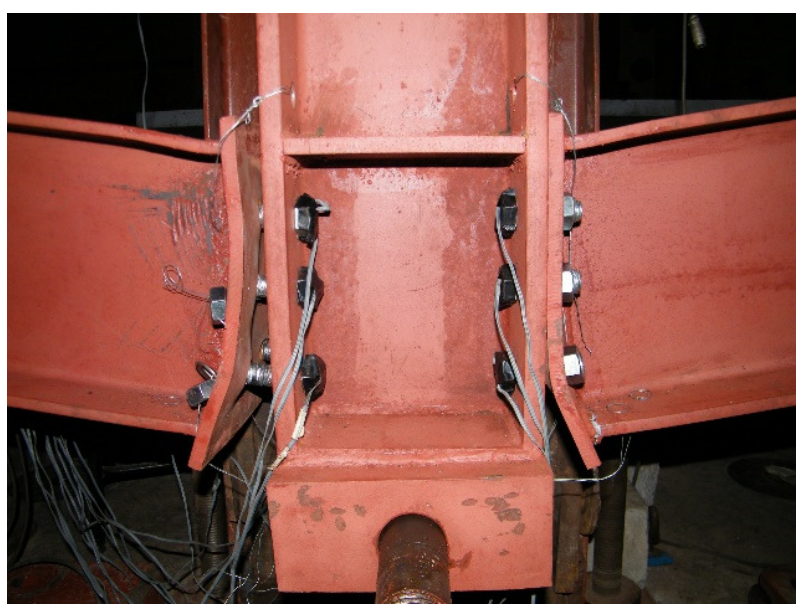

Fig. 5. Failure of a beam-column joint in a specimen tested by Yang and Tan [161]. Photo by courtesy of Bo Yang (Chongqing University)

Sadek et al. [167], Lew et al. [168], and Dinu et al. [169] used another test configuration in which the specimens were formed by two span beams, two exterior columns, and a central column with simulated removal (see Fig. 6). In this type of specimen, the external columns were given the necessary constraints to simulate the contribution of the neighbouring bays. Sadek et al. [167] and Lew et al. [168] tested two types of beam-column connections (IMF-intermediate moment frame and SMF-special moment frame) subjected to a monotonic load on the central column. Dinu et al. [169] worked in a similar fashion to Sadek et al. [167] and Lew et al. [168], with four types of beam-column connections: welded cover plate connection (CWP), haunch end plate bolted connection (EPH), reduced beam section welded connection (RBS), and unstiffened 
extended end plate bolted connection (EP).

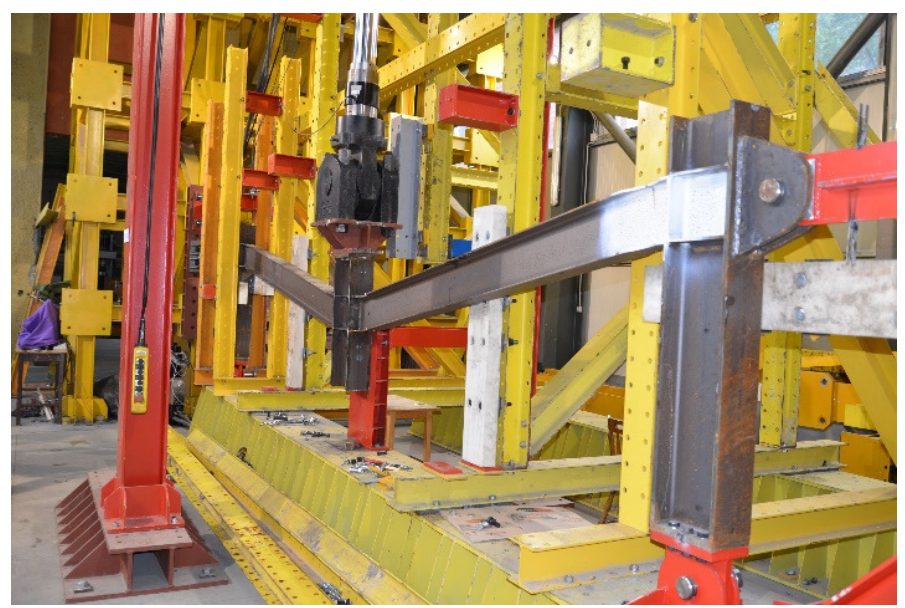

Fig. 6. Testing of a sub-assemblage by Dinu et al. [169]. Photo by courtesy of Florea Dinu (Politehnica University Timisoara)

Another type of test configuration uses T-shaped specimens, different to those described above, formed by a beam, a column and the beam-column connection. The most important tests using this type were those by Oosterhof and Driver [170], Weigand and Berman [171], Kim et al. [172], and Tyas et al. [173]. Although these tests are cheaper to run than those previously described, they only allow beam-column connections to be studied and cannot consider catenary beam behaviour.

In the field of composite structures, the studies by Yang et al. [174, 175] and Wang et al. [176] stand out. They used sub-assemblages to study how the presence of composite slabs can increase the load-carrying capacity of beam-column connections subjected to a column removal. Yang et al. [175] worked on a similar test configuration to Yang et al. [161, 162], using two span beams and a central column, with pin conditions at the ends of the beams. Two types of test were involved, known as: middle joints under a sagging moment, and side joints under a hogging moment. Types of connection used included: web cleat, strengthened web cleat, and flush end plate. Yang et al.'s [175] test configuration was subsequently improved by Yang et al. [175], who changed the beam-end pin conditions for columns, with specimens formed by two exterior columns, two span beams and a central column. Appropriate boundary conditions were given to the exterior columns to simulate the contribution of neighbouring bays. Another recent test was carried out by Wang et al. [176] with a configuration similar to that of Qin et al. [157, 158], except for the inclusion of a composite slab on the beams. Wang et al.'s [176] specimens were subjected to a sagging and hogging moment.

\subsubsection{Cast-in-place RC structures}

In the field of tests on sub-assemblages of cast-in-place RC structures, the studies by Sadek et al. [167] and Lew et al. [177] stand out on sub-assemblages formed by two span beams, two exterior columns, and a central column. The exterior columns were supported on RC footings and their tops were retrained from 
horizontal movements by rollers. The load was applied to the central column by means of four post-tensioning rods that were pulled down by four hydraulic rams. Two types of specimen were tested designed for different seismic categories: intermediate moment frames (IMF) and special moment frames (SMF). The tests were able to perfectly characterise the catenary action of beams. Yu and Tan [178] tested two specimens, with different seismic detailing, formed by two span beams and a central column. The load on the central column was applied by a hydraulic actuator. To simulate the axial restraints of indirectly-affected frames to a directly-affected frame, the ends of specimens were connected to a steel frame and a reaction wall through two horizontal pin connections (see Fig. 7). Yu and Tan $[179,180]$ tested sub-assemblages with geometry and conditions that mimicked the real behaviour of a frame with specimens formed by two span beams, two exterior columns, and a central column. Appropriate boundary conditions were applied to simulate the integration of sub-assemblages in a frame. As in Yu and Tan [178], the load was applied to the central column by a hydraulic actuator. Yu et al. [179] tested four specimens, one of which had conventional detailing, while the other three had special detailing to improve the catenary capacity action of beams and joints. Yu and Tan [1780] also tested four specimens with conventional non-seismic and seismic detailing to analyse the different behaviour of structures specially designed to withstand seismic loads and others with no special protection. Another recent study was carried out by Forquin and Chen [181] on five types of specimen (sub-assemblages) composed of one or three columns and two span beams, loaded on the central column. Sliding and pin connections were used to evaluate the influence of the boundary conditions. Digital image correlation (DIC) was used to analyse in detail the cracks and strains during different stages of the tests. Yu et al. [182] tested three sub-assemblages using a different method to those described above to study the dynamic behaviour caused by sudden column failure. The specimens were formed by two span beams and a central column and all specimens had conventional non-seismic detailing. The failure of the central column was due to an explosion when the specimen was supporting its self-weight only.

Other researchers such as Ren et al. [183] and Lu et al. [184] tested sub-assemblages that included the presence of slabs to quantify how slabs contributed to resisting progressive collapse. These authors used beam-slab specimens (see Fig. 8a) and beam specimens without slabs (see Fig. 8b) to compare the results. The ends of the beams were clamped to large concrete bases and the load was applied to the central column by a hydraulic actuator. 


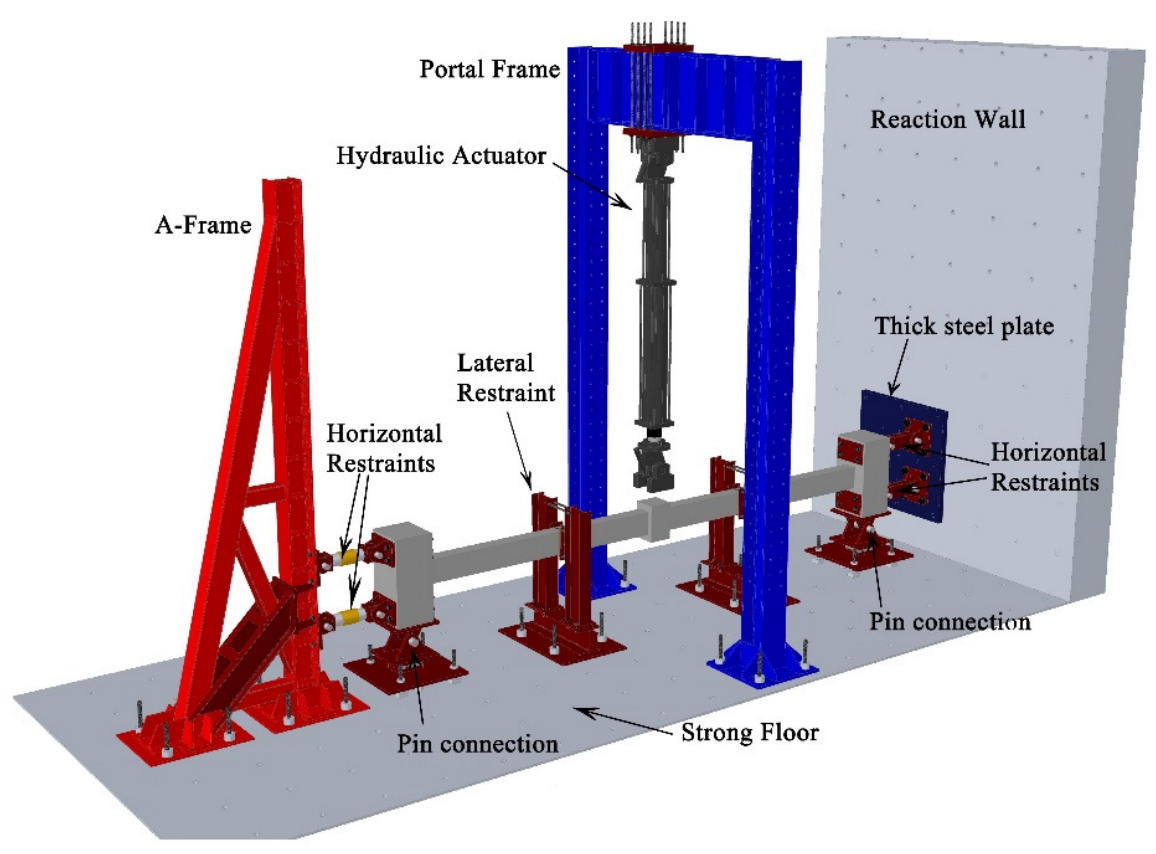

Fig. 7. Test set-up used by Yu and Tan [178]. Image by courtesy of Jun Yu (Nanyang Technological University)

a

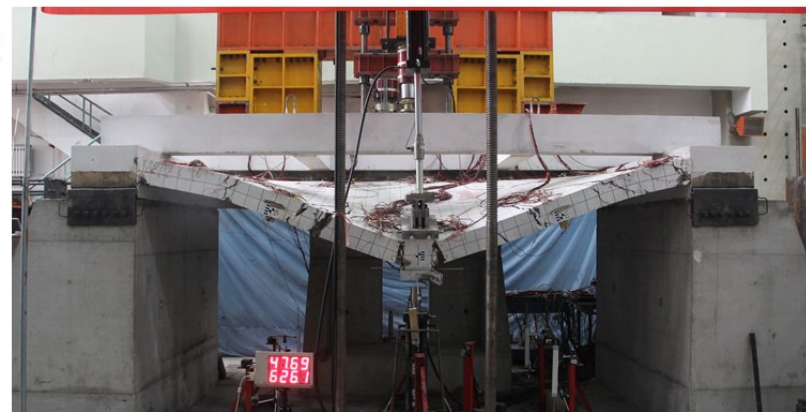

b

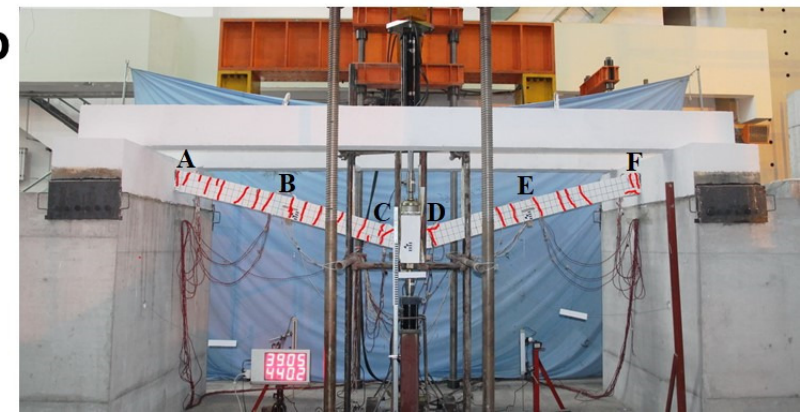

Fig. 8. (a) Test carried out by Lu et al. [184] on a beam-slab specimen; (b) Test by Ren et al. [183] on a beam specimen without slab. Photos by courtesy of Yi Li (Beijing University of Technology)

Apart from the commonly used configurations described above, formed by two span beams and one or three columns, other researchers resorted to different configurations. Yap et al. [185] tested six beam-column sub-assemblages subjected to the loss of an exterior ground column. The T-shaped specimens were rotated $90^{\circ}$ around their horizontal axis and the test setup was specially designed to ensure that boundary conditions were representative of the actual scenario (loss of exterior column). For this, joints were attached to the ends of both beams and the column and a load was applied to the centre of the beam by a hydraulic jack. Qian and Li [186] tested four interior beam-column sub-assemblages subjected to the loss of an exterior ground column. The specimens were in the form of a cross consisting of two span beams and one column. Joints were attached to both ends of the column and to one end of one beam, while the load was applied to the other free beam end by a hydraulic jack. Kai and Li [187] and Qian and Li [188] studied a corner column failure within the frame of a building. L-shaped specimens were tested in a horizontal position (see Fig.9). The ends had joints at the base and horizontal constraints to simulate the effect of neighbouring bays. The loss of a 
corner column was simulated at the angle of the L. Kai and Li [187] tested six specimens to study the dynamic effect associated with the loss of a corner column. The beams were loaded by steel plates and a mechanism was used to simulate the sudden removal of the column. Qian and Li [188] tested six specimens with a similar geometry to that used by Kai and Li [187], with the difference that the load was applied monotonically by a jack at the corner of the L.

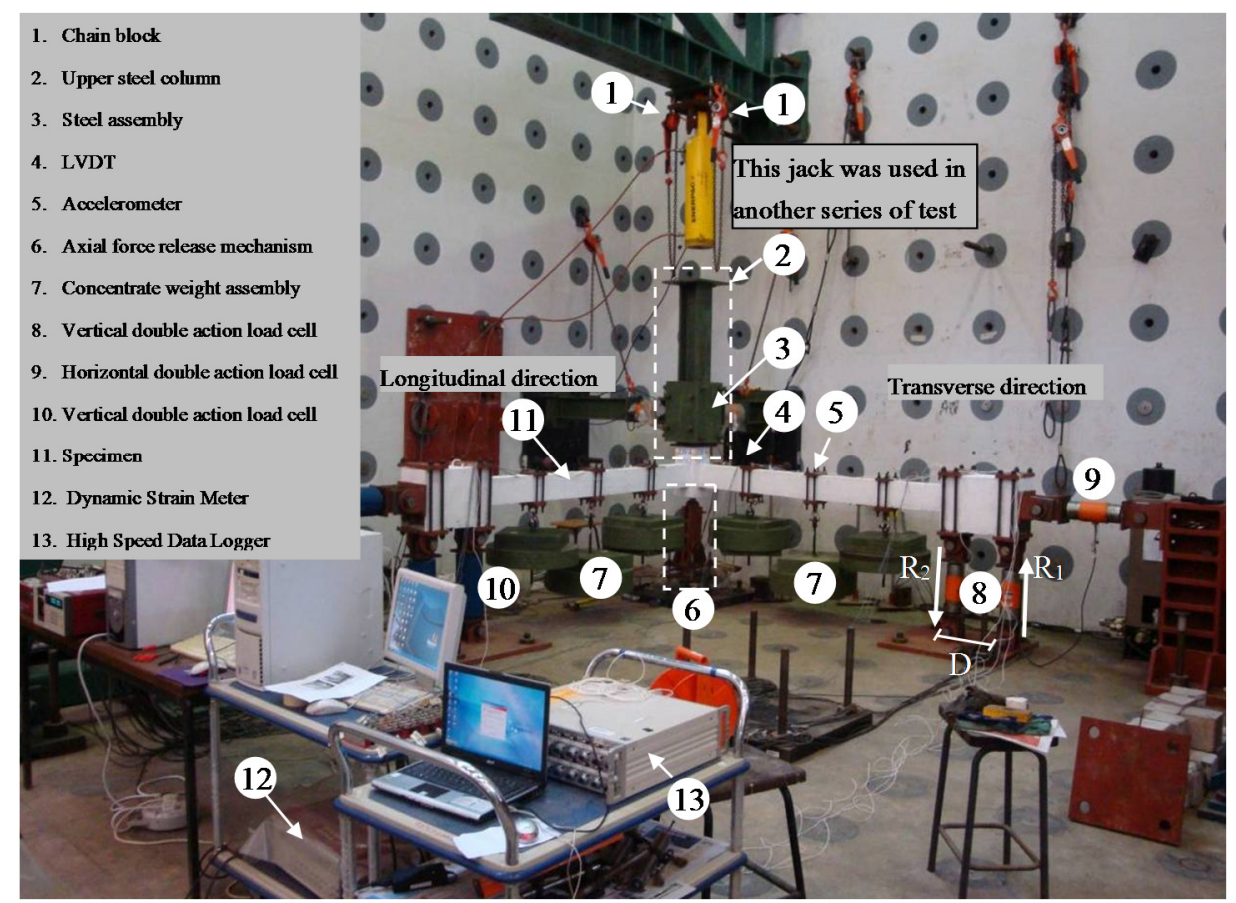

Fig. 9. Test set-up used by Kai and Li [187] to study corner column removal. Photo by courtesy of Bing Li (Nanyang Technological University)

\subsubsection{Precast concrete structures}

In recent years, there have also been advances in the field of precast RC structures, especially by means of tests on sub-assemblages. Nimse et al. [189] tested four specimens, including three different beam-column connections and a monolithic connection. The specimens consisted of two span beams, two exterior columns and a central column. The load was applied to the central column by a hydraulic jack and the boundary conditions of the exterior columns were designed to avoid horizontal movements. Kang and Tan [190] tested six specimens made of precast elements, with cast-in-place concrete in the topping and beam-column joint. The test configuration was similar to that used by Yu and Tan [178]. Kang et al. [191] tested six specimens similar to those of Kang and Tan [190], with the same test configuration. The special feature of Kang et al.'s [191] tests was that they used cementitious composites in the topping and beam-column joint. Kang and Tan [192] tested four specimens consisting of two span beams, two exterior columns, and a central column to which a load was applied by a hydraulic jack to simulate an exterior building frame with the appropriate boundary conditions, with joints in the bases of the end columns and a horizontal constraint on its upper part. 
Elsanadedy et al. [193] tested three specimens, two with precast concrete and cast-in-place concrete in the other. The specimens were formed of two span beams, two exterior columns and a central column. The main difference between these tests and the others made up to that time was that they used dry connections (see Fig.10). Finally, Lew et al. [194] tested two precast concrete moment-frame sub-assemblages in a procedure similar to that used in Lew et al. [177].

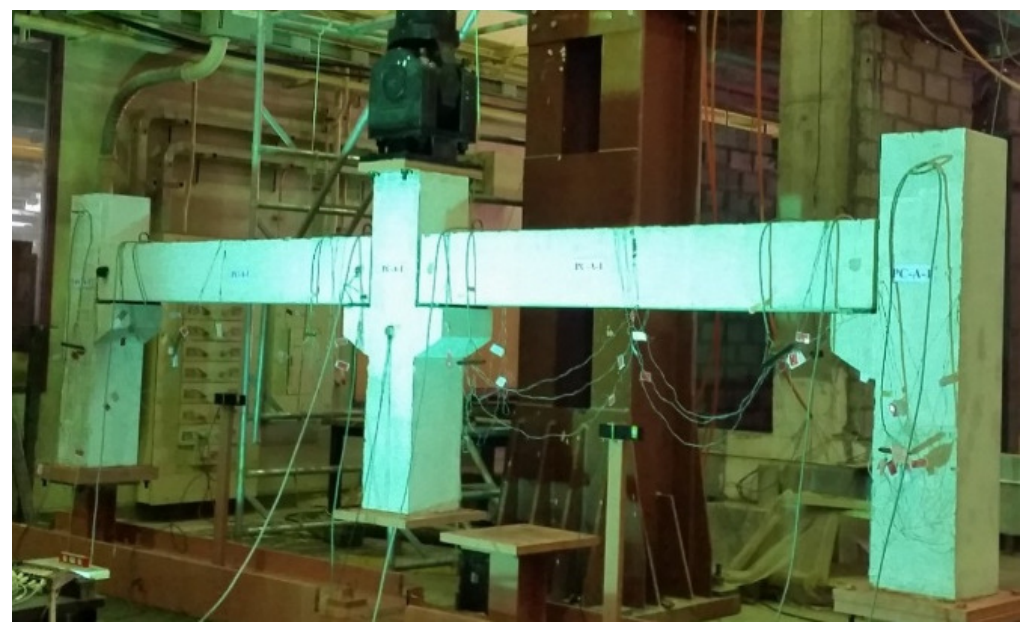

Fig. 10. Test set-up used by Elsanadedy et al. [193] to test precast concrete sub-assemblages. Photo by courtesy of Hussein M. Elsanadedy (King Saud University)

\subsection{Tests on $2 D$ frames}

The tests on two-dimensional frames represent a further step in the study of the progressive collapse of structures. Although the studies on sub-assemblages enabled the study of the behaviour of the beam and the beam-column connection affected by a column failure, the studies on frames go further and permit the analysis, apart from the arch and catenary action, of the general behaviour of the connection, the Vierendeel action and how a column failure affects elements (beams and columns) and neighbouring joints.

In the field of steel and composite structures, the tests by Guo et al. [195, 196] on 1/3 scale frames formed by a floor and 4 bays stand out. As a special feature, the specimens included part of a concrete slab in order to analyse the behaviour of composite beams after the failure of an intermediate column (see Fig. 11). The load on the intermediate column was applied by a hydraulic jack in a simulated pushdown process. In Guo et al. [195], the beam-column connections were rigid, while in Guo et al. [196] they were semi-rigid (flush-end plate connections). In both tests, the connection was seen to have a good progressive collapse resistance, although as expected, the flush-endplate connections had lower load and deformation capacities than the rigid beam-to-column connections. 


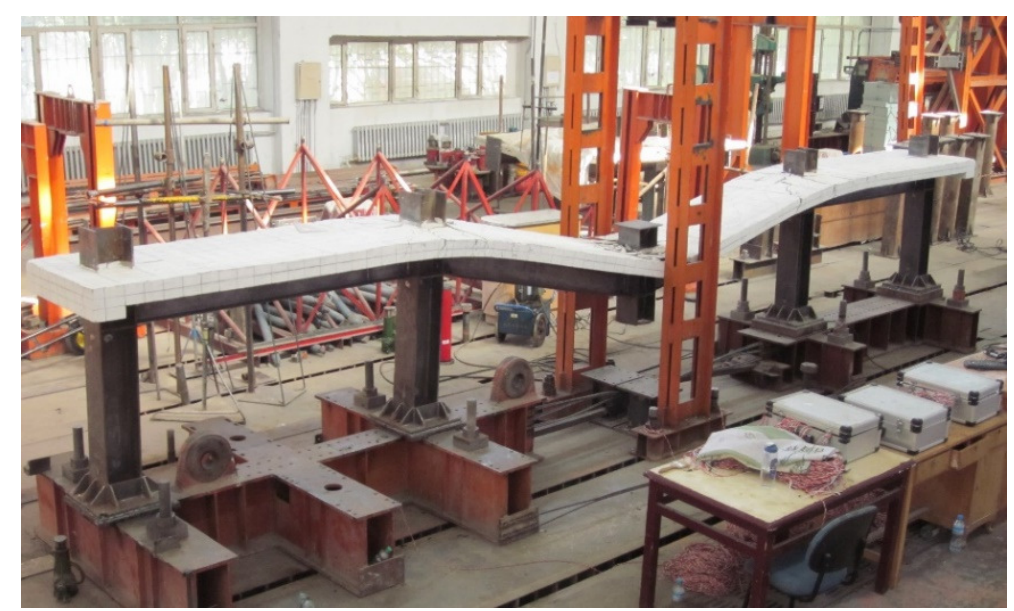

Fig. 11. View of a test by Guo et al. [196] on a composite frame. Photo by courtesy of Lanhui Guo (Harbin Institute of Technology)

Yi et al. [31] performed one of the first laboratory tests on progressive collapse resistance of RC frame structures. This research was followed by other experimental programs performed by, amongst others: Stinger and Orton [197], Orton and Kirby [198], Shan et al. [199], Li et al. [200], and Qian and Li [201]. In Yi et al. [31], the experimental test was conducted on a 1/3 scale, 4-bay, 3-storey specimen consisting of a 2-dimensional RC frame subjected to the loss of the central column at the base. The test was performed in a quasi-static fashion. Experimental observations evidenced a redistribution and transition of load resisting mechanisms from beam behaviour to arch and catenary action. Stinger and Orton [197] tested three 1/4 scale frames formed by 2 bays and 2 storeys. The specimen was axially restrained to a lateral reaction frame at beam end locations, in order to simulate the interaction with the remaining part of the prototype structure. Loss of the central column was simulated by a pushdown test. Later, Orton and Kirby [198] carried out a dynamic test on specimens identical to those tested by Stinger and Orton [197]. Orton and Kirby [198] studied the sudden removal of the central column by a special device in a test with dead loads applied to the beams as a special feature.

Shan et al. [199] and Li et al. [200] studied how the presence of infill walls affects the behaviour of RC frames after a column failure, using three specimens of $1 / 3$ scale frames, 4 bays and 2 storeys in quasi-static tests (pushdown test) to simulate a central column failure. In Li et al. [200], the frames had full-height infill walls on the second storey, while in Shan et al. [199] the infill walls had windows (see Fig. 12). The behaviour of both specimens was compared with a reference specimen with no infill walls. The tests were used to better understand the alternative load path opened by infill walls after a column fails in a building. Another recent study with the presence of infill walls in RC frames was that by Qian and Li [201], who tested six $1 / 4$ scale specimens formed by 2 bays and 3 storeys in the simulated removal of the penultimate column. 


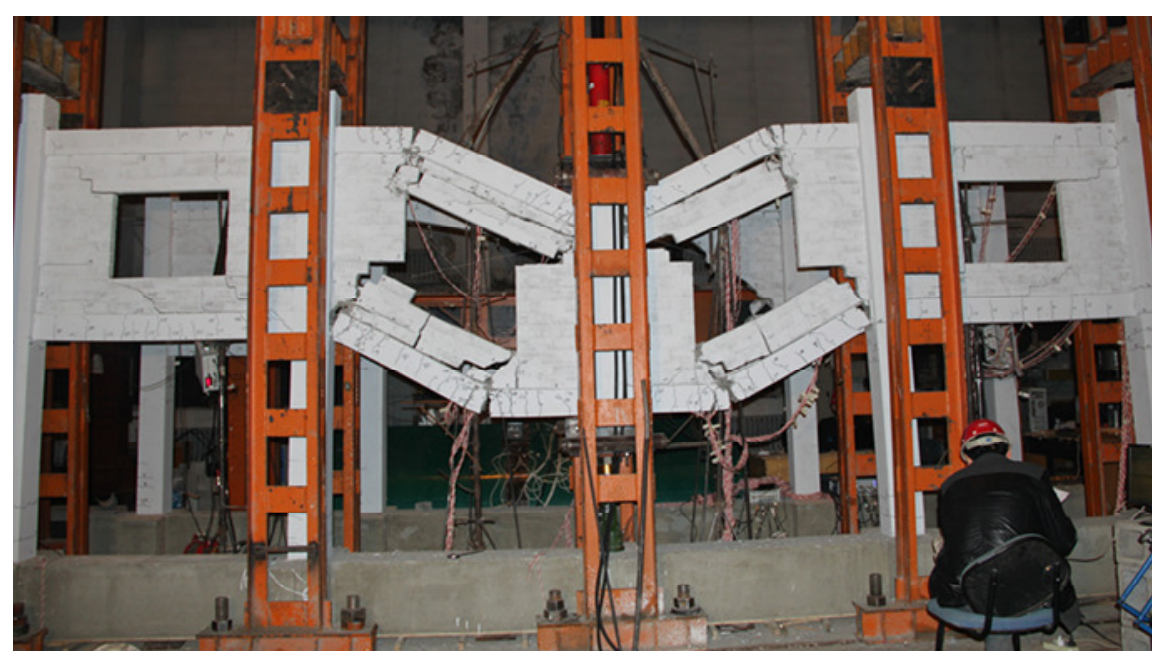

Fig. 12. Test by Shan et al. [199] on an RC frame with infill walls. Photo by courtesy of Shuang Li (Harbin Institute of Technology)

\subsection{Tests on building structures purpose-built for research purposes}

Tests on building structures constructed solely to act as "specimens" can give particularly reliable results when care is given to their design, construction, monitoring, data acquisition and treatment of the results. In fact, the reliability of this method of testing means that the results obtained can be used as a dependable source for calibrating numerical models and proposed measures for codes and design recommendations. However, tests are rarely carried out on purpose-built structures due to the high costs involved, the difficulty of performing the tests in laboratories and the potential dangers of deliberately causing the failure of one or more columns in a full-scale specimen.

In the field of steel and composite structures, the best-known studies are those by Johnson et al. [202], Zandonini et al. [203] and Chen et al. [204]. The first of these studies was on a half-scale building with $3 \times 3$ bays and a steel-composite floor in 4 different column failure scenarios (a corner column, two edge columns, and an interior column) while the floor was loaded with water tanks. These tests underlined the importance of the slab's capacity to redistribute loads after a column failure. Zandonini et al. [203] worked on a full-scale 2 -storey building structure with $2 \times 2$ bays. The first storey had a concrete slab and the second had a frame of beams and columns with no slab. The central column was replaced by a hydraulic jack that was unloaded to simulate failure. In the third study, Chen et al. [204] carried out tests on a full-scale 2-storey building with $2 \times 2$ bays. After removing one of the exterior columns, once again the importance of the slab was shown in the process of redistributing the loads after the column failure.

There were also other tests on steel structures in which the specimen had no slabs. Dinu et al. [205] experimented on an approximately $1 / 3$ scale $3 \mathrm{D}$ frame without slabs with $2 \times 2$ bays (see Fig.13). As this frame contained only one floor, the contribution of the upper floors was simulated by loads on the heads of 
the columns. The failure of a central column was simulated by applying a vertical load through a hydraulic jack. Li et al. [206] worked on a frame that simulated a 1/3 scale, 2 -storey building with $2 \times 2$ bays without slabs. Central column failure was simulated by loading from a hydraulic jack in a static pushdown test.

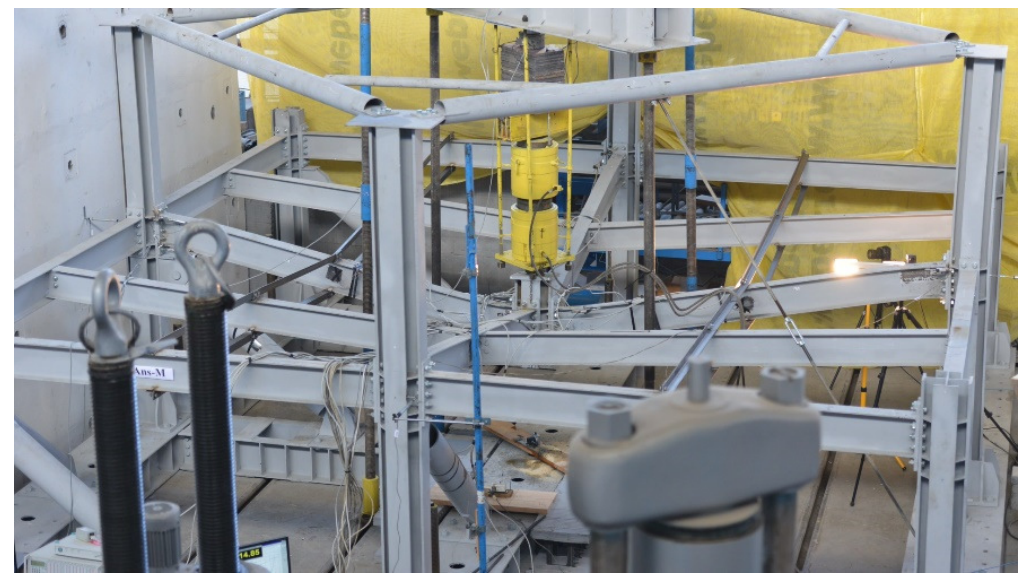

Fig. 13. Test on a 3D steel frame by Dinu et al. [205]. Photo by courtesy of Florea Dinu (Politehnica University Timisoara)

Of all the tests on RC building structures, the most ambitious to date was carried out by Xiao et al. [207], due to the building's dimensions, the large investment of funds required, the scenarios considered, and the results obtained. Xiao et al. [207] constructed a half-scale 3 -storey building with $3 \times 3$ bays, which was tested in five sudden-removal scenarios: corner column, column adjacent to the corner column, two middle exterior columns, and one interior column. Columns were suddenly removed by a hydrogen gas cannon while the slab was loaded with concrete and steel blocks. In another recent study by Bermejo et al. [208] the specimen consisted of a 2 -storey building with $2 \times 1$ bays (see Fig.14) while the slabs were loaded by sandbags. The sudden failure of a central column was caused by explosives placed in drill holes in the column itself, after which the building totally collapsed. Peng et al. [209] built a single-storey $2 / 5$ scale building. The floor consisted of an RC flat plate loaded with fabric bags filled with adobe soil during the tests. The dynamic test was performed by the sudden removal of an exterior column. Total slab collapse was initiated by punching at an interior column connection. Another test was performed by Yi et al. [210] on a 1/2.34 scale building with $2 \times 2$ bays and a single slab loaded with sandbags and steel blocks. The column to be eliminated was replaced by a hydraulic jack attached to a load cell, which was unloaded to simulate the column failure. This test procedure did not allow for the dynamic effects associated with possible sudden column failure. In the test performed by Jian et al. [211], the specimen was a $1 / 3$ scale single-storey building with $2 \times 2$ bays. A quasi-static test with displacement control was carried out under central column loss on the perimeter of the frame. Unlike the tests by Xiao et al. [207] and Bermejo et al. [208], which were carried out in the open air, Peng et al. [209], Yie et al. [210] and Jian et al. [211] did their tests in a laboratory. 


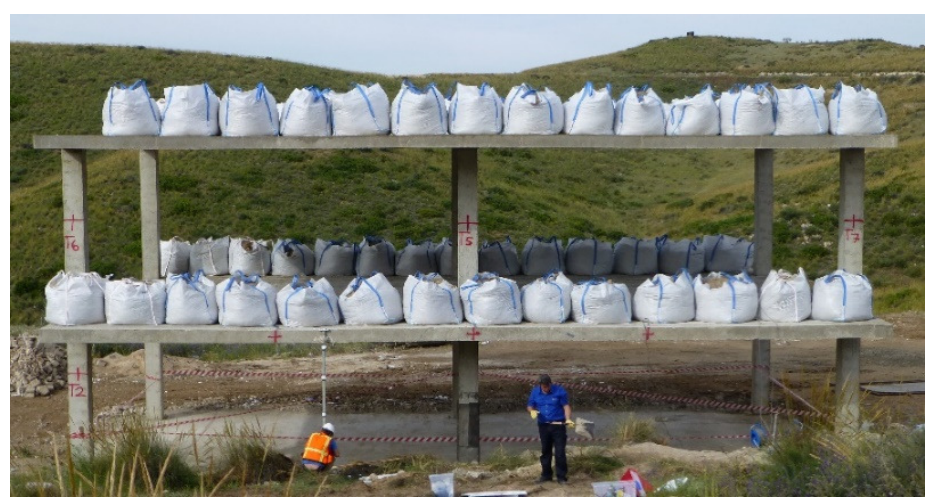

Fig. 14. Building structure tested by Bermejo et al. [208]. Photo by courtesy of Mario Bermejo (Technical University of Madrid)

Other researchers, such as Qian and Li [212-214] and Lim et al. [215], carried out tests on parts or components of buildings. Qian and $\operatorname{Li}[212,213]$ tested specimens formed by a slab supported by 4 columns and simulated the failure of a corner column. In some tests the slabs were strengthened with CFRP [213], whereas in others no type of strengthening was used [212]. In the case of Lim et al. [215], four specimens were tested to simulate corner and exterior column failures in a pushdown test. Two specimens consisted of beam-column frames, while the other two had 1- and 2-bay slabs, respectively. Qian and Li [214] dynamically tested 3 quarter-scale specimens formed by a 2-bay slab with the sudden removal of a column.

\subsection{Tests on buildings scheduled for demolition}

As indicated in Section 7.3, tests on full-scale buildings under laboratory conditions can be complicated, expensive and sometimes dangerous. Some authors have therefore taken advantage of buildings about to be demolished, in which they have simulated the failure of one or more columns.

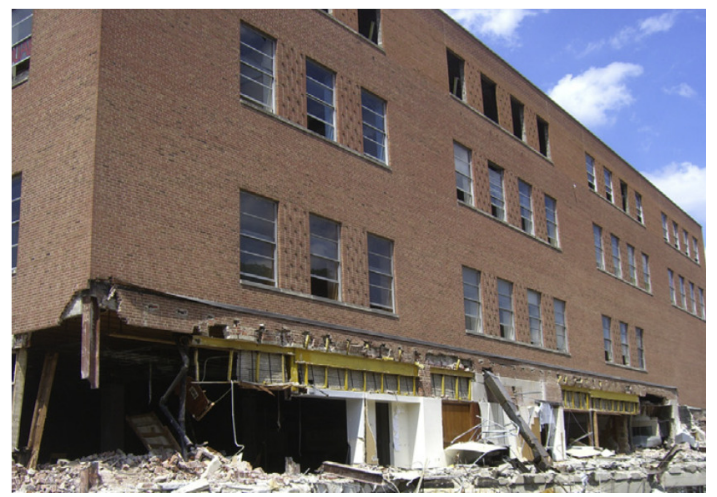

Fig. 15. Ohio Union Building used for testing by Song and Sezen [216]. Photo by courtesy of Halil Sezen (Ohio State

$$
\text { University) }
$$

In the field of steel structures, the tests by Song and Sezen [216] and Song et al. [217] stand out, involving the sudden removal of four of the first-storey columns from the perimeter frame of two buildings. Song and Sezen [216] performed their tests on the Ohio Union Building (see Fig. 15) in the Ohio State University campus. This building had 4 storeys and had been built in 1950. Song et al. [217] carried out their tests on the 3-storey Bankers Life and Casualty Company building in Northbrook, Illinois, which had been 
built in 1968. In both cases, the building frames consisted of steel columns and beams. The test results showed that both buildings were sufficiently robust to withstand the failure of four perimeter columns, since the damage detected in the structures of both buildings after the failures was insignificant. It should be noted that both tests were performed without removing the external walls and partitions, which highlights their contribution to establishing alternative load paths.

The most important studies on RC structures are those by Sasani et al. [218], Sasani and Sagiroglu [219], Sasani [220], Sasani and Sagiroglu [221], and Sasani et al. [222]. Sasani et al. [218] worked on a 10-storey building at the University of Arkansas in Little Rock constructed in 1958. After the sudden removal of a perimeter column, the load redistribution was seen to be dominated by Vierendeel action of the frames above the failed column. Sasani and Sagiroglu [219] and Sasani [220] describe the tests carried out on the 6-storey Hotel San Diego (see Fig. 16) in San Diego, built in 1914. Before the test, all non-structural elements were removed (partitions, plumbing, etc.), leaving only the perimeter infill walls. After causing the failure of two columns by means of explosives, the vertical displacement of the slabs was quite small thanks to the appearance of Vierendeel action-based alternative load paths and the contribution of the infill walls. Sasani and Sagiroglu [221] carried out tests on the 20-storey Baptist Memorial Hospital in Memphis, dating from 1956, simulating the failure of an interior column after eliminating the partitions and exterior walls. This test showed that the more storeys a building has, the greater its load redistribution capacity after the failure of a column. Sasani et al. [222] worked on the 11-storey Crowne Plaza Hotel in Houston, built in 1973 in a test that simulated the simultaneous failure of four columns on the first floor and two deep-beam segments on the second floor. After the test, the structural elements were seen to have suffered little damage due to the load redistribution paths, flexural-axial response of the second-floor deep beams, and the Vierendeel action of the upper floors.

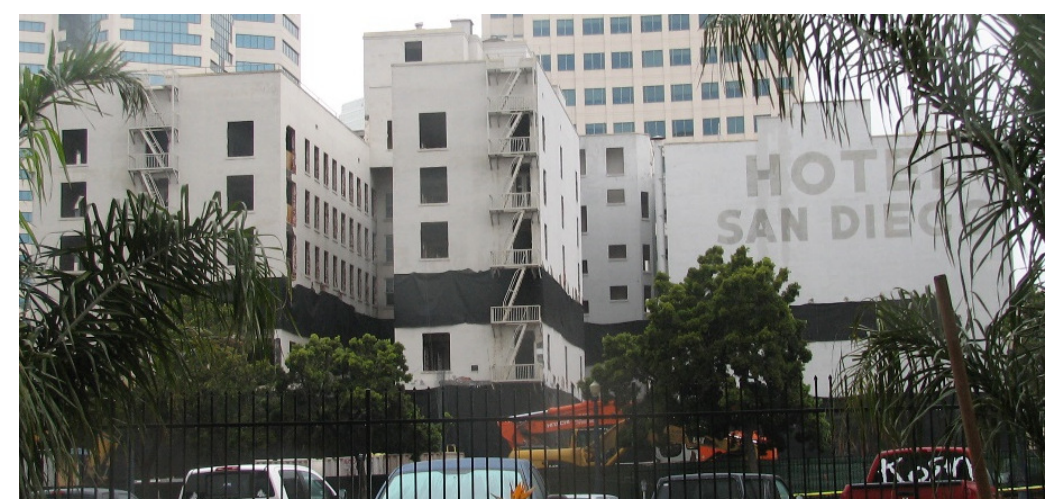

Fig. 16. Hotel San Diego used for testing by Sasani and Sagiroglu [219] and Sasani [220]. Photo by courtesy of Mehrdad Sasani (Northeastern University) 


\section{Numerical modelling}

Together with the advances in the field of computing and the use of high-performance computers, the evolution of structural calculation software has now made it possible to analyse in detail structural failures or collapses by numerical models and has led to a considerable rise in the numbers of papers published that analyse failures by this means [223].

The progressive collapse of building structures is a complex phenomenon involving nonlinear material behaviour, impacts/collisions, large deformation and dynamics. Researchers have made good use of the capacity of modern computers and software to make considerable advances in understanding the mechanisms involved in the progressive collapse of a building. Today's numerical models are highly reliable and accurate and thus can faithfully represent progressive structural collapse, as has been demonstrated on many occasions by comparing experimental and numerical results. The advantages of numerical simulation in this field are undeniable, since they mean that fewer experimental tests are required, thus making considerable financial savings and avoiding the possible dangers involved in experimental tests.

Among the techniques used to simulate the progressive collapse of structures, the following stand out:

a) Finite Element Method (FEM). This is the technique most often used at the present time on different levels and different degrees of approximation. The FEM allows macromodels (with solid elements) to be used, or micromodels (with beam/shell elements), macromodels of joints-connections and hybrid models.

b) Discrete Element Method (DEM). Even though the scientific community has so far paid little attention to this technique of simulating the progressive collapse of buildings, its possibilities are undeniable. One of its particularly interesting aspects is the ability to combine DEM and FEM to obtain very accurate results at an acceptable computational cost.

c) Applied Element Method (AEM). This technique is being used more and more in simulations of both sub-assemblages and entire buildings. Although it is relatively recent, it has been shown to give good results in processes involving structural failure or collapse.

d) Cohesive Element Method (CEM). This technique has been little used to date to simulate the progressive collapse of structures but has proved very effective for work in the field of fracture mechanics. The few studies in this field that have used the method so far obtained results equal to or better than those of conventional nonlinear analysis.

El-Tawil et al. [3] and Kunnath et al. [6] recently brought out two excellent reviews of the present situation of numerical modelling of the progressive collapse of structures in the fields of steel and concrete 
structures, respectively. The aim of this section is to carry out an up-to-date review including the most recent studies and go deeper into techniques other than FEM. Below, the techniques most frequently used at the present time to simulate the progressive collapse of structures are enumerated, accompanied by a brief description of each one, together with examples of their application.

\subsection{Finite Element Method}

FEM is the most widely used method in the numerical simulation of structures and has traditionally been used to simulate the progressive collapse of structures. The simulation of progressive collapse by FEM can be done at different levels of approximation and complexity, such as, for example: a) using micro or macromodels, b) with linear or nonlinear analysis, c) static or dynamic behaviour, d) with 2D or 3D models, and e) with implicit or explicit calculation. Choosing between micro or macromodels will basically depend on the dimensions of the structure to be analysed and the level of precision required. Micromodels are preferred for small elements while macromodels are often used to simulate entire buildings. The present codes and recommendations allow either linear or nonlinear analysis to be used, although nonlinear simulations are always more accurate as they can follow a structure up to its failure point. The same happens with static and dynamic analyses; nonlinear dynamic analyses will have a higher computational cost than linear static analyses. However, the present calculation software and modern computers can safely handle complex nonlinear calculations. Another consideration is the possible use of 2D or 3D simulations, although, for example, the DoD [19] does not allow 2D simulations for calculating building structures against progressive collapse. Implicit calculations usually involve convergence problems in nonlinear dynamic simulations, while explicit calculations are usually more robust and achieve more accurate results.

Micromodels with continuum finite-element models (solid elements) can simulate complex geometries with a high degree of accuracy, even with the presence of reinforcement rebars and their adherence to concrete, welds and bolts in steel structures, etc. Micromodels with solid elements have been used by different authors in the field of steel or composite structures, such as, for example: Sadek et al. [167], Guo et al. [196], Liu et al. [165], Pirmoz and Liu [224], Qin et al. [158], Wang et al. [159], Dinu et al. [169], and Gao et al. [225]. In the field of cast-in-place RC structures, the work of Sadek et al. [167], Li et al. [200] and Pham et al. [226] stand out, whereas in precast concrete there are those by Elsanadedy et al. [193] and Bao et al. [194]. This method has also been successfully used in threat-dependent analysis situations, as in the studies by Albrifkani and Wang [227] and Shi et al. [228]. In all cases, the models have high fidelity because the details of both components and connections can be directly represented.

As micromodels with solid elements have a very high computational cost, they are not often used to 
simulate entire buildings, but they are frequently used to simulate parts of structures or sub-assemblages. Fig. 17 shows a simulation of a steel sub-assemblage with solid elements formed by two beams and a central column. In this figure, the level of detail of the geometry can be appreciated, including the presence of the bolts used to join the different components.

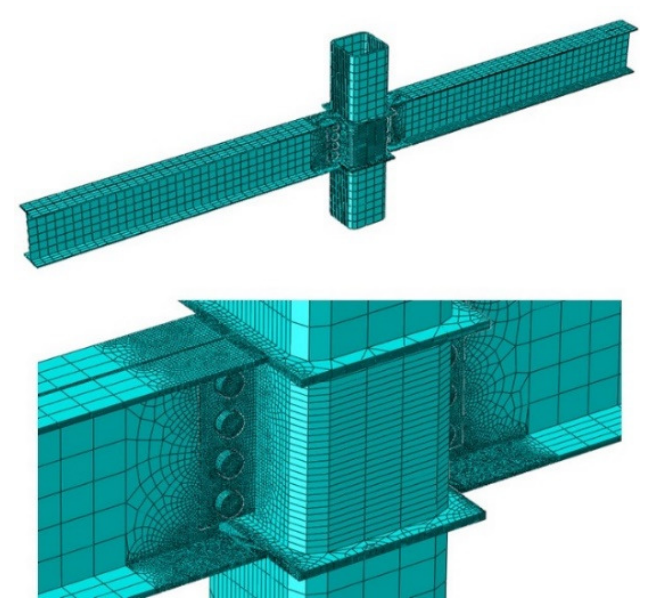

Fig. 17. Simulation with solid elements (micromodelling) of a sub-assemblage formed by two beams and a column [159]. Images by courtesy of Cheng Fang (Tongji University)

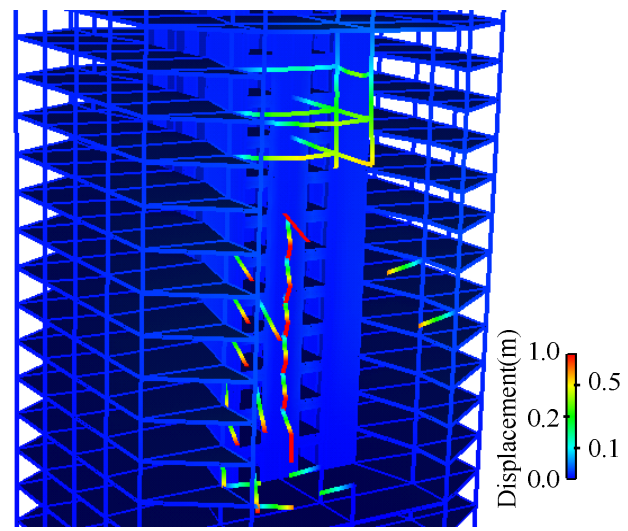

Fig. 18. Numerical simulation of a building with beam/shell elements [236]. Image by courtesy of Xinzheng Lu (Tsinghua University)

Macromodels, which simulate the structure with beam/shell elements, are another option more suitable for simulating complete buildings. This method has high computational efficiency and has been used by different authors, as for example: Izzuddin et al. [30], Kwasniewski [229], Fu [230], Chen et al. [204], Kokot et al. [231], Li et al. [75], Song and Sezen [216], Brunesi and Nascimbene [232], Brunesi and Parisi [285], Kazemi-Moghaddam and Sasani [233], Li et al. [153], Bermejo et al. [208], and Olmati et al. [79]. Beam-type elements are often used to simulate beams and columns, while shell elements are used to simulate floor slabs or steel components with small thicknesses [229]. Macromodels with beam/shell elements are also habitually used to analyse progressive collapse from a threat-dependent perspective. Some interesting studies in this area include those by: Parisi and Augenti [18], Sun et al. [234], Agarwal and Varma [235], and Lu et al. [236]. Fig. 18 shows the simulation with beam/shell elements of a building suffering progressive 
collapse due to fire action.

Macromodels with beam/shell elements represent the most popular technique and are the most frequently used by structural engineers in their daily activities on the progressive collapse and robustness of building structures. However, the beam-column and slab-beam joints are complex zones of a building structure, as beam-slabs behave as catenary-membranes and suffer large rotations and deformations, as well as the interaction of shear and axial and flexural loading. In order to consider these effects in models with beam/shell elements, diverse macromodels of beam-column joints have been proposed to date. Some interesting proposals of this type include those by: Bao et al. [37], Sadek et al. [237], Vlassis et al. [35], Kim et al. [238], Bao and Kunnath [239], Liu et al. [240], Khandelwal and El-Tawil [83], Jahromi et al. [241], Li and El-Tawil [242], Yu and Tan [178], and Sun et al. [243]. Macromodels of joints are formed by a series of springs and rigid elements (see Fig. 19) and are joined to the beam/shell elements that simulate the structure to achieve an adequate representation of the real situation after the sudden collapse of one or more columns in a building.

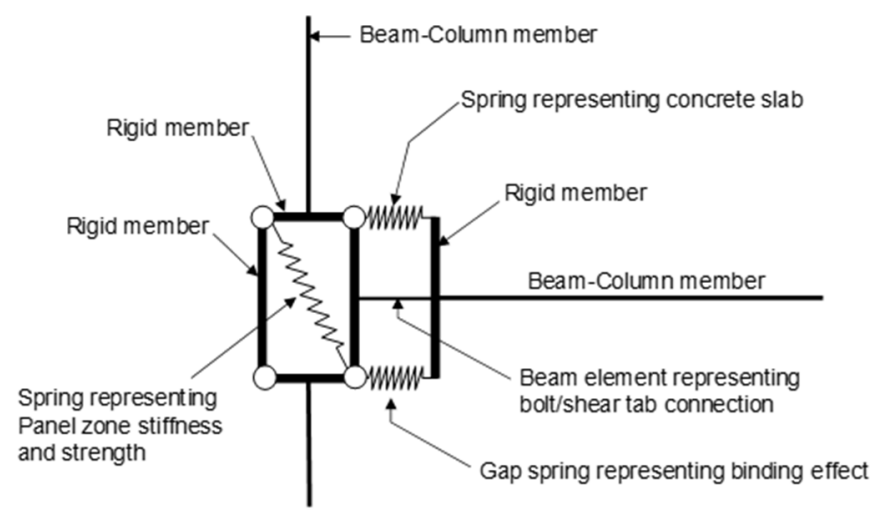

Fig. 19. Macromodel of a beam-column joint in a steel structure [83]. Image by courtesy of Kapil Khandelwal (University of Notre Dame)

In order to better capture the structural behaviour under large deformations, different types of element are sometimes combined and are recognised as multi-scale or hybrid models. By modelling different parts of the structure on different scales, both the overall structural behaviour and local nonlinear damages can be well captured [244, 245]. More importantly, both the number of elements and the computational cost can be significantly reduced. However, one of the critical issues in this type of modelling strategy is coordinating the interaction between the different types of elements to ensure deformation compatibility and reasonable constraint conditions.

\subsection{Discrete Element Method}

The Discrete Element Method (DEM) is typically used to study problems involving granular and discontinuous materials. In this technique, material is treated as an assembly/collection of mobile and 
interacting discrete elements, and the behaviour of the material on the macro-length-scale is deduced from the statistical analysis of the (normal, tangential, rolling and twisting) contact-interactions and motions of these elements [246]. Although the computational cost of using DEM for large elements or structures is usually high, fortunately the latest advances in the field of computers and supercomputers means it is now possible to do so. As the technique is based on the discontinuity of materials/elements, DEM can successfully simulate the large deformations, nonlinearity and discontinuity associated with progressive $\mathrm{s}$ collapse of structures and has in fact been used to do so for some years.

One of the first studies that used DEM to simulate progressive collapse was carried out by Pekau and Cui [247], who analysed the progressive collapse of a building with precast panel shear walls. Masoero et al. [248] later analysed the progressive collapse of three-dimensional RC framed structures after the sudden loss of a column. Masoero et al. [249] studied the progressive collapse of two-dimensional frames subjected to the sudden removal of columns. More recently, Grujicic et al. [246] analysed the structural collapse and survivability of a building subjected to blast attack by a close-proximity vehicle-borne improvised device (VBIED). Another recent work by Gu et al. [250] studied the collapse behaviour of RC moment frame structures subjected to seismic loads or explosions. The results obtained by Gu et al. [250] in their simulations were successfully validated by comparing them with others obtained from experimental testing (see Fig. 20).

DEM can also be combined with FEM to obtain very satisfactory results at an acceptable computational cost. Munjinza et al. [251] combined DEM with FEM to study failures of beams and columns and achieved a good correlation between the experimental and numerical results. Taking advantage of the discovery of Munjinza et al. [251], Lu et al. [252] used the technique to study the progressive collapse of building structures.

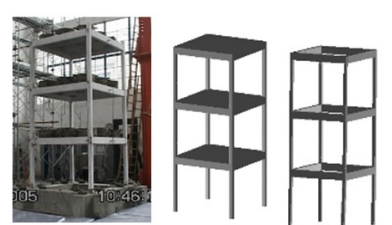

(a) $3.0 \mathrm{~s}(3.0 \mathrm{~s}, 3.0 \mathrm{~s})$

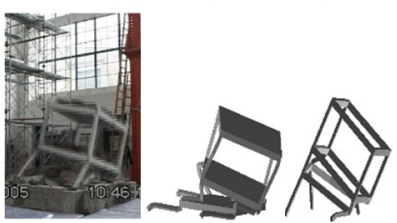

(e) $4.8 \mathrm{~s}(5.00 \mathrm{~s}, 5.25 \mathrm{~s})$

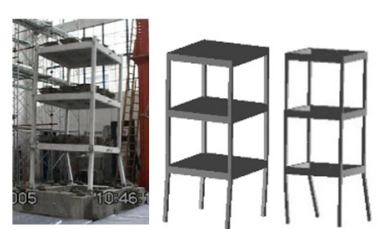

(b) $4.2 \mathrm{~s}(4.2 \mathrm{~s}, 4.35 \mathrm{~s})$

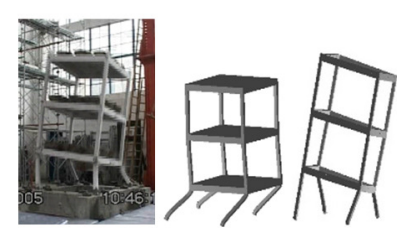

(c) $4.4 \mathrm{~s}(4.5 \mathrm{~s}, 4.65 \mathrm{~s})$

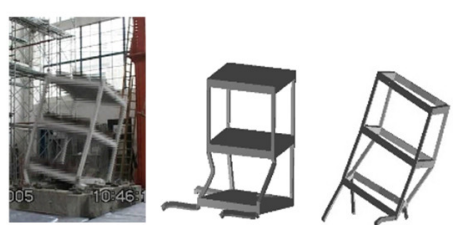

(d) $4.6 \mathrm{~s}(4.70 \mathrm{~s}, 4.85 \mathrm{~s})$

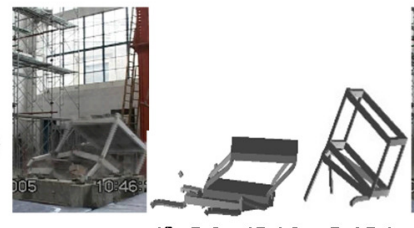

(f) $5.0 \mathrm{~s}(5.10 \mathrm{~s}, 5.45 \mathrm{~s})$

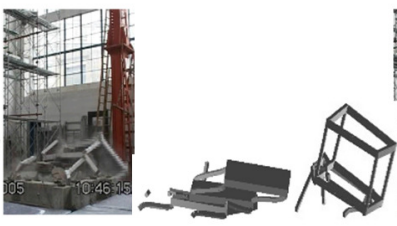

(g) $5.2 \mathrm{~s}(5.30 \mathrm{~s}, 5.70 \mathrm{~s})$

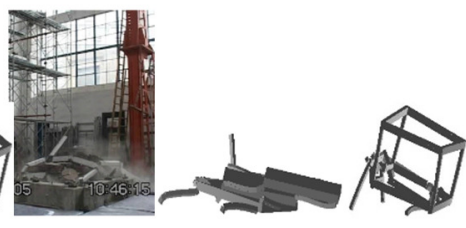

(h) $5.8 \mathrm{~s}(5.80 \mathrm{~s}, 6.05 \mathrm{~s})$

Fig. 20. Comparison of numerical and experimental results obtained from the Discrete Element Method in a simulated structural collapse. Time from start of test is indicated below each test phase [250]. Images by courtesy of Xianglin Gu

(Tongji University) 


\subsection{Applied Element Method}

The relatively recent Applied Element Method (AEM) was developed and first published by Tagel-Din and Meguro [253] and Meguro and Tagel-Din [254]. In AEM, a structure is simulated by an assembly of relatively small elements connected by springs at the points of contact between the surfaces of the elements. Normal and shear springs are responsible for the transfer of normal and shear stresses from one element to the next. AEM is an excellent tool for simulating processes with large displacements and rotations and can faithfully simulate the cracking and collision of structural elements. The main advantage of this method is its ability to track structural collapse behaviour in all its stages: load applications, initiation and propagation of cracks, and the separation of elements until total collapse of the structure [255].

Due to its capacities, AEM is a very suitable technique to simulate the processes involved in the failure and collapse of structures and has been used with success to analyse the collapse of bridges [256-259] and buildings subjected to seismic actions [260].

AEM has also been used in recent years to simulate the progressive collapse of building structures. The present calculation programs and advances in computing have reduced the computation times of simulating structures with AEM to acceptable levels. The technique has gone from simulating sub-assemblages (see Fig. 21a) to complete buildings (see Fig. 21b). Some of the latest and most important works on simulating complete building structures by this technique are those by: Sasani et al. [220], Galal and El-Sawy [26], Salem et al. [262], Helmy et al. [80, 263, 264], Khalil [265], Hefez et al. [266], Dinu et al [267], Kim and Wee [268], Ehab et al. [269], and Attia et al. [270]. In all these studies the simulations were able to follow the structures until collapse after a sudden column removal.
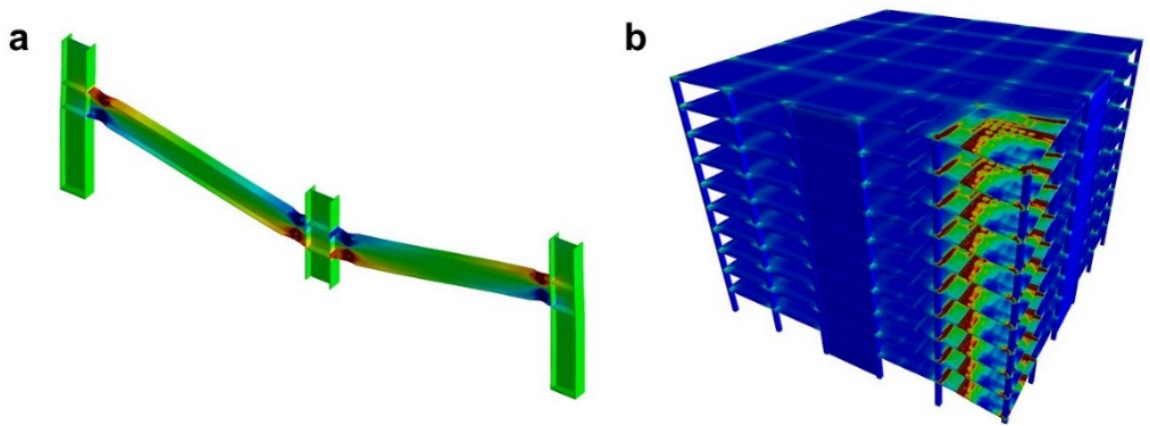

Fig. 21. Use of Applied Element Method to simulate: (a) sub-assemblage; (b) building structure. Images by courtesy of Ayman El-Fouly (Applied Science International LLC)

Other studies have used AEM to simulate elements smaller than complete buildings, for example those by Salem et al. [262], Ehab et al. [269] and Dinu et al. [205] simulated previously lab-tested specimens subjected to removal of a column in which the results of the numerical simulations were remarkably similar to those of the experimental tests. 


\subsection{Cohesive Element Method}

The Cohesive Element Method (CEM) has been widely used in the field of fracture mechanics [98]. The essential idea behind CEM is that it smears a finite-size damage zone at the crack tip by a zero-thickness nonlinear element, whereas the rest of the structure is considered to behave linear-elastically. It can be used to analyse the collapse or failure of building structures. In such cases the nonlinear behaviour of each structural member such as beams, columns, walls, and slabs can be fully captured by a set of nonlinear cohesive elements, which represent the potential damage zones (PDZs) that could possibly form during the collapse process $[271,272]$.

Although CEM has so far been little used in the field of the progressive collapse of structures, Le and Xue [98] and Xue and Le [154, 271] have produced interesting studies. Le and Xue [98] defined a two-scale numerical model for assessing the risk of progressive collapse of RC structures that was used to study the behaviour of a 30-storey building with an RC structure under different column removal scenarios. Xue and Le [271] validated the two-scale model defined by experimental results and applied it to the study of a 10-storey building subjected to sudden column removal (see Fig. 22). Xue and Le [154] formulated a simplified method for evaluating the risk of progressive collapse of RC building structures based on a two-scale model developed in previous work. Xue and Le [154] studied a prototype building by the simplified method, obtaining better results than those from conventional nonlinear analysis.

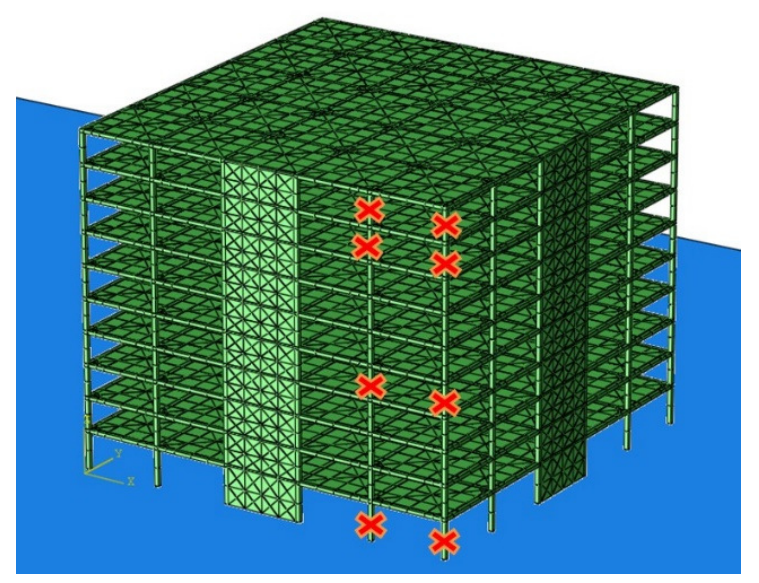

Fig. 22. Use of Cohesive Element Method to simulate progressive building collapse [271]. Image by courtesy of Jia-Ling Le (University of Minessota)

\section{Conclusions and needs}

This paper presents an ambitious review of the most significant advances in the field of the progressive collapse of structures this century. It has been shown that recent years have seen considerable progress in this field, responding to the present need for robust buildings able to withstand extreme events without collapsing, 
and even resilient buildings that can remain operational after an extreme event (case of critical and strategic structures). New codes and design recommendations have been brought out, while those already existing have been adapted to allow for the latest advances. In addition, the scientific community, engineers and architects are now fully aware of the need for resilient buildings. Nevertheless, there is still a long way to go, there are still some areas that require deeper study and others that need to be studied for the first time. Based on the results of this review, the present and future needs in the field of progressive collapse and robustness of building structures can be defined as follows:

a) Precast concrete construction. To date, most studies on progressive collapse have been carried out on cast-in-place concrete and steel or composite structures. It is noteworthy that structures composed of precast elements are becoming more frequent in critical infrastructures and public buildings like hospitals, passenger terminals, power plants, schools, administrative buildings, shopping centres, sports centres, etc. Although some progress has been made in the field of precast construction by means of lab tests on sub-assemblages [189-194], there is still a lot of work to be done and the scientific community must give more attention to this type of construction. For example, at the present time no studies are available on frames and complete buildings of this type, or on macromodels of beam-column joints, as has been done in the case of cast-in-place concrete, steel and composite structures.

b) Prestressed concrete structures. The prestressing technique is commonly used in situations that require long spans in the form of slabs or prestressed beams, in which if a column should fail the risk of progressive collapse is even greater than that of RC structures. Unfortunately, the state of research on the progressive collapse of prestressed concrete structures is simply insufficient [272-274] and progress needs to be made in this field.

c) Masonry structures. There are still a large number of buildings with masonry load-bearing walls that could be possible targets for terrorist attacks (emblematic buildings, premises open to the public, military headquarters, etc.). Other masonry buildings may be subjected to accidental explosions, impact loading or fire. In the latter case, the vulnerability of buildings with timber floors or roofs is particularly high. A few studies have been recently carried out on blast resistance of masonry walls (see e.g. $[275,276]$ ), but this subject deserves further investigation to assess and reduce the vulnerability of buildings to catastrophic explosions that frequently occur as a result of gas leaks from building utility service systems. At the larger scale of structural systems, comprehensive studies need to be made on how a local failure in any part of these buildings could propagate elsewhere and how 
alternative load paths can be created to avoid progressive collapse.

d) Tall and supertall buildings. There has recently been a notable increase in the number of tall and supertall buildings. Some of these buildings have been targeted by terrorists and have suffered severe fires that in some cases have led to progressive collapse, while others have been so heavily damaged that they had to be demolished. Research is now needed on how the loss of one or more load-bearing elements can affect a tall or supertall building and how to create alternative load paths to avoid progressive collapse or introduce design or constructions measures to arrest or limit a collapse to mitigate its consequences.

e) Retrofitting. Many existing buildings need retrofitting to increase their robustness and avoid possible collapse after extreme events. Although a limited number of studies have been carried out so far on retrofitting building structures, some advances have been made, for example by Liu [277, 278], Kim et al. [279], Hadi and Alruidaini [280], Tsai [281], Kim and Shin [282], Qian and Li [213] and Schachter Adaros and Smilowitz [283]. However, more research is required in this field, especially on equipping the large number of existing buildings to meet the requirements of the present codes and recommendations.

f) Numerical modelling. Numerical simulation is perhaps where most progress has been made in the field of the progressive collapse of structures. However, one topic that needs special attention is how slabs should be considered in numerical models. Although slabs can make an important contribution to withstanding a progressive collapse, the present calculation tools do not allow plastic hinges to be assigned to the shell-type elements used in simulations, e.g. reinforced concrete slabs. Although some engineers use nonlinear shell elements in their analysis, this approximation is not altogether adequate for evaluating progressive collapse, since it does not allow the transition from flexural to membrane behaviour.

g) Experimental testing. Research based on experimental testing has helped in the advancement of the present codes and recommendations and in validating the numerical models that have been developed. Although many tests have been carried out on sub-assemblages, tests are needed on 3D structures that consider all the mechanisms that contribute to creating alternative load paths. Dynamic tests are also required for a more accurate definition of the dynamic amplification factors to be considered in static analysis procedures.

h) Segmentation. The advantages of segmentation for avoiding the progressive collapse of bridges and buildings have often been expressed. For example, Starossek [65] proposed conceptual design ideas 
for achieving robustness of high-rise buildings through segmentation. Unfortunately, no studies (or research) have been carried out on segmentation in relation to building structures. Suitable vertical and horizontal segmentation can avoid a failure or collapse from propagating to the rest of the building. This aspect is particularly important when there is severe damage after an extreme event with the failure of different structural elements (various columns or one or more slab bays). Segmentation can provide a good solution in situations where it is difficult to establish alternative load paths to avoid progressive collapse.

i) Temporary structures. Temporary structures such as shoring are normally used to support newly poured slabs in buildings under construction. A significant number of structural failures during construction have been reported in recent years, leading in some cases to the progressive collapse of the whole structure [284]. Design guidelines for temporary works are now starting to introduce clauses to avoid progressive collapse with the idea that local failure of the temporary structure does not lead to failure of the whole structure [285]. This is a shift from traditional views in design practice in which local failures in construction works were generally assumed to have less serious consequences than permanent works, so that a collapse due to an accidental event would be acceptable if agreed to by the client or relevant authority. The only study to date on the progressive collapse of a building under construction attributable to the failure of temporary structures was carried out by Buitrago et al. [286], so that much more work needs to be done on this topic.

j) Punching in flat slabs. As failures due to punching in flat slabs are normally propagated both vertically and horizontally inside a building the consequences tend to be catastrophic. Very few studies have been made on the subject, calling for further investigations.

k) Evaluation of structures and decision making after a failure. After the failure of one or more structural elements, the residual construction should be assessed to help in making the appropriate decisions, such as restricting or granting access to the building, defining retrofitting actions, or deciding whether the building needs to be demolished. It is thus necessary to have the right tools to assess the state of the building after the failure of one or more elements, in order to help in deciding on the actions to be taken.

\section{Acknowledgements}

The figures included in this paper were provided by courtesy of the following researchers: Wei Wang (Tongji University), Bo Yang (Chongqing University), Florea Dinu (Politehnica University of Timisoara), 
Jun Yu (Nanyang Technological University), Yi Li (Beijing University of Technology), Bing Li (Nanyang Technological University), Hussein M. Elsanadedy (King Saud University), Lanhui Guo (Harbin Institute of Technology), Shuang Li (Harbin Institute of Technology), Mario Bermejo (Technical University of Madrid), Halil Sezen (Ohio State University), Mehrdad Sasani (Northeastern University), Cheng Fang (Tongji University), Kapil Khandelwal (University of Notre Dame), Xianglin Gu (Tongji University), Ayman El-Fouly (Applied Science International LLC), and Jia-Ling Le (University of Minessota). The authors are extremely grateful to these researchers without whose help the paper would not have achieved the required quality and clarity. Fig. 1 was compiled by Manuel Buitrago (Universitat Politècnica de València), to whom the authors owe their gratitude for the contribution of his time and effort.

The authors also wish to express their gratitude for the invitation received from Phillip Gould (Editor-in-Chief of Engineering Structures) to write this review to accompany the Special Issue in which the most interesting papers on progressive collapse and robustness published this century are collected.

The first author (Jose M. Adam) is grateful to the BBVA Foundation for their financial support through the Beca Leonardo a Investigadores y Creadores Culturales 2017, in the project "Mejora de la resiliencia de edificios frente a eventos extremos: El desafio de las columnas de esquina”.

\section{References}

[1] Ellingwood BR. Mitigating risk from abnormal loads and progressive collapse. J Perform Constr Facil 2006;20(4):315-323.

[2] Baker JF, Williams EL, Lax D. The design of framed buildings against high explosive bombs. In: The civil engineer in war: Properties of materials, structures, hydraulics, tunnelling and surveying. London: Institution of Civil Engineers; 1948, Vol.3, p. 80-112.

[3] El-Tawil S, Li,H, Kunnath S. Computational simulation of gravity-induced progressive collapse of steel-frame buildings: Current trends and future needs. J Struct Eng 2014;140(8):1-12.

[4] Byfield M, Mudalige W, Morison C, Stoddart E. A review of progressive collapse research and regulations. Proc Inst Civ Eng Struct Build 2014;167(SB8):447-456.

[5] Qian K, Li B. Research advances in design of structures to resist progressive collapse. J Perform Constr Facil 2015;29(5):1-11.

[6] Kunnath SK, Bao Y, El-Tawil S. Advances in computational simulation of gravity-induced disproportionate collapse of RC frame buildings. J Struct Eng 2018;144(2):1-18.

[7] Starossek U. Typology of progressive collapse. Eng Struct 2007; 29(9): 2302-2307. 
[8] Allen DE, Schriever WR. Progressive collapse, abnormal loads and building codes. Québec: Division of Building Research Council; 1972.

[9] Gross JL, McGuire W. Progressive collapse resistant design. J Struct Eng 1983; 109(1):1-15.

[10] General Services Administration (GSA). Progressive Collapse Analysis and Design Guidelines for New Federal Office Buildings and Major Modernization Projects. Office of Chief Architects, Washington DC, 2003.

[11] American Society of Civil Engineers (ASCE). Minimum Design Loads for Buildings and Other Structures (ASCE/SEI 7-05). Structural Engineering Institute of the ASCE, 2005.

[12] Canisius TDG, Sorensen JD, Baker JW.Robustness of structural systems - A new focus for the Joint Committee on Structural Safety (JCSS). Proc, 10th Int Conf on Applications of Statistics and Probability in Civil Engineering (ICASP10), Taylor and Francis, London; 2007.

[13] NISTIR 7396. Best practices for reducing the potential for progressive collapse in buildings. National Institute of Standards and Technology, Gaithersburg; 2007.

[14] Agarwal J, England J. Recent developments in robustness and relation with risk. Proc Inst Civ Eng, Struct Build 2008; 161(SB4): 183-188.

[15] Krauthammer T. Modern protective structures. Boca Raton: CRC Press; 2008.

[16] Starossek U, Haberland M. Disproportionate collapse: terminology and procedures. J Perform Construct Facil 2010; 24(6): 519-528.

[17] Kokot S, Solomos G. Progressive collapse risk analysis: literature survey, relevant construction standards and guidelines. Ispra: Joint Research Centre, European Commission; 2012.

[18] Parisi F, Augenti N. Influence of seismic design criteria on blast resistance of RC framed buildings: A case study. Eng Struct 2012; 44:78-93.

[19] Department of Defence (DoD). Design of Buildings to Resist Progressive Collapse (UFC 4-023-03). Unified Facilities Criteria, Washington DC, 2013.

[20] Nafday AM. Consequence-based structural design approach for black swan events. Structural Safety 2011; 33(1): 108-114.

[21] Slotine JJE, Li W. Applied nonlinear control. Englewood Cliffs: Prentice Hall; 1991.

[22] Huber PJ. Robust statistical procedures - CBMS-NSF regional conference series in applied mathematics (2nd ed), Vol. 68. Philadelphia: Society for Industrial and Applied Mathematics; 1996.

[23] CEN Comité Européen de Normalisation. EN 1991-1-7: Eurocode 1 - Actions on structures - Part 1-7: General actions - Accidental actions. Brussels, Belgium: CEN 2006. 
[24] Bontempi F, Giuliani L, Gkoumas K. Handling the exceptions: Robustness assessment of a complex structural system. Proc, 3rd Int Conf on Structural Engineering, Mechanics and Computation (SEMC 2007). Rotterdam: Millpress; 2007, pp. 1747-1752.

[25] Biondini F, Frangopol DM, Restelli S. On structural robustness, redundancy and static indeterminacy. Proc, ASCE/SEI 2008 Structures Congress. Reston: ASCE/SEI; 2008.

[26] Vrouwenvelder T. Treatment of risk and reliability in the Eurocodes. Proc Inst Civ Eng, Struct Build 2008; 161(SB4): 209-214.

[27] Joint Committee of Structural Safety (JCSS). Risk assessment in engineering — Principles, system representation and risk criteria. Zurich; 2008.

[28] fib Model Code for Concrete Structures 2010. Fédération Internationale du Béton, Lausanne; 2012.

[29] Brett C, Lu Y. Assessment of robustness of structures: Current state of research. Front Struct Civ Eng 2013; 7(4): 356-368.

[30] Izzuddin BA, Vlassis AG, Elghazouli AY, Nethercot DA. Progressive collapse of multi-storey buildings due to sudden column loss - Part I: Simplified assessment framework. Eng Struct 2008;30(5):1308-1318.

[31] Yi WJ, He Q, Xiao Y, Kunnath SK. Experimental study on progressive collapse-resistant behavior of reinforced concrete frame structures. ACI Struct J 2008;105(4):433-439

[32] Marjanishvili S, Agnew E. Comparison of various procedures for progressive collapse analysis. J Perform Constr Facil 2006;20(4):365-374.

[33] Kim J, Kim T. Assessment of progressive collapse-resisting capacity of steel moment frames. J Constr Steel Res 2009;65(1):169-179.

[34] Ellingwood B, Leyendecker EV. Approaches for design against progressive collapse. ASCE J Struct Div 1978;104(3):413-423.

[35] Vlassis AG, Izzuddin BA, Elghazouli AY, Nethercot DA. Progressive collapse of multi-storey buildings due to sudden column loss-Part II: Application. Eng Struct 2008;30(5):1424-1438.

[36] Kaewkulchai G, Williamson EB. Beam element formulation and solution procedure for dynamic progressive collapse analysis. Comput Struct 2004;82(7-8):639-651.

[37] Bao Y, Kunnath SK, El-Tawil S, Lew HS. Macromodel-based simulation of progressive collapse: RC frame structures. J Struct Eng 2008;134(7):1079-1091.

[38] Su Y, Tian Y, Song X. Progressive collapse resistance of axially-restrained frame beams. ACI Struct J 2009;106(5):600-607. 
[39] Marjanishvili SM. Progressive analysis procedure for progressive collapse. J Perform Constr Facil 2004;18(2):79-85.

[40] Minister of Housing and Local Government. The Building (Fifth Amendment) Regulations 1970. Statutory Instruments of the UK, S.I. 26 1970, No. 109, 1970.

[41] Department of Communities and Local Government, "The Building Regulations 2010 - Structure: Approved Document A", HM Government, UK, 2010.

[42] CEN Comité Européen de Normalisation. EN 1990: Eurocode - Basis of structural design. Brussels, Belgium. CEN 2002.

[43] US Department of Housing and Urban Development (HUD), Federal Housing Administration (FHA). Provisions to prevent progressive collapse. Washington DC, 1971.

[44] NYC Department of Buildings. Building code (Chapter 16 - Structural Design). NYC Construction Codes, 2014.

[45] Department of Defence (DoD). Design of Buildings to Resist Progressive Collapse (UFC 4-023-03). Unified Facilities Criteria, Washington DC, 2009.

[46] International Code Council. 2009 International Building Code (IBC 2009). International Code Council, 2009.

[47] American Society of Civil Engineers (ASCE). Minimum Design Loads for Buildings and Other Structures (ASCE/SEI 7-98). Structural Engineering Institute of the ASCE, 1998.

[48] American Society of Civil Engineers (ASCE). Minimum Design Loads for Buildings and Other Structures (ASCE/SEI 7-02). Structural Engineering Institute of the ASCE, 2002.

[49] American Society of Civil Engineers (ASCE). Minimum Design Loads and Associated Criteria for Buildings and Other Structures (ASCE/SEI 7-16). Structural Engineering Institute of the ASCE, 2016.

[50] General Services Administration (GSA). Alternative path analysis and design guidelines for progressive collapse resistance. Office of Chief Architects, Washington DC, 2013.

[51] Starossek U, Smilowitz R, Waggoner M, Rubenacker K J, Haberland, M. Report of the Terminology and Procedures Sub-Committee (SC1): Recommendations for design against disproportionate collapse of structures. ASCE SEI 2011 Structures Congress, Las Vegas; 2011.

[52] National Research Council of Canada. National Building Code of Canada. Canadian Commission on Building and Fire Codes, 1975.

[53] National Research Council of Canada. National Building Code of Canada. Canadian Commission on Building and Fire Codes, 1995. 
[54] Ellingwood BR, Smilowitz R, Dusenberry DO, Duthinh D, Lew HS, Carino NJ. Best practices for reducing the potential for progressive collapse in buildings. NISTIR 7396. National Institute of Science and Technology, US Deparment of Commerce, 2007.

[55] Arup. Review of International Research on Structural Robustness and Disproportionate Collapse. Department for Communities and Local Government, 2011.

[56] Standards Australia. Australian/New Zealand Standards AS/NZS 1170.0 2002 Structural design actions - General principles. Standards Australia, 2002.

[57] Pham L. Actions on structures: Regulations and standards. EJSE Special issue: loading on structures 2007.

[58] Australian Building Codes Board (ABCB). National Construction Code (NCC): Volumes 1 \& 2. Council of Australian Governments 2016.

[59] Ministry of Construction of the People's Republic of China. Unified standard for reliability design of building structures. GB50068-2001, Beijing, China; 2001.

[60] Ministry of Housing and Urban-Rural Development of the People's Republic of China (MOHURD). Code for design of concrete structures. GB50010-2010, Beijing, China; 2010.

[61] Ministry of Housing and Urban-Rural Development of the People's Republic of China (MOHURD). Technical specification for concrete structures of tall building. JGJ 3-2010, Beijing, China; 2010.

[62] China Association for Engineering Construction Standardization (CECS). Code for anti-collapse design of building structures. CECS 392: 2014, Beijing, China; 2014.

[63] Cormie D, Mays G, Smith P. Blast effects on buildings (second edition). Thomas Telford Limited, 2009.

[64] European Cooperation in the field of Scientific and Technical Research (COST). Robustness of Structures - Proceedings of the 1st Workshop, ETH Zurich, Switzerland. COST Action TU0601, 2008.

[65] Starossek U. Progressive collapse of structures (second edition). Thomas Telford Limited, 2018.

[66] Institution of Structural Engineers (IStructE). Manual for the systematic risk assessment of high-risk structures against disproportionate collapse. IStructE and supported by the Department for Communities and Local Goverment, London, 2013.

[67] Institution of Structural Engineers (IStructE). RP/68/05: The Resistance of Buildings to Accidental Damage. IStructE, London, 1971.

[68] Fintel M. Schultz D.M. Iqbal M. Design and construction of large-panel concrete structures: report 2 philosophy of structural response to normal and abnormal loads. Published by PCA for the Department 
of Housing and Urban Development, 1976.

[69] Comité Européen du Betón (CEB). Bulletin d’information n.60. CEB, 1967 (in French).

[70] Christopherson DG. Structural Defence, RC 450. Ministry of Home Security Research \& Experiments Department, London, 1945.

[71] Walley F. Memorandum on the design of bomb-resisting structures against HE attack. Ministry of works, London, 1954.

[72] Smith PP, Byfield MP, Goode DJ. Building robustness research during World War II. J Perform Constr Facil 2010;24(06):529-535.

[73] Byfield MP, Paramasivam S. Catenary Action in Steel-Framed Buildings. Proc Inst Civ Eng Struct Build 2007;160(SB5):247-257.

[74] Moore DB. The UK and European regulations for accidental actions. Prevention of progressive collapse: national workshop of the Multihazard Mitigation Council of the National Institute of Building Sciences, Washington DC, 2002.

[75] Li Y, Lu X, Guan H, Ye L. An improved tie force method for progressive collapse resistance design of reinforced concrete frame structures. Eng Struct 2011;33(10):2931-2942.

[76] Sagaseta J, Ulaeto N, Russell J. Structural robustness of concrete flat slab structures. fib Bulletin 81, ACI SP-315, published by Fédération internationale du béton (fib) and American Concrete Institute (ACI), 2017, 273-298.

[77] American Society of Civil Engineers (ASCE). Seismic rehabilitation of existing buildings. ASCE, 2006.

[78] Stoddart EP, Byfield MP, Davidson JB, Tyas A. Strain rate dependent component based connection modelling of use in non-linear dynamic progressive collapse analysis. Eng Struct 2013;55:35-43.

[79] Olmati P, Sagaseta J, Cormie D, Jones AEK. Simplified reliability analysis of punching in reinforced concrete flat slab buildings under accidental actions. Eng Struct 2017;130:83-98.

[80] Helmy H, Salem H, Mourad S. Progressive collapse assessment of framed reinforced concrete structures according to UFC guidelines for alternative load path method. Eng Struct 2012;42:127-141.

[81] Izzudin, BA, Nethercot, D. Design-oriented approaches for progressive collapse assessment: load-factor vs ductility-centred methods. ASCE Structures Congress, Austin, 2009.

[82] Liu J, Tian Y, Orton SL, Said AM. Resistance of flat-plate buildings against progressive collapse. II: system response. J Struct Eng 2015;141(12):1-11.

[83] Khandelwal K, E-Tawil S. Pushdown resistance as a measure of robustness in progressive collapse. 
Engineering Structures 2011;33(9):2653-2661

[84] Danish Standards Association (DS/INF). Robustness - Background and principles - Guidance - 2003. DS/INF 146, 2003.

[85] Bussell MN, Jones AEK. Robustness and the relevance of Ronan Point today. The Structural Engineer 2010;88:(23/24)

[86] US Army. Structures to resist the effects of accidental explosions. TM 5-1300, Department of the Army 1990.

[87] Ministry of Housing and Urban-Rural Development of the People's Republic of China (MOHURD). Load code for the design of building structures. GB5009-2012, Beijing, China; 2012.

[88] Department of Defence (DoD). DoD Minimum antiterrorism standards for buildings (UFC 4-10-01). Unified Facilities Criteria, Washington DC, 2013.

[89] Vrouwenvelder A, Stiefel U, Harding G. Eurocode 1, Part 1.7 - Accidental actions: background document. 2008.

[90] Jones AEK, Wainwright F. Robustness building regulations guidance: guidance on the new robustness building regulations for Class 3 structures. Arup internal design guidance. Arup Research \& Development, Ove Arup and Partners Ltd, 2006.

[91] Harding G, Carpenter J. Disproportionate collapse of 'Class 3' buildings: the use of risk assessment. The Structural Engineer 2009;87(16/18):29-34.

[92] European Cooperation in the field of Scientific and Technical Research (COST). Theoretical framework on structural robustness. COST Action TU0601, 2011.

[93] Alexander S. New approach to disproportionate collapse. The Structural Engineer 2004, 72(23/24):14-28.

[94] Ellingwood BR. Structural reliability and performance-based engineering. Proc Inst Civ Eng Struct Build 2008;161(SB4):199-207.

[95] Faber MH, Maes MA, Straub D, Baker J. On the quantification of robustness of structures. Proceedings of the 25th International Conference on Offshore Mechanics and Arctic Engineering, Hamburg, 2006.

[96] Maes MA, Fritzsons KE, Glowienka S. Structural robustness in the light of risk and consequence analysis. Struct Eng Int 2006;16(2):101-107.

[97] Janssens V, O'Dwyer DW, Chryssanthopoulos M. Assessing the consequences of building failures. Struct Eng Int 2012;22(1):99-104.

[98] Le JL, Xue B. Probabilistic analysis of reinforced concrete frame structures against progressive 
collapse. Eng Struct 2014;76:313-323.

[99] Arshian AH, Morgenthal G, Narayanan S. Influence of modelling strategies on uncertainty propagation in the alternate path mechanism of reinforced concrete framed structures. Eng Struct 2016;110:36-47.

[100] Brunesi E, Nascimbene R, Parisi F, Augenti N. Progressive collapse fragility of reinforced concrete framed structures through incremental dynamic analysis. Eng Struct 2015;104:65-79.

[101] CEN Comité Européen de Normalisation. EN 1992-1-1: Eurocode 3: Design of concrete structures Part 1-1: General rules and rules for buildings. Brussels, Belgium. CEN 2004.

[102] ACI Committee 318. Building Code Requirements for Structural Concrete (ACI 318-14) and Commentary 38 (ACI 318R-14). American Concrete Institute 2014.

[103] Canadian Standards Association (CSA). Design of concrete structures (CSA A23.3-04). CSA, Mississauga, 2004.

[104] ANSI/AISC 360-10. Specification for Structural Steel Buildings. American Institute of Steel Construction, 2010.

[105] Way AGJ. Structural robustness of steel frame buildings. The Steel Construction Institute 2011, SCI P391.

[106] Brooker O. How to design concrete buildings to satisfy disproportionate collapse requirements. The Concrete Centre 2008, TCC/03/45.

[107] CEN Comité Européen de Normalisation. 1993-1-1: Eurocode 3: Design of steel structures - Part 1-1: General rules and rules for buildings. Brussels, Belgium. CEN 2005.

[108] Hanson K, Olesen O. Failure load and failure mechanism of keyed shear joints. Danish Academy of Engineers, Building Department Report 69/22, Copenhagen, 1969.

[109] Granstrom S. Stability of buildings after accidental damage (Forces in element joint - model tests). Swedish Building Research Report R20, 1971.

[110] Regan PE. Catenary action in damage concrete structures. ACI SP 48-9. American Concrete Institute, 1975.

[111] Popoff A. Design against progressive collapse. PCI J 1975;20(2):45-57.

[112] PCI Committee on Precast Concrete Bearing Wall Buildings. Considerations for the design of precast concrete bearing wall buildings to withstand abnormal loads. PCI J 1976;21(2):18-51.

[113] Portland Cement Association (PCA). An engineer's guide to: concrete buildings and progressive collapse resistance. PCA, 2005.

[114]Fédération Internationale du Béton (fib). Design of precast concrete structures against accidental 
actions. fib, bulletin 63, 2012.

[115] Matthews S. Reeves B. Handbook for the structural assessment of large panel system (LPS) dwelling blocks for accidental loading. Published by BRE for the Department of Communities and Local Government, 2012.

[116] Brick Development Association (BDA), Autoclaved Aerated Concrete Products Association (AACPA), Concrete Block Association (CBA). Masonry design for disproportionate collapse requirements under regulation A3 of the Building Regulations (England \& Wales). Published by CBA, 2005.

[117] British Standards Institution (BSI). BS 5628-1: Code of practice for the use of masonry; Part 1: Structural use of unreinforced masonry. BSI, 2009.

[118] Grantham R. Enjily V. Multi-storey timber frame buildings - a design guide. BRE and TRADA Technology, 2003.

[119]Dietsch P. Robustness of large-span timber roof structures - Structural aspects. Eng Struct 2011;33:3106-3112.

[120] Lind NC. A measure of vulnerability and damage tolerance. Reliab Eng Sys Saf 1995;48(1):1-6.

[121] Starossek U, Haberland M. Approaches to measures of structural robustness. Struct Infrastruct Eng 2011;7:625-631.

[122] Baker JW, Schubert M, Faber MH. On the assessment of robustness. Struct Saf 2008;30(3):253-267.

[123] Frangopol DM, Curley JP. Effects of damage and redundancy on structural reliability. J Struct Eng 1987;113:1533-1549.

[124] Fu G, Frangopol DM. Balancing weight, system reliability and redundancy in a multi objective optimization framework. Struct Saf 1990;7(2):165-175.

[125] Sørensen JD. Framework for robustness assessment of timber structures. Eng Struct 2011;33(11):30873092.

[126] Chen Y-L, Huang L, Lu Y-Q, Deng L, Tan H-Z. Assessment of structural robustness under different events according to vulnerability. J Perform Constr Facil 2016; 10.1061/(ASCE)CF.1943-5509.0000854, 04016004.

[127] ISO 19902:2007. Petroleum and natural gas industries — Fixed steel offshore structures. 2007.

[128] Biondini F, Frangopol DM. Structural robustness of deteriorating systems. Proc, Handling exceptions in structural engineering, Rome; 2008.

[129] Tsai M-H, Lin B-H. Investigation of progressive collapse resistance and inelastic response for an earthquake-resistant RC building subjected to column failure. Eng Struct 2008;30(12):3619-3628. 
[130] Bontempi F, Gkoumas K, Arangio S. Systemic approach for the maintenance of complex structural systems. Struct Infrastruct Eng 2008;4(2):77-94.

[131] Fallon CT, Quiel SE, Naito CJ. Uniform pushdown approach for quantifying building-frame robustness and the consequence of disproportionate collapse. J Perform Constr Facil 2016; 10.1061/(ASCE)CF.1943-5509.0000912, 04016060.

[132] Agarwal J, Blockley DI, Woodman NJ. Vulnerability of structural systems. Struct Saf 2003;25(3):263286.

[133] England J, Agarwal J, Blockley D. The vulnerability of structures to unforeseen events. Comput Struct 2008;86(10):1042-1051.

[134] Bennett RM. Formulations for probability of progressive collapse. Struct Safety 1988; 5(1): 66-77.

[135]Elms DG. Risk assessment. In: Blockley D (ed). Engineering Safety. McGraw-Hill International, Berkshire; 1992, p. 28-46.

[136]Ellingwood BR, Dusenberry DO. Building design for abnormal loads and progressive collapse. Comput Aided Civ Infrastruct Eng 2005; 20: 194-205.

[137] Stewart MG. Acceptable risk criteria for infrastructure protection. Int J Protect Struct 2010; 1(1): 2340.

[138] Grant M, Stewart MG. Probabilistic risk assessment for improvised explosive device attacks that cause significant building damage. J Perform Construct Facil 2015; 29(5):B4014009

[139] Quiel SE, Marjanishvili SM, Katz BP. Performance-based framework for quantifying structural resilience to blast-induced damage. J Struct Eng 2015; 10.1061/(ASCE)ST.1943-541X.0001310, C4015004.

[140] Stewart MG. Risk of progressive collapse of buildings from terrorist attacks: Are the benefits of protection worth the cost? J Perform Construct Facil 2016; 10.1061/(ASCE)CF.1943-5509.0000954, 04016093.

[141] Pate-Cornell ME. Quantitative safety goals for risk management of industrial facilities. Struct Safety 1994; 13(3):145-57.

[142] Stewart MG, Melchers RE. Probabilistic risk assessment of engineering systems. London: Chapman \& Hall; 1997.

[143] Russo P, Parisi F. Risk-targeted safety distance of reinforced concrete buildings from natural-gas transmission pipelines. Rel Eng Sys Safety 2016; 148: 57-66.

[144] Porter K, Kennedy R, Bachman R. Creating fragility functions for performance-based earthquake 
engineering. Earthq Spectra 2007; 23(2): 471-489.

[145] Parisi F. Blast fragility and performance-based pressure-impulse diagrams of European reinforced concrete columns. Eng Struct 2015; 103: 285-297.

[146] Olmati P, Petrini F, Vamvatsikos D, Gantes C. Simplified fragility-based risk analysis for impulse governed blast loading scenarios. Eng Struct 2016; 117: 457-469.

[147] Stewart MG, Netherton MD, Rosowsky DV. Terrorism risks and blast damage to built infrastructure. Nat Hazard Rev 2006; 7(3):114-22.

[148]ElSayed M, Campidelli M, El-Dakhakhni W, Tait M. Simplified framework for blast-risk-based cost-benefit analysis for reinforced concrete-block buildings. J Perform Construct Facil 2015; 10.1061/(ASCE)CF.1943-5509.0000767, 04015077.

[149] Kelliher D, Sutton-Swaby K. Stochastic representation of blast load damage in a reinforced concrete building. Struct Safety 2012; 34: 407-417.

[150] Hao H, Li Z-X, Shi Y. Reliability analysis of RC columns and frame with FRP strengthening subjected to explosive loads. J Perform Construct Facil 2015; 10.1061/(ASCE)CF.1943-5509.0000748, 04015017.

[151] Yu XH, Lu DG, Qian K, Li B. Uncertainty and sensitivity analysis of reinforced concrete frame structures subjected to column loss. J Perform Construct Facil 2017; 31(1), 04016069.

[152] Arshian AH, Morgenthal G, Narayanan S. Influence of modelling strategies on uncertainty propagation in the alternate path mechanism of reinforced concrete framed structures. Eng Struct 2016;110: 36-47.

[153] Li Y, Lu X, Guan H, Ren P, Qian L. Probability-based progressive collapse-resistant assessment for reinforced concrete frame structures. Adv Struct Eng 2016; 19(11):1723-1735.

[154] Xue B, Le J-L. Stochastic computational model for progressive collapse of reinforced concrete buildings. J Struct Eng 2016; 142(7):1-14.

[155] Park J, Kim J. Fragility analysis of steel moment frames with various seismic connections subjected to sudden loss of a column. Eng Struct 2010; 32(6): 1547-1555.

[156] Xu G, Ellingwood BR. Probabilistic robustness assessment of pre-Northridge steel moment resisting frames. J Struct Eng 2011; 137(9): 925-934.

[157] Qin X, Wang W, Chen Y, Bao Y. Experimental study of through diaphragm connection types under a column removal scenario. J Constr Steel Res 2015;112:293-304.

[158] Qin X, Wang W, Chen Y, Bao Y. A special reinforcing technique to improve resistance of beam-to-tubular column connections for progressive collapse prevention. Eng Struct 2016;117:26-39. 
[159] Wang W, Fang C, Qin X, Chen Y, Li L. Performance of practical beam-to-SHS column connections against progressive collapse. Eng Struct 2016;106:332-347.

[160] Li L, Wang W, Chen Y, Lu Y. Experimental investigation of beam-to-tubular column moment connections under column removal scenario. J Constr Steel Res 2013;88:244-255.

[161] Yang B, Tan KH. Experimental tests of different types of bolted steel beam-columns joints under a central-column-removal scenario. Eng Struct 2013;54:112-130.

[162] Yang B, Tan KH. Robustness of bolted-angle connections against progressive collapse: Experimental tests of beam-column joints and development of component-based models. J Struct Eng 2013;139(9):1498-1514.

[163] Gong Y. Test, modeling and design of bolted-angle connections subjected to column removal. J Constr Steel Res 2017;139:315-326.

[164] Liu C, Tan KH, Fung TC. Dynamic behaviour of web cleat connections subjected to sudden column removal scenario. J Constr Steel Res 2013;86:92-106.

[165] Liu C, Tan KH, Fung TC. Investigations of nonlinear dynamic performance of top-and-seat with web angle connections subjected to sudden columns removal. Eng Struct 2015;99:449-461.

[166] Liu C, Fung TC, Tan KH. Dynamic performance of flush end-plate beam-column connections and design applications in progressive collapse. J Struct Eng 2016;142(1):1-14.

[167] Sadek F, Main JA, Lew HS, Bao Y. Testing and analysis of steel and concrete beam-column assemblies under a column removal scenario. J Struct Eng 2011;137(9):881-892.

[168] Lew HS, Main JA, Robert SD, Sadek F, Chiarito VP. Performance of steel moment connections under a column removal scenario. I: Experiments. J. Struct Eng 2013;139(1):98-107.

[169] Dinu F, Marginean I, Dubina D. Experimental testing and numerical modelling of steel moment-frame connections under column loss. Eng Struct 2017;151:861-878.

[170] Oosterhof SA, Driver RG. Behaviour of steel shear connections under column-removal demands. J Struct Eng 2015;141(4):1-14.

[171] Weigand JA, Berman JW. Integrity of bolted angle connections subjected to simulated column removal. J Struct Eng 2016;142(3):1-13.

[172] Kim T, Kim US, Kim J. Collapse resistance of unreinforced steel moment connections. Struct Design Tall Spec Build 2012;21:724-735.

[173] Tyas A, Warren JA, Stoddart EP, Davison JB, Tait SJ, Huang Y. A methodology for combined rotation-extension testing of simple steel beam to column joints at high rates of loading. Exp Mech 
2012;52:1097-1109.

[174] Yang B, Tan KH. Behavior of composite beam-column joints in a middle-column-removal scenario: Experimental tests. J Struct Eng 2014;140(2):1-20.

[175] Yang B, Tan KH, Xiong G, Nie SD. Experimental study about composite frames under an internal column-removal scenario. J Constr Steel Res 2016;121:341-351.

[176] Wang W, Wang J, Sun X, Bao Y. Slab effect of composite subassemblies under a column removal scenario. J Constr Steel Res 2017;129:141-155.

[177]Lew HS, Bao Y, Pujol S, Sozen MA. Experimental study of reinforced concrete assemblies under column removal scenario. ACI Struct J 2014;11(4):881-892.

[178] Yu J, Tan KH. Experimental and numerical investigation on progressive collapse resistance of reinforced concrete beam column sub-assemblages. Eng Struct 2013;55:90-106.

[179] Yu J, Tan KH. Special detailing techniques to improve structural resistance against progressive collapse. J Struct Eng 2014;140(3):1-15.

[180] Yu J, Tan KH. Structural behaviour of reinforced concrete frames subjected to progressive collapse. ACI Struct J 2017;114(1):63-74.

[181]Forquin P, Chen W. An experimental investigation of the progressive collapse resistance of beam-column RC sub-assemblages. Constr Build Mat 2017;152:1068-1084.

[182] Yu J, Rinder T, Stolz A, Tan KH, Riedel W. Dynamic progressive collapse of an RC assemblage induced by contact detonation. J Struct Eng 2014;140(6):1-13.

[183] Ren P, Li Y, Lu X, Guan H, Zhou Y. Experimental investigation of progressive collapse resistance of one-way reinforced concrete beam-slab substructures under a middle-column-removal scenario. Eng Struct 2016;118:28-40.

[184] Lu X, Lin K, Li Y, Guan H, Ren P, Zhou Y. Experimental investigation of RC beam-slab substructures against progressive collapse subjected to an edge-column-removal scenario. Eng Struct 2017; 149:91-103.

[185] Yap SL, Li B. Experimental investigation of reinforced concrete exterior beam-column subassemblages for progressive collapse. ACI Struct J 2011;108(5):542-552.

[186] Qian K, Li B. Experimental and analytical assessment on RC interior beam-column subassemblages for progressive collapse. J Perform Constr Facil 2012;26(5):576-589.

[187] Kai Q, Li B. Dynamic performance of RC beam-column substructures under the scenario of the loss of a corner column - Experimental results. Eng Struct 2012;42:154-167. 
[188] Qian K, Li B. Performance of three-dimensional reinforced concrete beam-column substructures under loss of a corner column scenario. J Struct Eng 2013;139(4):584-594.

[189] Nimse RB, Joshi DD, Patel PV. Behaviour of wet precast beam column connections under progressive collapse scenario: an experimental study. Int J Adv Struct Eng 2014;6:149-159.

[190] Kang SB, Tan KH. Behaviour of precast concrete beam column sub-assemblages subject to column removal. Eng. Struct 2015;93:85-96.

[191] Kang SB, Tan KH, Yang EH. Progressive collapse resistance of precast beam-column sub-assemblages with engineered cementitious-composites. Eng. Struct 2015; 98:186-200.

[192] Kang SB, Tan KH. Robustness assessment of exterior precast concrete frames under column removal scenarios. J Struct Eng 2016;142(12):1-12.

[193] Elsanadedy HM, Almusallam TH, Al-Salloum YA, Abbas H. Investigation of precast RC beam-column assemblies under column loss scenario. Constr Build Mat 2017;142:552-571.

[194]Lew HS, Main JA, Bao Y, Sadek F, Chiarito VP, Robert SD, Torres JO. Performance of precast concrete moment frames subjected to column removal: Part 1, experimental study. PCI J 2017;Sept-Oct:35-52.

[195] Guo L, Gao S, Fu F, Wang Y. Experimental study and numerical analysis of progressive collapse resistance of composite frames. J Constr Steel Res 2013;89:236-251.

[196] Guo L, Gao S, Fu F. Structural performance of semi-rigid composite frame under columns loss. Eng Struct 2015;95:112-126.

[197] Stinger SM, Orton SL. Experimental evaluation of disproportionate collapse resistance in reinforced concrete frames. ACI Struct J 2013;110(3):521-529.

[198] Orton SL, Kirby JE. Dynamic response of a R frame under column removal. J Perform Constr Facil 2014;28(4):1-8.

[199] Shan S, Li S, Xu S, Xie L. Experimental study on the progressive collapse performance of RC frames with infill walls. Eng Struct 2016;111:80-92.

[200] Li S, Shan S, Zhai C, Xie L. Experimental and numerical study on progressive collapse process of RC frames with full-height infill walls. Eng Fail Anal 2016;59:57-68.

[201] Qian K, Li B. Effects of masonry infill wall on the performance of RC frames to resist progressive collapse. J Struct Eng 2017;143(9):1-17.

[202] Johnson ES, Meissner JE, Fahnestock LA. Experimental behavior of a half-scale steel concrete composite floor system subjected to column removal scenarios. J Struct Eng 2016;142(2):1-12. 
[203] Zandonini R, Baldassino N, Freddi F. Robustness of steel-concrete floring systems - an experimental assessment. Stahlbau 2014;83(9):608-613.

[204] Chen J, Huang X, Ma R, He M. Experimental study on the progressive collapse resistance of a two-story steel moment frame. J Perform Constr Facil 2012;26(5):567-575.

[205] Dinu F, Marginean I, Dubina D, Petran I. Experimental testing and numerical analysis of 3D steel frame system under column loss. Eng Struct 2016;113:59-70.

[206] Li H, Cai X, Zhang L, Zhang B, Wang W. Progressive collapse of steel moment-resisting frame subjected to loss of interior column: Experimental tests. Eng Struct 2017;150:203-220.

[207] Xiao Y, Kunnath S, Li FW, Zhao YB, Lew HS, Bao Y. Collapse test of three-storey half-scale reinforced concrete frame building. ACI Struct J 2015;112(4):429-438.

[208] Bermejo M, Santos AP, Goicolea JM. Development of practical finite element models for collapse of reinforced concrete structures and experimental validation. Shock Vib 2017:1-9.

[209] Peng Z, Orton SL, Liu J, Tian Y. Experimental study of dynamic progressive collapse in flat-plate buildings subjected to exterior column removal. J Struct Eng 2017:143(9):1-13.

[210] Yi WJ, Kunnath S, Zhang FZ, Xiao Y. Large-scale experimental evaluation of building system response to sudden column removal. Structures Congress, ASCE; 2011, p. 2353-2357.

[211] Jian H, Li S, Huanhuan L. Testing and analysis on progressive collapse-resistance behaviour of RC frame substructures under a side column removal scenario. J Perform Constr Facil 2016;30(5):1-7.

[212] Qian K, Li B. Slab effects on response of reinforced concrete substructures after loss of corner column. ACI Struct J 2012;109(6):845-855.

[213] Qian K, Li B. Strengthening and retrofitting of RC flat slabs to mitigate progressive collapse by externally bonded CFRP laminates. J Struct Eng 2013;17(4):554-565.

[214] Qian K, Li B. Dynamic and residual behaviour of reinforced concrete floors following instantaneous removal of a column. Eng Struct 2017;148:175-184.

[215] Lim NS, Tan KH, Lee CK. Experimental studies of 3D RC substructures under exterior and corner removal scenarios. Eng Struct 2017;150:409-427.

[216] Song BI, Sezen H. Experimental and analytical progressive collapse assessment of a steel frame building. Eng Struct 2013;56:664-672.

[217] Song BI, Giriunas KA, Sezen H. Progressive collapse testing and analysis of a steel frame building." J Constr Steel Res 2014;94:76-83.

[218] Sasani M, Bazan M, Sagiroglu S. Experimental and analytical progressive collapse evaluation of actual 
reinforced concrete structure. ACI Struct J 2007;104(6):731-739.

[219] Sasani M, Sagiroglu S. Progressive collapse resistance of Hotel San Diego. J Struct Eng 2008;134(3):478-488.

[220] Sasani M. Response of a reinforced concrete infilled-frame structure to removal of two adjacent columns. Eng Struct 2008;30:2478-2491.

[221] Sasani M, Sagiroglu S. Gravity load redistribution and progressive collapse resistance of 20-story reinforced concrete structure following loss of interior column. ACI Struct J 2010:107(6):636-644.

[222] Sasani M, Kazemi A, Sagiroglu S, Forest S. Progressive collapse resistance of an actual 11-story structure subjected to severe initial damage. J Struct Eng 2011;137(9):893-902.

[223] Adam JM, Parisi F, Delatte NJ, Carper KL. Using numerical models for the analysis of structural failures. IF CRASC'17, Milan, 2017.

[224] Pirmoz A, Liu M. Finite element modeling and capacity analysis of post-tensioned steel frames against progressive collapse. Eng Struct 2016; 126:446-456.

[225] Gao S, Guo L, Fu F, Zhang S. Capacity of semi-rigid composite joints in accommodating columns loss. J. Constr Steel Res 2017; 139:288-301.

[226] Pham AT, Lim NS, Tan KH. Investigations of tensile membrane action in beam-slab systems under progressive collapse subject to different loading configurations and boundary conditions. Eng Struct 2017; 150:520-536.

[227] Albrifkani S, Wang YC. Explicit modelling of large deflection behaviour of restrained reinforced concrete beams in fire. Eng Struct 2016; 121:97-119.

[228] Shi Y, Li ZX, Hao H. A new method for progressive collapse analysis of RC frames under blast loading. Eng Struct, 2010; 32(6):1691-1703.

[229] Kwasniewski L. Nonlinear dynamic simulations of progressive collapse for a multistory building. Eng Struct 2010: 32(5):1223-1235.

[230] Fu F. 3-D nonlinear dynamic progressive collapse analysis of multi-storey steel composite frame buildings - Parametric study. Eng Struct 2011; 32(12):3974-3980.

[231] Kokot S, Anthoine A, Negro P, Solomos G. Static and dynamic analysis of a reinforced concrete flat slab frame building for progressive collapse. Eng Struct 2012; 40:205-217.

[232] Brunesi E, Nascimbene R. Extreme response of reinforced concrete buildings through fiber force-based finite element analysis. Eng Struct 2014; 69:206-215.

[233] Kazemi-Moghaddam A, Sasani M. Progressive collapse evaluation of Murrah Federal Building 
following sudden loss of column G20. Eng Struct 2015; 89:162-171.

[234] Sun R, Huang Z, Burgess IW. Progressive collapse analysis of steel structures under fire conditions. Eng Struct 2012; 34(1):400-413.

[235] Agarwal A, Varma AH. Fire induced progressive collapse of steel building structures: The role of interior gravity columns. Eng Struct 2014; 58:129-140.

[236] Lu X, Li Y, Guan H, Ying M. Progressive collapse analysis of a typical super-tall reinforced concrete frame-core tube building exposed to extreme fires. Fire Technol 2017; 53(1):107-133.

[237] Sadek F, El-Tawil S, Lew HS. Robustness of composite floor systems with shear connections: Modeling, simulation and evaluation. J Struct Eng 2008; 134(11):1717-1725.

[238] Kim T, Kim J. Progressive collapse-resisting capacity of steel moment frames considering panel zone deformation. Adv Struct Eng 2009; 12(2): 231-240.

[239] Bao Y, Kunnath SK. Simplified progressive collapse simulation of RC frame-wall structures. Eng Struct 2010; 32(10):3153-3162.

[240] Liu Y, Xu L, Grierson DE. Influence of semi-rigid connections and local joint damage on progressive collapse of steel frameworks. Comput Aided Civ Infrastruct Eng 2010; 25(3):184-204.

[241] Jahromi HZ, Vlassis AG, Izzuddin BA. Modelling approaches for robustness assessment of multi-storey steel-composite buildings. Eng Struct 2013; 51:278-294.

[242] Li H, El-Tawil S. Three-dimensional effects and collapse resistance mechanisms in steel frame buildings. J Struct Eng 2013; 140(3):1-11.

[243] Sun R, Burgess I W, Huang Z, Dong G. Progressive failure modelling and ductility demand of steel beam-to-column connections in fire. Eng Struct 2015; 89(17):66-78.

[244] Alashker Y, Li H, El-Tawil S. Approximations in progressive collapse modelling. J Struct Eng 2011; 137(9):914-924.

[245] Wang W, Li H, Wang J. Progressive collapse analysis of concrete-filled steel tubular column to steel beam connections using multi-scale model. Structures 2017; 9:123-133.

[246] Grujicic M, Snipes JS, Ramaswami S, Yavari R. Discrete element modeling and analysis of structural collapse/survivability of a building subjected to improvised explosive device (IED) attack. Advances in Materials Science \& Applications 2013;2(1):9-24.

[247] Pekau OA, Cui Y. Progressive collapse simulation of precast panel shear walls during earthquakes. Comput Struct 2006;84:400-412.

[248] Masoero E, Wittel FK, Herrmann HJ, Chiaia B. Progressive collapse mechanisms of brittle and ductile 
framed structures. J Eng Mech 2010;136(8):987-995.

[249] Masoero E, Wittel FK, Herrmann HJ, Chiaia B. Hierarchical structures for a robustness-oriented capacity design. J Eng Mech 2012;138(11):1339-1347.

[250] Gu X, Wang X, Yin X, Lin F, Hou J. Collapse simulation of reinforced concrete moment frames considering impact actions among blocks. Eng Struct 2014;65:30-41.

[251] Munjiza A, John NWM, Bangash T. The combined finite-discrete element method for structural failure and collapse. Eng Fract Mech, 2004; 71(4-6):469-483.

[252] Lu X, Lin X, Ye L. Simulation of structural collapse with coupled finite element-discrete element method. Computational Structural Engineering. Springer Netherlands, 2009: 127-135.

[253] Tagel-Din H, Meguro K. Applied Element Method for simulation of nonlinear materials: Theory and application for RC structures. Structural engineering/earthquake engineering. Japan Society of Civil Engineers (JSCE) 2000; 17(2):137-148.

[254] Meguro K, Tagel-Din H. Applied Element Method for structural analysis: Theory and application for linear materials. Structural engineering/earthquake engineering. Japan Society of Civil Engineers (JSCE) 2000; 17(1):21-35.

[255] Lupoae M, Bucur C. Use of applied element method to simulate the collapse of a building. Annual Symposium of the Institute of Solid Mechanics (SISOM) and Session of the Commission of Acoustics, Institute of Solid Mechanics of the Romanian Academy 2009.

[256] Wibowo H, Reshotkina SS, Lau DT. Modelling Progressive Collapse of RC Bridges during Earthquakes. CSCE 2009 Annual General Conference 2009.

[257] Salem HM, Helmy HM. Numerical investigation of collapse of the Minnesota I-35W bridge. Eng Struct 2014; 59(2):635-645.

[258] Salem H, Mohssen S, Kosa K, Hosoda A. Collapse analysis of Utatsu Ohashi Bridge damaged by Tohuku Tsunami using applied element method. Journal of Advanced Concrete Technology 2014; 12(10):388-402.

[259] Salem H, Mohssen S, Nishikiori Y, Hosoda A. Numerical collapse analysis of Tsuyagawa bridge damaged by Tohoku tsunami. J Perform Constr Facil 2016; 30(6):1-12.

[260] Karbassi A, Nollet MJ. Performance-based seismic vulnerability evaluation of masonry buildings using applied element method in a nonlinear dynamic-based analytical procedure. Earthq Spectra 2013; 29(2):399-426.

[261] Galal K, El-Sawy T. Effect of retrofit strategies on mitigating progressive collapse of steel frame 
structures. J Constr Steel Res 2010; 66(4):520-531.

[262] Salem HM, El-Fouly AK, Tagel-Din HS. Toward an economic design of reinforced concrete structures against progressive collapse. Eng Struct 2011; 33(12):3341-3350.

[263] Helmy H, Salem H, Mourad S. Computer-aided assessment of progressive collapse of reinforced concrete structures according to GSA code. J Perform Constr Facil 2013; 27(5):529-439.

[264] Helmy H, Hadhoud H, Mourad S. Infilled masonry walls contribution in mitigating progressive collapse of multistory reinforced concrete structures according to UFC guidelines. Int J Adv Struct Eng $2015 ; 7: 233-247$.

[265] Khalil AA. Enhanced modeling of steel structures for progressive collapse analysis using the Applied Element Method. J Perform Constr Facil 2012; 26(6):766-779.

[266] Hefez I, Khalil A, Mourad S. Alternate path method analysis of RC structures using Applied Element Method. Int J Prot Struct 2013; 4(1):45-64.

[267] Dinu F, Dan D, Marginean I. Improving the structural robustness of multi-story steel-frame buildings. Struct Infrastruct E 2014; 11(8):1028-1041.

[268] Kim HS, Wee HH. Separation strain for progressive collapse analysis of reinforced concrete building using applied element method. Adv Struct Eng 2016; 19(3):437-448.

[269] Ehab M, Salem H, Abdel-Mooty M. Progressive collapse assessment of precast concrete connections using the Applied Element Method (AEM). Int J Comp Meth and Exp Meas 2016: 4(3):269-279.

[270] Attia F, Salem H, Yehia N. Progressive collapse assessment of medium-rise reinforced concrete flat slab structures. Struct Concr 2017; 18(3):409-420

[271] Xue B, Le JL. Simplified energy-based analysis of collapse risk of reinforced concrete buildings. Struct Saf 2016; 63:47-58.

[272] Keyvani L, Sasani M. Analytical and experimental evaluation of progressive collapse resistance of a flat-slab posttensioned parking garage. J Struct Eng 2015; 141(11):1-8.

[273] Abdollahzadeh G, Mashmouli M. Use of steel tendons in designing progressive collapse-resistant reinforced concrete frames. J Perform Constr Fac 2017; 31(4): 1-11.

[274] Qian K, Liu Y, Li B. Progressive collapse resistance of posttensioned concrete beam-column subassemblages with unbonded posttensioning strands. J Struct Eng 2018; 144(1):1-12.

[275] Parisi F, Balestrieri C, Asprone D. Blast resistance of tuff stone masonry walls. Eng Struct 2016; 113:233-244.

[276] Li Z, Chen L, Fang Q, Hao H, Zhang Y, Chen W, Xiang H, Bao Q. Study of autoclaved aerated 
concrete masonry walls under vented gas explosions. Eng Struct 2017; 141:444-460.

[277] Liu JL. Preventing progressive collapse through strengthening beam-to-column connection, Part 1: Theoretical analysis. J Constr Steel Res 2010; 66:229-237.

[278] Liu JL. Preventing progressive collapse through strengthening beam-to-column connection, Part 2: Finite element analysis. J Constr Steel Res 2010; 66:238-247.

[279] Kim J, Choi H, Min KW. Use of rotational friction dampers to enhance seismic and progressive collapse resisting capacity of structures. Design Tall Spec Build 2011; 20:515-537.

[280] Hadi MNS, Alrudaini TMS. New building scheme to resist progressive collapse. J Archit Eng 2012; 18(4): 324-331.

[281] Tsai MH. A performance-based design approach for retrofitting regular building frames with steel braces against sudden column loss. J Constr Steel Res 2012; 77:1-11.

[282] Kim J, Shin WS. Retrofit of RC frames against progressive collapse using prestressing tendons. Struct Design Tall Spec Build 2013; 22:349-361.

[283] Schachter Adaros M, Smilowitz R. Challenges and considerations for the retrofit of existing structures for progressive collapse. J Perform Constr Fac 2015; 29(5):1-9.

[284] Buitrago M, Moragues JJ, Calderón PA, Adam JM, Structural failures in cast-in-place RC building structures under construction. In: Makhlouf ASH, Aliofkhazraei M (eds.), Handb. Mater. Fail. Anal. with Case Stud. from Constr. Ind., 1st ed, Butterworth-Heinemann, Elsevier, 2018. doi:10.1016/ B978-0-08-101928-3.00008-2.

[285] BS 5975. Code of practice for temporary works procedures and the permissible stress design of falsework. 2011.

[286] Buitrago M, Sagaseta J, Adam JM. Effects of sudden failure of shoring elements in concrete building structures under construction. Eng Struct 2018. Article accepted for publication on 14 June 2018 (article reference: JEST8085) 


\section{List of Figures}

- Fig. 1. Alternative load paths: (a) Vierendeel action; (b) catenary action; (c) contribution of non-structural elements.

- Fig. 2. Evolution of the number of papers published yearly in Scopus-indexed journals in relation to the progressive collapse of structures (1968 to 2017).

- Fig. 3. Number of papers by author's country of origin for the periods: 1968-2002, 2003-2007, 2008-2012, and 2013-2017.

- Fig. 4. Test set-up used by Qin et al. [158]. Image by courtesy of Wei Wang (Tongji University).

- Fig. 5. Failure of a beam-column joint in a specimen tested by Yang and Tan [161]. Photo by courtesy of Bo Yang (Chongqing University).

- Fig. 6. Testing of a sub-assemblage by Dinu et al. [169]. Photo by courtesy of Florea Dinu (Politehnica University Timisoara).

- Fig. 7. Test set-up used by Yu and Tan [178]. Image by courtesy of Jun Yu (Nanyang Technological University).

- Fig. 8. (a) Test carried out by Lu et al. [184] on a beam-slab specimen; (b) Test by Ren et al. [183] on a beam specimen without slab. Photos by courtesy of Yi Li (Beijing University of Technology).

- Fig. 9. Test set-up used by Kai and Li [187] to study corner column removal. Photo by courtesy of Bing Li (Nanyang Technological University).

- Fig. 10. Test set-up used by Elsanadedy et al. [193] to test precast concrete sub-assemblages. Photo by courtesy of Hussein M. Elsanadedy (King Saud University).

- Fig. 11. View of a test by Guo et al. [196] on a composite frame. Photo by courtesy of Lanhui Guo (Harbin Institute of Technology).

- Fig. 12. Test by Shan et al. [199] on an RC frame with infill walls. Photo by courtesy of Shuang Li (Harbin Institute of Technology).

- Fig. 13. Test on a 3D steel frame by Dinu et al. [205]. Photo by courtesy of Florea Dinu (Politehnica University Timisoara).

- Fig. 14. Building structure tested by Bermejo et al. [208]. Photo by courtesy of Mario Bermejo (Technical University of Madrid).

- Fig. 15. Ohio Union Building used for testing by Song and Sezen [216]. Photo by courtesy of Halil Sezen (Ohio State University).

- Fig. 16. Hotel San Diego used for testing by Sasani and Sagiroglu [219] and Sasani [220]. Photo by 
courtesy of Mehrdad Sasani (Northeastern University).

- Fig. 17. Simulation with solid elements (micromodelling) of a sub-assemblage formed by two beams and a column [159]. Images by courtesy of Cheng Fang (Tongji University).

- Fig. 18. Numerical simulation of a building with beam/shell elements [236]. Image by courtesy of Xinzheng Lu (Tsinghua University).

- Fig. 19. Macromodel of a beam-column joint in a steel structure [83]. Image by courtesy of Kapil Khandelwal (University of Notre Dame).

- Fig. 20. Comparison of numerical and experimental results obtained from the Discrete Element Method in a simulated structural collapse. Time from start of test is indicated below each test phase [250]. Images by courtesy of Xianglin Gu (Tongji University).

- Fig. 21. Use of Applied Element Method to simulate: (a) sub-assemblage; (b) building structure. Images by courtesy of Ayman El-Fouly (Applied Science International LLC).

- Fig. 22. Use of Cohesive Element Method to simulate progressive building collapse [271]. Image by courtesy of Jia-Ling Le (University of Minessota).

\section{List of Tables}

- Table 1. Selected definitions of progressive and disproportionate collapse.

- Table 2. Selected definitions of structural robustness.

- Table 3. Scopus-indexed journals with most papers published on progressive collapse of structures (up to 31 December 2017).

- Table 4. Most relevant papers on progressive collapse of structures by number of citations received (up to 31 December 2017).

- Table 5. Summary of design methods considered by international codes and guidelines.

- Table 6. Threat-dependent, reliability/risk-based measures of structural robustness.

- Table 7. Threat-dependent, deterministic measures of structural robustness.

- Table 8. Threat-independent, deterministic measures of structural robustness. 